Information Circular 9531

\section{Design, Testing, and Modeling of Environmental Enclosures for Controlling Worker Exposure to Airborne Contaminants}

John A. Organiscak, Andrew B. Cecala, and Ronald M. Hall

DEPARTMENT OF HEALTH AND HUMAN SERVICES

Centers for Disease Control and Prevention

National Institute for Occupational Safety and Health

Office of Mine Safety and Health Research

Pittsburgh, PA - Spokane, WA

June 2018 


\section{This document is in the public domain and may be freely copied or reprinted.}

\section{Disclaimer}

Mention of any company or product does not constitute endorsement by the National Institute for Occupational Safety and Health (NIOSH). In addition, citations to websites external to NIOSH do not constitute NIOSH endorsement of the sponsoring organizations or their programs or products. Furthermore, NIOSH is not responsible for the content of these websites. All web addresses referenced in this document were accessible as of the publication date.

\section{Ordering Information}

To receive NIOSH documents or more information about occupational safety and health topics, please contact NIOSH:

Telephone: 1-800-CDC-INFO (1-800-232-4636)

TTY: 1-888-232-6348

CDC INFO: www.cdc.gov/info

or visit the NIOSH website at www.cdc.gov/niosh.

For a monthly update on news at NIOSH, subscribe to NIOSH eNews by visiting www.cdc.gov/niosh/eNews.

\section{Suggested Citation}

NIOSH [2018]. Design, testing, and modeling of environmental enclosures for controlling worker exposure to airborne contaminants. By Organiscak JA, Cecala AB, and Hall RM.

Pittsburgh PA: U.S. Department of Health and Human Services, Centers for Disease Control and Prevention, National Institute for Occupational Safety and Health, DHHS (NIOSH) Publication No. 2018-123, IC 9531. https://doi.org/10.26616/NIOSHPUB2018123

DOI: https://doi.org/10.26616/NIOSHPUB2018123

DHHS (NIOSH) Publication No. 2018-123

June 2018

Cover photos by NIOSH. 


\section{Contents}

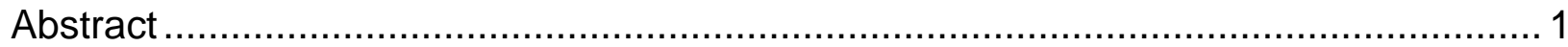

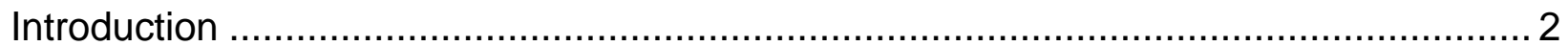

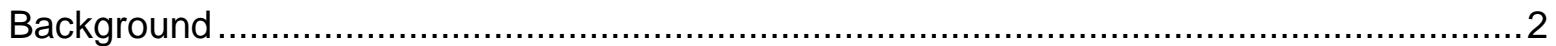

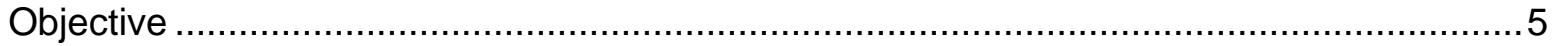

Key Environmental Enclosure Design Considerations ............................................ 5

Using a separate intake pressurizer fan and a high-efficiency respirable dust filter to

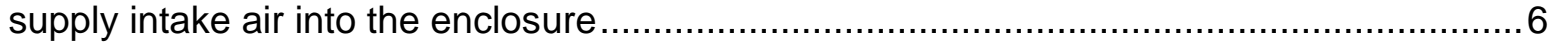

Ensuring good enclosure integrity to achieve positive pressurization against outside wind penetration and to minimize outside air leakage around the filtration system .............9

Providing effective respirable dust filtration on the enclosure's recirculated airflow ..........13

Applying secondary enclosure design considerations for maintaining an effective

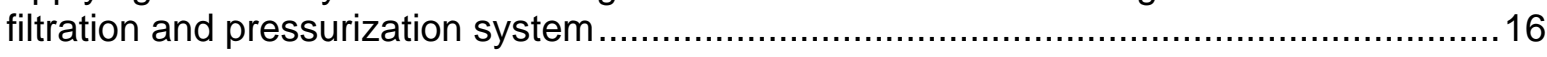

Testing and Monitoring Environmental Enclosures .............................................. 18

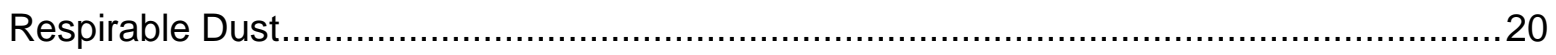

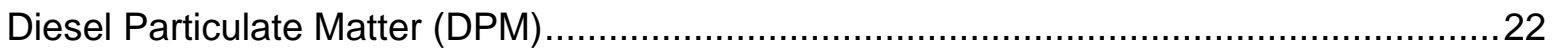

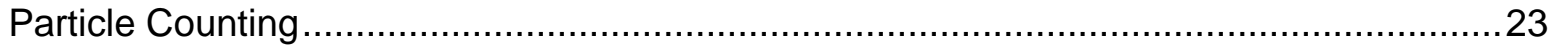

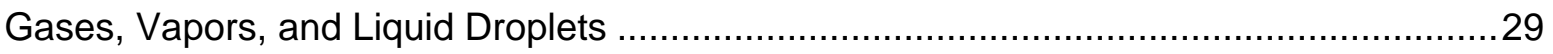

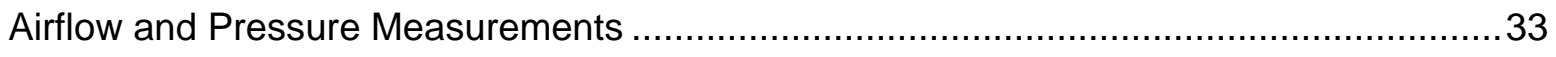

Enhanced Video Analysis of Dust Exposures (EVADE) software ..................................34

Data Analysis of Environmental Enclosure Performance .......................................... 36

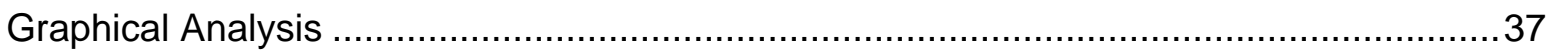

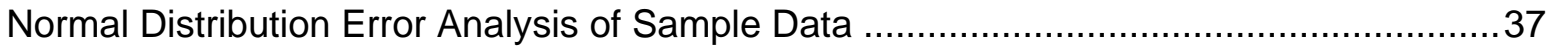

Propagation of Error Analysis of Protection Factor Ratios .........................................41

Poisson Distribution Error Analysis of Particle Counting Data .......................................44

Mathematical Modeling of Environmental Enclosure Filtrations Systems..................... 47

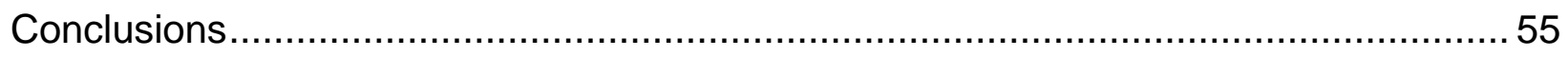

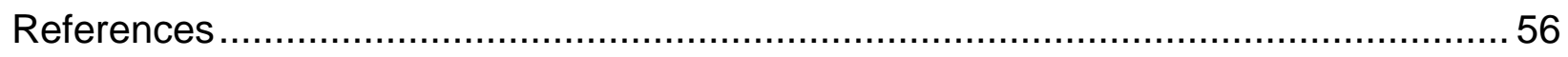




\section{Figures}

Figure 1. Relationship between cab pressure and its wind speed resistance to outside contaminants

Figure 2. Relationship between cab differential pressure and intake airflow during laboratory experiments

Figure 3. Relationship between intake leakage and differential pressure across the intake filter....

Figure 4. Filter housing using a contiguous series of pre-, HEPA, and charcoal panel filters (left); outside air leakage around filters on Nelson tractor cab (right)

Figure 5. Nelson tractor cab test results before and after fixing filtration system air leakage 13

Figure 6. Final filter system configuration tested with MERV 16 and HEPA filters ........ 15 Figure 7. Long-term field study test results of final filter system using MERV 16 and HEPA filters

Figure 8. Drill operator opening door to guide drill steel (left); one shift of real-time respirable dust levels inside the cab with the door closed and open (right). 17

Figure 9. Personal gravimetric sampler (left); passive nephelometer light-scattering instrument (right).

Figure 10. DPM sampler (left); real-time EC/diesel particulate monitor (right) 23

Figure 11. EC concentrations and cab pressure measurements made on an underground drill cab. 24

Figure 12. Particle size-related enclosure PFs measured in the laboratory 25

Figure 13. Particle size-related enclosure PFs measured during field studies 25

Figure 14. Desktop size selectable optical particle counter (left); handheld fixed-size optical particle counter (right)

Figure 15. Laboratory particle counting test replicates for the high-efficiency intake filter configuration with and without a recirculation filter and wind

Figure 16. Air leakage test measurements made on Clean Air Filter (CAF) Company's test stand

Figure 17. Digital (top) or analog (bottom) enclosure pressure monitoring (left); hot wire anemometer measurement (right)

Figure 18. Helmet-CAM technology used in the enclosed cab of haul truck for assessment of truck driver's respirable dust exposure relevant to the truck location as viewed by the video

Figure 19. Graphical information of long-term field study of roof bolter using a three-filter configuration 39

Figure 20. Two- and single-filter cab systems with and without a recirculation filter ..... 49

Figure 21. Comparison of laboratory measured cab protection factors to the modeled protection factors 
Figure 22. Three-filter cab system with final filter downstream of intake and

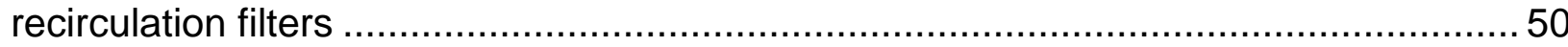

Figure 23. Field-measured protection factors shown with modeled ranges..................51

Figure 24. Visual observation of multiple air leaks within the air filtration system .........55

Figure 25. Three-filter cab system with potential leaks around the filters ...................... 52

Figure 26. Measured and modeled PFs of the face drill and roof bolter during the filter field study 


\section{Tables}

Table 1. Respirable dust sampling results of retrofitted cab filtration systems on mine vehicles

Table 2. Averages of laboratory cab performance testing for all filter combinations tested

Table 3. MERV rating efficiency values for three size ranges of dust particles .............. 8

Table 4. Comparison of environmental enclosure performance measures ................... 19

Table 5. $\mathrm{CO}_{2}$ measurements on the John Deere tractor cab..................................... 32

Table 6. Calculation of statistics for MERV 16 and HEPA filter comparisons on face drill and roof bolter cabs 40

Table 7. Initial cab filtration system particle counting test results using the HEPA final filter 


$\begin{array}{ll}\text { Acronyms and Abbreviations } \\ \text { ACGIH } & \text { American Conference of Governmental Industrial Hygienists } \\ \text { ASAE } & \text { American Society of Agricultural Engineers } \\ \text { ASHRAE } & \begin{array}{l}\text { American Society of Heating, Refrigerating and } \\ \text { Air-Conditioning Engineers }\end{array} \\ \text { CAF } & \text { Clean Air Filter } \\ \text { CRADA } & \text { Cooperative Research and Development Agreement } \\ \text { DPM } & \text { diesel particulate matter } \\ \text { EC } & \text { elemental carbon } \\ \text { EVADE } & \text { Enhanced Video Analysis of Dust Exposures } \\ \text { HVAC } & \text { heating, ventilation, and air conditioning } \\ \text { HEPA } & \text { high-efficiency particulate arrestance } \\ \text { MERV } & \text { minimum efficiency reporting value } \\ \text { MPPS } & \text { most penetrating particle size } \\ \text { NIOSH } & \text { National Institute for Occupational Safety and Health } \\ \text { OEM } & \text { original equipment manufacturer } \\ \text { PF } & \text { protection factor } \\ \text { TWA } & \text { time-weighted average } \\ \text { TC } & \text { total carbon }\end{array}$




$\begin{array}{ll}\text { Unit of Measure Abbreviations } \\ \mathrm{CO}_{2} & \text { carbon dioxide } \\ \mathrm{ft}^{3} & \text { cubic feet } \\ \mathrm{ft}^{3} / \mathrm{min} & \text { cubic feet per minute } \\ \mathrm{ft} & \text { feet } \\ \text { in } & \text { inches } \\ \mathrm{L} & \text { liters } \\ \mathrm{L} / \mathrm{min} & \text { liters per minute } \\ \mu \mathrm{m} & \text { micrometers } \\ \mathrm{mg} / \mathrm{m}^{3} & \text { milligrams per cubic meter } \\ \mathrm{mm} & \text { millimeters } \\ \mathrm{min} & \text { minutes } \\ \% & \text { percent } \\ \mathrm{sec} & \text { seconds } \\ \text { in } \mathrm{wg} & \text { water gauge }\end{array}$




\title{
Design, Testing, and Modeling of Environmental Enclosures for Controlling Worker Exposure to Airborne Contaminants
}

\author{
John A. Organiscak ${ }^{1}$, Andrew B. Cecala², and Ronald M. Hall ${ }^{3}$
}

\begin{abstract}
Environmental enclosures such as cabs, booths, rooms, etc. are one of the mainstay engineering control methods for reducing operators' exposure to airborne contaminants generated outside the enclosure. In order to achieve a cleaner air environment, air filtration is typically incorporated into the enclosure's heating, ventilation, and air conditioning (HVAC) system. The National Institute for Occupational Safety and Health (NIOSH) has jointly conducted collaborative research efforts with HVAC system manufacturers, cab filtration/pressurization component manufacturers, original equipment manufacturers (OEMs) of industrial vehicles, and companies using these cabs/environmental enclosures. This report summarizes NIOSH's laboratory and field research results, provides key design guidelines for environmental enclosures, shows measurement methods for enclosure performance, and demonstrates mathematical modeling of filtration system designs.

Two key elements of an effective environmental enclosure are a good filtration system and an enclosure with good integrity (sealed isolation from the outside environment). A good filtration system should include filtering out at least $95 \%$ or greater of airborne respirable aerosols (dust, diesel particulate matter, liquid droplets, etc.) from the intake airflow with an additional recirculation filtering component for the inside air. Good enclosure integrity is also needed to achieve positive pressure to prevent wind-driven aerosol penetration into the enclosure, as well as to minimize air leakage around the filtration system. Test methods and mathematical modeling of environmental enclosures are also beneficial for quantifying and optimizing filtration system designs, as well as maintaining optimum protection factor (PF) performance for enclosure occupants. Occupational exposure sampling, particle counting methods, airflow measurements, and enclosure pressurization measurements are used to assess the effectiveness of environmental enclosures. Node analysis of filtration system designs are beneficial for examining the effects of filter placement, filter efficiency, airflow quantities, air leakage, and wind penetration on the environmental enclosure's air cleaning performance.
\end{abstract}

\footnotetext{
${ }^{1}$ Senior Mining Engineer, Dust, Ventilation, and Toxic Substances Branch, NIOSH Pittsburgh Mining Research Division (PMRD), Pittsburgh, PA.

2 Principal Supervisory Mining Engineer, Dust, Ventilation, and Toxic Substances Branch, NIOSH PMRD, Pittsburgh, PA.

${ }^{3}$ Deputy Branch Chief, Engineering and Physical Hazards Branch, NIOSH Division of Applied Research and Technology, Cincinnati, $\mathrm{OH}$.
} 


\section{Introduction}

Enclosed cabs are an engineering control that can provide a safe, comfortable, and healthy work environment for equipment operators. Most modern day enclosed cabs have heating, ventilation, and air conditioning (HVAC) systems for primarily maintaining a comfortable temperature and providing a breathable ventilation quantity of air for their occupants. Various levels of filtration can be incorporated into the HVAC system to improve the ventilation quality of the air inside the cab by removing airborne pollutants such as dusts, diesel particulate matter (DPM), and other aerosols. Enclosed operator cabs have been used on agriculture, mining, and construction vehicles for several decades and were comprehensively studied by NIOSH for their engineering control effectiveness on these respirable aerosols. Several larger stationary enclosures or booths were further evaluated to verify respirable filtration system effectiveness within these larger enclosure volumes.

\section{Background}

Examination of dust levels found in agriculture indicate that ground preparation and harvesting operations generate some of the highest dust levels, with enclosed cabs providing a sixtyfold reduction on larger size dusts and more than fourfold reduction on respirable sized dusts [Nieuwenhuijsen et al. 1998]. Agriculture pesticide sprayers typically generate droplet diameters between 50 and $500 \mu \mathrm{m}$, but some pesticide spraying research shows that the mass median aerodynamic diameter of spray aerosols that stay suspended outside a cab can range between 4 and $15 \mu \mathrm{m}$, with $3 \%$ to $23 \%$ of the droplet mass concentrations less than $3 \mu \mathrm{m}$ in size [Bémer et al. 2007; Hall et al. 2002]. These findings illustrate the need for enclosed cabs to reduce operator exposure to these respirable aerosols.

In addition to these findings for agriculture, surface mining respirable dust surveys conducted by NIOSH show that rotary drills generate some of the highest respirable dust levels at mining operations, with dust levels one order of magnitude higher than generated by bulldozers [Organiscak and Page 1999]. Enclosed cab respirable dust protection factors (PFs) (ratio of outside to inside respirable dust concentrations) measured on rotary drills range from 2.6 to 84 , while those measured on bulldozers range from less than 1 to 45 [Organiscak and Page 1999].

In these earlier studies, few details were revealed about the design of the enclosed cab filtration systems. Therefore, NIOSH partnered with HVAC suppliers, filter/pressurizer manufacturers, regulatory agencies, and mining companies in conducting field studies to modify older mining equipment cab filtration systems, with the goal of identifying the key factors involved in achieving effective dust control [Organiscak et al. 2004; Chekan and Colinet 2003; Cecala et al. 2004; Cecala et al. 2005; Cecala et al. 2009]. These studies highlighted several important key factors, such as using high-efficiency respirable dust filters, a separate intake pressurizer fan, and a cab with good integrity to achieve positive pressurization [Cecala et al. 2014]. Respirable dust concentration measurements made inside and outside of these cabs during mining operations also showed a wide range of cab PFs from 2.8 to 89 , indicating that highly variable operational conditions were present during these cab performance field studies.

The effectiveness of enclosed cab filtration systems can be difficult to quantify in the field under diverse operating conditions. Relative measures of enclosed cab performance (such as protection 
factor, penetration, and reduction efficiency) from field data can be quite variable or unreliable if the outside dust mass concentrations are low or vary significantly between working shifts [Organiscak et al. 2004]. Using particle counters to evaluate cabs over shorter periods of time can increase the reliability of performance measurements, because of the larger number of smaller particles available at lower dust concentrations [Organiscak et al. 2004; Organiscak et al. 2016]. The American Society of Agricultural Engineers (ASAE) previously devised a consensus standard for field testing a cab's PF performance with particle counters, and specified a minimum 50:1 cab PF performance criteria for pesticide applications. This procedure required two optical particle counters; one is placed inside and the other outside the cab to examine its PF on 2- $\mu \mathrm{m}$ to $4-\mu \mathrm{m}$ particles as the agricultural tractor is driven over unpaved ground surfaces for at least four 30-min tests [ASAE 1997]. NIOSH examination of this test procedure indicated that inconsistent and low particle count data for the $2-\mu \mathrm{m}$ to $4-\mu \mathrm{m}$ particles outside the cab can also yield unreliable cab performance results between replicated cab tests [Heitbrink et al. 1998].

Alternative particle counting cab field test procedures have been examined and used by NIOSH with submicron particles $(0.3-\mu \mathrm{m}$ to $0.5-\mu \mathrm{m})$ to quantify and improve agricultural tractor cab protection performance for pesticide spray applications [Heitbrink et al. 2003; Moyer et al. 2005]. One procedure used two optical particle counters alternated between the inside and outside locations of the tractor cab during four 30-min tests, similar to the ASAE consensus standard test, except that $0.3-\mu \mathrm{m}$ to $0.4-\mu \mathrm{m}$ particle sizes were used as the test medium. This field study identified and sealed several tractor cab filtration system leaks around a highefficiency particulate air (HEPA) filter, which effectively reduced particle penetration into the cab from $11 \%$ to less than $1 \%$ [Heitbrink et al. 2003]. Another study measured $0.3-\mu \mathrm{m}$ to $0.5-\mu \mathrm{m}$ particles inside and outside a stationary unoccupied cab parked inside a temporary enclosure filled with incense smoke contaminants. In this procedure, a two-channel particle counting instrument sampled alternate positions inside and outside an unoccupied cab using equal lengths of sample hoses to these locations. This procedure was used to quantify cab PFs of at least 50:1 (outside to inside particle concentrations) for a pesticide spraying company after refurbishing and performing maintenance on 13 tractor cabs [Moyer et al. 2005].

Particle counting measurements of submicron $(0.3-\mu \mathrm{m}$ to $1.0-\mu \mathrm{m})$ particulates in ambient air were further used by NIOSH during laboratory experiments with multiple instruments to study the key design factors of enclosed cab dust filtration systems [Organiscak and Cecala 2008; NIOSH 2008b]. These experiments were conducted to methodically study these systems under more strictly controlled laboratory operating conditions. During these experiments, two particle counting instruments were alternated between test replicates to average out any measurement biases between instruments, similar to the ASAE procedure described above. These laboratory experiments quantified the effects of intake filter efficiency, intake filter loading, intake air leakage around the filter, recirculation filter use, and wind infiltration on cab filtration system performance under controlled conditions. Laboratory measurements showed that the largest number of particles in the ambient air were submicron $(0.3-\mu \mathrm{m}$ to $1.0-\mu \mathrm{m})$ and that concentrations remained relatively constant during the testing on a particular day, but varied noticeably from day to day [NIOSH 2008b]. Experimental cab test results determined that intake filter efficiency and the use of a recirculation filter component were the two most important influential factors on cab filtration system performance. The addition of a recirculation filter component to the cab's filtration system significantly reduced its particulate penetration performance by an order of magnitude, and reduced the time it took to reach its lowest stable concentration after the door was closed by about $60 \%$. Finally, a mathematical model was 
developed that describes cab particulate penetration in terms of intake filter efficiency, intake air quantity, intake air leakage, recirculation filter efficiency, recirculation filter quantity, and wind infiltration [NIOSH 2008b].

NIOSH also developed another quantification method for evaluating the environmental integrity of cabs in conjunction with Clean Air Filter (CAF) Company, Defiance, IA, under a Cooperative Research and Development Agreement (CRADA). This cab test method was developed as an alternative to particle counting test methods for negating any interior cab particle generation interferences such as dirty floors, interior surfaces, and abraded blower motor brushes [Cecala et al. 2005; Heitbrink and Collingwood 2005]. This method involves replacing the HVAC intake filter with a carbon dioxide $\left(\mathrm{CO}_{2}\right)$ gas filter, running the HVAC system with an unoccupied cab, measuring $\mathrm{CO}_{2}$ concentrations inside and outside the cab filtration system, and applying a mathematical formula to calculate outside air leakage into the cab enclosure [NIOSH 2012b; NIOSH 2012c]. This method was shown to be capable of quantifying a greater than $2 \%$ outside air leakage into the cab's filtration system [NIOSH 2012b].

In cooperation with a mining equipment manufacturer, NIOSH examined the performance of a new three-filter cab filtration system (intake, recirculation, and final filters) designed for the underground industrial minerals industry. Particle count testing and airflow measurements were initially conducted at the company's manufacturing shop to examine the cab filtration system performance with several types of final filters and intake/pressurizer filter configurations. The performance of this cab filtration system design was further studied in the field on several pieces of underground mining equipment. Underground dust and diesel field sampling results during a seven-month field study showed inconsistent cab PFs among production shifts because of unpredictable equipment operator practices, such as the frequency and duration of opening the cab door and the variability in HVAC system operation [Cecala et al. 2012; Noll et al. 2014a]. Particle counting and HVAC airflow measurements made on these cabs in ambient air outside the mine between production shifts provided a better quantification or benchmarking of their optimum long-term PF performance under consistent near steady state cab testing conditions, termed "static testing" [Cecala et al. 2012; Organiscak et al. 2013]. Mathematical modeling of this three-filter cab filtration system using node analysis techniques was validated by the particle counting PF field test results, thereby demonstrating the model's usefulness as a filtration system design tool [Organiscak et al. 2014].

NIOSH further examined the cab filtration performance effects of using a HEPA (High Efficiency Particulate Arrestance, $\geq 99.97 \%$ efficiency on $\geq 0.3-\mu \mathrm{m}$ particles) filter as compared to a MERV 16 (Minimum Efficiency Reporting Value, $\geq 95 \%$ efficiency on $0.3-\mu \mathrm{m}$ to $1.0-\mu \mathrm{m}$ and larger particles) filter as defined by American Society of Heating, Refrigerating and AirConditioning Engineers [ASHRAE 1999]. Filter efficiency comparisons were initially made and validated on diesel particulate matter (DPM) in the laboratory [Noll et al. 2011]. DPM measurements made on several equipment cabs in an underground limestone mine for multiple shifts with HEPA filters showed reduction efficiencies from $41 \%$ to $96 \%$, while several cabs using MERV 16 filters in another underground limestone mine showed similar reduction efficiencies of $46 \%$ to $95 \%$ [Noll et al. 2011; Noll et al. 2014a]. This wide variation in DPM cab reduction efficiencies was a result of operator practices with regard to opening and closing doors and windows during the shift [Noll et al. 2011; Noll et al. 2014a].

A long-term HEPA and MERV 16 filter comparative study showed no overall significant difference between these filters [Cecala et al. 2016]. This study was conducted on enclosed cabs 
on both an underground face drill and a roof bolter using particle counting test methods between shifts in order to benchmark protection factor performance under consistent operating procedures. Airflow and cab pressure measurements made on these cabs during this long-term study, including several other filter combinations tested, showed that multiple leakages around the filters in the HVAC system had a noticeable impact on the overall cab's PF performance, and that these additional leakages could be incorporated into mathematical modeling of these filtration systems [Cecala et al. 2016].

Finally, several larger control room/booth case studies were conducted to examine the PF effectiveness of three different types of filtration system installations on much larger enclosures than typical mobile equipment cabs. One installation used a ductless heat pump to cool and heat the inside control room $\left(1,440 \mathrm{ft}^{3}\right.$ of volume) at a mineral processing plant, with a separate standalone two-filter system for cleaning the intake and recirculated air [Noll et al. 2015]. Another installation used a wall-mounted HVAC system on a crusher booth ( $368 \mathrm{ft}^{3}$ of volume) with two filtered intake pressurizers and recirculation filter units integrated into the HVAC system [Organiscak et al. 2016]. A third installation used a ductless heat pump to temper the inside of an underground limestone mine crusher booth ( $458 \mathrm{ft}^{3}$ of volume), with a separate standalone single-filter system for cleaning both the intake and recirculation air [Patts et al. 2017]. All of these systems provided a significant improvement in PF performance (8 to 216) compared to the negligible protection offered to workers in the previously unfiltered enclosures using typical window air conditioner units. However, these larger enclosures were more difficult to seal and pressurize than smaller cab enclosures on mobile equipment. Only 0.01 to 0.02 inches of water gauge (in wg) of positive pressure was achieved with 80 to $118 \mathrm{ft}^{3}$ of intake air blown into the largest control room, which provided PFs from 8 to 25 [Noll et al. 2015]. The smallest crusher booth achieved 0.04 to 0.12 in wg positive pressure for an intake airflow range of 97 to $213 \mathrm{ft}^{3}$, providing PFs of 35 to 127 [Organiscak et al. 2016]. Continuous differential pressure monitoring of the third underground limestone crusher booth indicated that its pressure was increased from $0.02 \mathrm{in} w g$ to $0.11 \mathrm{in} w \mathrm{w}$ because of the 1.8 -times increase in filtered airflow due to switching from a more restrictive $99 \%$ efficient filter to a less restrictive $95 \%$ efficient filter, which also improved the booth PF by more than four times [Patts et al. 2017]. The booth's pressure was further increased by 0.07 in wg by sealing a leaky exterior roof duct plenum [Patts et al. 2017].

\section{Objective}

The objective of this report is to compile the results of NIOSH's environmental enclosure research, provide key design guidelines for environmental enclosures, describe the measurement methods used for quantifying enclosure performance, and demonstrate mathematical modeling of filtration system designs.

\section{Key Environmental Enclosure Design Considerations}

Environmental enclosures such as cabs, booths, and rooms can be effectively designed for removing outside airborne contaminants to reduce the exposure of occupants to respiratory hazards. NIOSH field and laboratory research has identified several key factors that affect an 
enclosure's protection factor from outside contaminants [Cecala et al. 2014]. These key components for an effective environmental enclosure are detailed in the following sections.

Using a separate intake pressurizer fan and a high-efficiency respirable dust filter to supply intake air into the enclosure

Initial NIOSH field testing of retrofitted cab filtration systems on older mining equipment included adding separate intake pressurizer units and using intake filters with collection efficiencies of at least 95\% on respirable-sized dusts [Organiscak et al. 2004; Chekan and Colinet 2003; Cecala et al. 2004; Cecala et al. 2005; Cecala et al. 2009]. Table 1 shows the respirable dust sampling results from these field studies in ascending order of PFs with their associated publication references. The average PFs for the various cabs measured over multiple shifts were 2.8 to 89 , with other factors likely affecting their performance. As can be seen from Table 1, a wide range of PFs were observed for the various shifts of dust sampling with the same $\mathrm{cab}$, indicating notable day-to-day operational influences on cab PF measurements.

Table 1. Respirable dust sampling results of retrofitted cab filtration systems on mine vehicles

\begin{tabular}{|c|c|c|c|c|c|}
\hline $\begin{array}{l}\text { Vehicle Cab Tested } \\
\text { (No. of Shifts) } \\
\text { [Reference] }\end{array}$ & $\begin{array}{l}\text { Mining } \\
\text { Type }\end{array}$ & $\begin{array}{l}\text { Cab } \\
\text { Pressure, } \\
\text { in wg }\end{array}$ & $\begin{array}{l}\text { Inside Cab } \\
\text { Dust Level } \\
\text { Average } \\
\text { (Range), } \\
\mathrm{mg} / \mathrm{m}^{3}\end{array}$ & $\begin{array}{l}\text { Outside Cab } \\
\text { Dust Level } \\
\text { Average } \\
\text { (Range), } \\
\mathrm{mg} / \mathrm{m}^{3}\end{array}$ & $\begin{array}{l}\text { Protection } \\
\text { Factor } \\
\text { Average } \\
\text { (Range) }\end{array}$ \\
\hline $\begin{array}{l}\text { Rotary Drill (4) } \\
\text { [Organiscak et al. 2004] }\end{array}$ & Surface & $\begin{array}{l}\text { None } \\
\text { detected }\end{array}$ & $\begin{array}{r}\mathbf{0 . 0 8} \\
(0.02 \text { to } 0.17)\end{array}$ & $\begin{array}{r}\mathbf{0 . 2 2} \\
(0.12 \text { to } 0.46)\end{array}$ & $\begin{array}{r}\mathbf{2 . 8} \\
(2.0 \text { to } 7.9)\end{array}$ \\
\hline $\begin{array}{l}\text { Haul Truck (3) } \\
\text { [Chekan and Colinet } \\
\text { 2003] }\end{array}$ & $\begin{array}{l}\text { Underground/ } \\
\text { Surface }\end{array}$ & 0.01 & $\begin{array}{r}\mathbf{0 . 3 2} \\
(0.23 \text { to } 0.43)\end{array}$ & $\begin{array}{r}\mathbf{1 . 0 1} \\
(0.92 \text { to } 1.07)\end{array}$ & $\begin{array}{r}\mathbf{3 . 2} \\
(2.4 \text { to } 4.0)\end{array}$ \\
\hline $\begin{array}{l}\text { Front-End Loader (6) } \\
\text { [Organiscak et al. 2004] }\end{array}$ & Surface & 0.015 & $\begin{array}{r}\mathbf{0 . 0 3} \\
(0.01 \text { to } 0.07)\end{array}$ & $\begin{array}{r}\mathbf{0 . 3 0} \\
(0.09 \text { to } 0.47)\end{array}$ & $\begin{array}{r}\mathbf{1 0} \\
(2.1 \text { to } 50)\end{array}$ \\
\hline $\begin{array}{l}\text { Rotary Drill (7) } \\
\text { [Cecala et al. 2009] }\end{array}$ & Surface & $0.10-0.40$ & $\begin{array}{r}\mathbf{0 . 1 6} \\
(0.06 \text { to } 0.21)\end{array}$ & $\begin{array}{r}\mathbf{2 . 8 5} \\
(0.68 \text { to } 4.20)\end{array}$ & $\begin{array}{r}\mathbf{1 8} \\
(3.7 \text { to } 42)\end{array}$ \\
\hline $\begin{array}{l}\text { Rotary Drill (3) } \\
\text { [Cecala et al. 2004] }\end{array}$ & Surface & $0.20-0.40$ & $\begin{array}{r}\mathbf{0 . 0 5} \\
(0.03 \text { to } 0.07)\end{array}$ & $\begin{array}{r}\mathbf{2 . 8 0} \\
(0.73 \text { to } 6.25)\end{array}$ & $\begin{array}{r}\mathbf{5 2} \\
(24 \text { to } 89)\end{array}$ \\
\hline $\begin{array}{l}\text { Rotary Drill (7) } \\
\text { [Cecala et al. 2005] }\end{array}$ & Surface & $0.07-0.12$ & $\begin{array}{r}\mathbf{0 . 0 7} \\
(0.02 \text { to } 0.13)\end{array}$ & $\begin{array}{r}\mathbf{6 . 2 5} \\
(0.25 \text { to } 31.8)\end{array}$ & $\begin{array}{r}89 \\
(3.6 \text { to } 245)\end{array}$ \\
\hline
\end{tabular}

As seen in Table 2, laboratory cab enclosure testing under more consistent steady state conditions more clearly shows the direct relationship between the intake filter efficiency on enclosure PFs and the direct relationship of an intake pressurizer on intake airflow and cab pressure. 
Table 2. Averages of laboratory cab performance testing for all filter combinations tested

\begin{tabular}{|c|c|c|c|c|c|c|c|c|}
\hline $\begin{array}{l}\text { Intake } \\
\text { Filter } \\
\text { (\% Eff.) }\end{array}$ & $\begin{array}{l}\text { Intake } \\
\text { Filter } \\
\text { Loading }\end{array}$ & $\begin{array}{l}\text { Recir. } \\
\text { Filter } \\
\text { (\% Eff.) }\end{array}$ & $\begin{array}{r}\text { Intake } \\
\text { Airflow, } \\
\mathrm{ft}^{3} / \mathrm{min}\end{array}$ & $\begin{array}{r}\text { Intake Air } \\
\text { Leakage, } \\
\%\end{array}$ & $\begin{array}{r}\text { Recir. } \\
\text { Airflow, } \\
\mathrm{ft}^{3} / \mathrm{min}\end{array}$ & $\begin{array}{r}\text { Cab } \\
\text { Pressure, } \\
\text { in wg }\end{array}$ & $\begin{array}{c}\text { Decay } \\
\text { Time, } \\
\text { min }\end{array}$ & $\begin{array}{r}\text { Protection } \\
\text { Factor, } \\
\boldsymbol{C}_{o} / C_{i}\end{array}$ \\
\hline $\begin{array}{l}\text { Low } \\
(35 \%)\end{array}$ & Unloaded & No & 48.8 & 0.8 & 358 & 0.24 & 16 & 1.5 \\
\hline $\begin{array}{l}\text { Low } \\
(32 \%)\end{array}$ & Unloaded & $\begin{array}{l}\text { Yes } \\
(72 \%)\end{array}$ & 58.7 & 0.8 & 318 & 0.31 & 7 & 7.2 \\
\hline $\begin{array}{l}\text { Low } \\
(44 \%)\end{array}$ & Loaded & No & 21.5 & 3.7 & 378 & 0.08 & 18 & 1.7 \\
\hline $\begin{array}{l}\text { Low } \\
(42 \%)\end{array}$ & Loaded & $\begin{array}{l}\text { Yes } \\
(72 \%)\end{array}$ & 25.2 & 4.3 & 337 & 0.09 & 9 & 17.8 \\
\hline $\begin{array}{l}\text { High } \\
(>99 \%)\end{array}$ & Unloaded & No & 22.8 & 3.4 & 383 & 0.09 & 27 & 22.9 \\
\hline $\begin{array}{l}\text { High } \\
(>99 \%)\end{array}$ & Unloaded & $\begin{array}{l}\text { Yes } \\
\text { (72\%) }\end{array}$ & 28.7 & 3.2 & 332 & 0.10 & 7 & 223.8 \\
\hline $\begin{array}{l}\text { High } \\
(>99 \%)\end{array}$ & Loaded & No & 14.9 & 3.7 & 388 & 0.06 & 29 & 21.4 \\
\hline $\begin{array}{l}\text { High } \\
(>99 \%)\end{array}$ & Loaded & $\begin{array}{l}\text { Yes } \\
(72 \%)\end{array}$ & 18.8 & 6.3 & 344 & 0.06 & 9 & 195.9 \\
\hline $\begin{array}{l}\text { Low* } \\
\text { (29\%) }\end{array}$ & Unloaded & No & 80.1 & 0.8 & 342 & 0.44 & 22 & 1.4 \\
\hline $\begin{array}{l}\text { Low* } \\
\text { (29\%) }\end{array}$ & Unloaded & $\begin{array}{l}\text { Yes } \\
(72 \%)\end{array}$ & 91.8 & 0.9 & 310 & 0.47 & 8 & 4.8 \\
\hline $\begin{array}{l}\text { Low* } \\
\text { (39\%) }\end{array}$ & Loaded & No & 30.2 & 3.8 & 383 & 0.10 & 17 & 1.6 \\
\hline $\begin{array}{l}\text { Low* } \\
\text { (39\%) }\end{array}$ & Loaded & $\begin{array}{l}\text { Yes } \\
(72 \%)\end{array}$ & 33.2 & 3.8 & 338 & 0.12 & 11 & 13.3 \\
\hline $\begin{array}{l}\text { High* } \\
(>99 \%)\end{array}$ & Unloaded & No & 39.2 & 2.8 & 370 & 0.16 & 25 & 26.5 \\
\hline $\begin{array}{l}\text { High* } \\
(>99 \%)\end{array}$ & Unloaded & $\begin{array}{l}\text { Yes } \\
(72 \%)\end{array}$ & 44.8 & 2.7 & 335 & 0.20 & 8 & 173.8 \\
\hline $\begin{array}{l}\text { High* } \\
(>99 \%)\end{array}$ & Loaded & No & 23.1 & 4.0 & 387 & 0.07 & 20 & 20.2 \\
\hline $\begin{array}{l}\text { High* } \\
(>99 \%)\end{array}$ & Loaded & $\begin{array}{l}\text { Yes } \\
(72 \%)\end{array}$ & 26.4 & 4.9 & 341 & 0.08 & 6 & 176.0 \\
\hline
\end{tabular}

*Cab test stand operated with intake pressurizer fan.

The American Society of Heating, Refrigerating and Air-Conditioning Engineers (ASHRAE) devised air filter efficiency performance standards that are tested, rated, and reported as minimal efficiency reporting values (MERV) [ASHRAE 1999]. Table 3 shows these ASHRAE MERV filter ratings with their collection efficiency performance standards [ASHRAE 1999]. Only the filters in Group 4 (MERV 14 to MERV 16) have quantified average collection efficiencies for 
the smallest respirable particulate range $(0.3-\mu \mathrm{m}$ to1.0- $\mu \mathrm{m})$. Also included at the bottom of this table is a high-efficiency particulate arrestance (HEPA) filter as specified by the United States Department of Energy (DOE), which must be capable of at least $99.97 \%$ filtering efficiency on all particle sizes $>0.3 \mu \mathrm{m} .{ }^{4}$ Although there is a considerable jump in the filtering efficiency from the MERV 16 to HEPA quality filters-increasing from $>95 \%$ to $>99.97 \%$ collection efficiency throughout similar respirable particle size ranges, respectively — a long-term particle counting field comparison of these two types of filters on two underground limestone equipment cabs showed on average an insignificant difference in overall cab PFs [Cecala et al. 2016]. The MERV 16 filter started off with a lower cab PF than the HEPA, but reached similar PFs with some filter loading. The HEPA intake filter restricted the intake airflow quantity into the cab and had to be replaced more often than the MERV 16 intake filter [Cecala et al. 2016].

\section{Table 3. MERV rating efficiency values for three size ranges of dust particles*}

\begin{tabular}{|c|c|c|c|c|}
\hline Group & $\begin{array}{l}\text { MERV } \\
\text { Rating }\end{array}$ & $\begin{array}{r}\text { Average particle } \\
\text { size efficiency } \\
\text { (PSE) } \\
0.3 \text {-microns to } \\
1.0 \text {-microns }\end{array}$ & $\begin{array}{r}\text { Average particle } \\
\text { size efficiency } \\
\text { (PSE) } \\
\text { 1.0-microns to } \\
3.0 \text {-microns }\end{array}$ & $\begin{array}{r}\text { Average particle } \\
\text { size efficiency } \\
\text { (PSE) } \\
\text { 3.0-microns to } \\
\text { 10.0-microns }\end{array}$ \\
\hline \multirow[t]{4}{*}{1} & 1 & & & $<20 \%$ \\
\hline & 2 & & & $<20 \%$ \\
\hline & 3 & & & $<20 \%$ \\
\hline & 4 & & & $<20 \%$ \\
\hline \multirow[t]{4}{*}{2} & 5 & & & $20-34.9 \%$ \\
\hline & 6 & & & $35-49.9 \%$ \\
\hline & 7 & & & $50-69.9 \%$ \\
\hline & 8 & & & $70-84.9 \%$ \\
\hline \multirow[t]{4}{*}{3} & 9 & & $<50 \%$ & $\geq 85 \%$ \\
\hline & 10 & & $50-64.9 \%$ & $\geq 85 \%$ \\
\hline & 11 & & $65-79.9 \%$ & $\geq 85 \%$ \\
\hline & 12 & & $80-89.9 \%$ & $\geq 90 \%$ \\
\hline \multirow[t]{4}{*}{4} & 13 & $<75 \%$ & $\geq 90 \%$ & $\geq 90 \%$ \\
\hline & 14 & $75-84.9 \%$ & $\geq 90 \%$ & $\geq 90 \%$ \\
\hline & 15 & $85-94.9 \%$ & $\geq 90 \%$ & $\geq 90 \%$ \\
\hline & 16 & $\geq 95 \%$ & $\geq 95 \%$ & $\geq 95 \%$ \\
\hline HEPA & & $\geq 99.97 \%$ & $\geq 99.97 \%$ & $\geq 99.97 \%$ \\
\hline
\end{tabular}

*Minimum efficiency reporting values (MERV) according to the American Society of Heating, Refrigerating and Air-Conditioning Engineers (ASHRAE)

\footnotetext{
${ }^{4}$ HEPA filter efficiencies are specified for all particles $\geq 0.3 \mu \mathrm{m}$, whereas the ASHRAE filter specifications represent an average filtering efficiency for the smallest $0.3-\mu \mathrm{m}$ to $1.0-\mu \mathrm{m}$ submicron particle range and may not be inferred as the same filtering efficiency on the smallest particles of this size range.
} 
Many agricultural tractor cabs used in pesticide spray applications use HEPA filters. Mobile particle counting field tests of a John Deere 7000 series tractor (John Deere, Moline, IL) and a retrofitted Nelson spray cab (Nelson Mfg. Co. Inc., Yuba City, CA) on a Massy Ferguson 396 tractor (Massey Ferguson, Duluth, GA) equipped with a HEPA intake filter exhibited PFs of 43 and 16, respectively, on particle sizes $<1 \mu \mathrm{m}$ [Hall et al. 2002]. Stationary particle count field testing of 13 Massy Ferguson tractors equipped with HEPA filters in Nelson cabs after routine maintenance showed PFs of 30 to 445 for $0.3-\mu \mathrm{m}$ to $0.5-\mu \mathrm{m}$ particles. Additional repairs increased two of the cabs' PFs below 50 to greater than 50 after cab filtration leaks were identified and repaired [Moyer et al. 2005]. This shows that using high-efficiency intake filters on respirable sized dusts is important in reducing respiratory hazards in environmental enclosures.

Testing procedures for quantifying the performance of filter elements loaded with dust can be found in ASHRAE 1999, ASABE 2013b, and ASABE 2017b. Another particulate filter test standard and classification system that can be used to quantify high-efficiency filters $(\geq 95 \%$ efficiency on the most penetrating particle sizes, MPPS) is ISO 2011. Vapor testing procedures for quantifying activated charcoal filter efficiency and assessing filter life for use in agricultural pesticide applications can be found in ASABE 2013b and CEN 2009b.

\section{Ensuring good enclosure integrity to achieve positive pressurization against outside wind penetration and to minimize outside air leakage around the filtration system}

In addition to high-efficiency intake filters as a key building block for providing clean air into environmental enclosures, having environmental enclosure integrity (sealed isolation from the outside environment) is another key factor in achieving effective contaminant reductions inside the enclosure. Positive pressurization of the enclosure and minimizing any outside air leakage around the filtration system are needed to reduce outside contaminant penetration into the enclosure.

Low or negligible enclosure pressure provides the potential for wind and contaminants to infiltrate open areas into the enclosure. Some evidence of this can be seen from the field studies in Table 1. Lower respirable dust PFs of 2.8 to 10 were measured on the drill, truck, and loader cabs with pressurization less than or equal to 0.015 in wg. To prevent outside contaminants from being blown into the enclosure, its static pressure must be higher than the wind's velocity pressure [Heitbrink et al. 2000; NIOSH 2008b].

Equation 1 shows the relationship developed and tested by Heitbrink using Bernoulli's Equation, when applied to orifice flow at turbulent and uncompressed airflow conditions. He found good agreement with outside airflow and contaminant infiltration into an enclosure through the circular holes, directly facing into the wind [Heitbrink et al. 2000]. The determination of the equivalent wind velocity for a given enclosure pressure that prevents this enclosure infiltration is shown in Equation 2 [NIOSH 2008b; NIOSH 2012a]. Figure 1 also graphically illustrates the wind speed equivalent relationship with enclosure pressure at standard air temperature and pressure. As can be seen from this figure, enclosure pressures of $0.05,0.1,0.25$, and 0.50 in wg would resist wind infiltration of 10.2, 14.4, 22.7, and $32.1 \mathrm{mph}$, respectively. 
$v_{o}=\frac{Q_{o}}{A_{o}}=C_{d} \sqrt{2 \frac{\left(0.5 \rho_{a i r} v_{w}^{2}-\Delta \mathrm{p}_{c}\right)}{\rho_{\text {air }}}} ;$ wind penetration when $0.5 \rho_{\text {air }} v_{w}^{2}>\Delta \mathrm{p}_{c}$

where:

$v_{o}=$ air velocity through an orifice,

$Q_{o}=$ air quantity through an orifice,

$A_{o}=$ area of cab orifice openings directly facing into the wind,

$C_{d}=$ orifice discharge coefficient; 0.61 circular orifice coefficient used by Heitbrink,

$\rho_{\text {air }}=$ air density,

$v_{w}=$ wind velocity, and

$\Delta p_{c}=$ cab static pressure; inside to outside differential pressure.

$v_{w}=\left(4000 \sqrt{\Delta p_{c}}\right) \times 0.011364$ at standard air temperature and pressure

where:

$v_{w}=$ wind velocity, $\mathrm{mph}$, and

$\Delta p_{c}=$ cab static pressure, in $\mathrm{wg}$.

Another factor influencing enclosure pressurization is the quantity of intake airflow. Laboratory testing shows that enclosure pressure is directly related to intake airflow quantity delivered into the enclosure [Organiscak and Cecala 2008; NIOSH 2008b]. Figure 2 illustrates this enclosure differential pressure $\left(\Delta p_{c}\right)$ relationship with intake airflow $\left(Q_{I}\right)$ measured during laboratory testing. As can be seen in this figure, when adding a separate intake air booster fan or pressurizer fan to the filtration system, the enclosure intake air quantity and pressure were significantly increased. This figure also shows that the wind slightly boosts enclosure pressures at the lower intake airflows without the pressurizer, indicating that the enclosure exiting airflow directly facing into the wind is restricted/reversed and being forced to exit other openings unopposed by the wind [NIOSH 2008b]. However, higher enclosure pressures should not necessarily be associated with high PFs. The laboratory results shown in Table 2 clearly demonstrate that the lower intake filter efficiency provided the highest intake airflows and enclosure pressures at reduced PFs. A minimum specified intake airflow quantity of filtered air into a cab enclosure is $25 \mathrm{ft}^{3} / \mathrm{min}$ per occupant (or $43 \mathrm{~m}^{3} / \mathrm{hr}$ per occupant) [ASAE 1997; ASABE 2013a]. Another source specifies a minimum of $18 \mathrm{ft}^{3} / \mathrm{min}$ ( or $30 \mathrm{~m}^{3} / \mathrm{hr}$ ) filtered intake air into a cab enclosure during pesticide spraying [CEN 2009a]. Fifteen $\mathrm{ft}^{3} / \mathrm{min}$ is the calculated intake ventilation rate per person at rest for maintaining exhaled $\mathrm{CO}_{2}$ concentrations at $700 \mathrm{ppm}$ above incoming intake air levels into a room or enclosure [ASHRAE 2007]. In order to ensure a breathable filtered air supply for enclosed cab occupants, it is recommended that the intake air quantity per person exceed all of these specified and calculated minimum intake air quantities. 


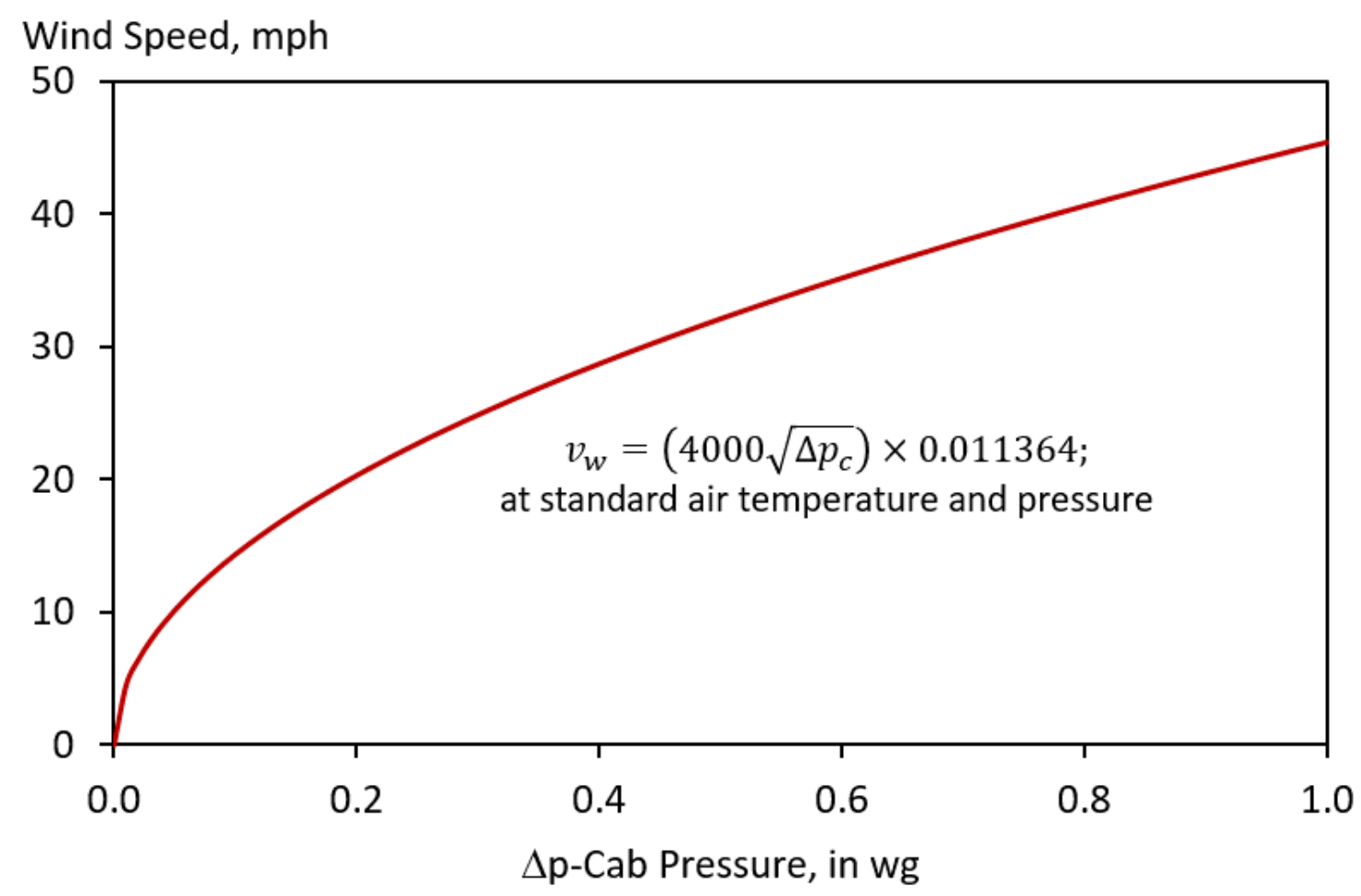

Figure 1. Relationship between cab pressure and its wind speed resistance to outside contaminants (from Equation 2).

Finally, good enclosure integrity is important for minimizing outside air leakage around the HVAC/filtration system. Air leakage around the intake filter reduces its cleaning efficiency of the air being blown into the enclosure. NIOSH laboratory experiments showed that a 0.5 -indiameter hole bypassing the intake filter was the third most significant influence on environmental enclosure penetration after intake filter efficiency and recirculation filter use [NIOSH 2008b]. Figure 3 shows the direct relationship between the percent leakage $(l)$ of intake air and differential pressure across the intake filter $\left(\Delta p_{f}\right)$ for the four filtration system configurations tested in the laboratory with simulated intake filter loading conditions. Visual field evidence of a significant air/dust leak inside the filter housing of the contiguous series of pre-, HEPA, and charcoal filters of a Nelson spray cab during a mobile particle counting study can be seen in Figure 4 [Heitbrink et al. 2003]. The cab penetration with this leakage was $11 \%$ (a PF less than 10) for $0.3-\mu \mathrm{m}$ to $0.4-\mu \mathrm{m}$ particles [Heitbrink et al. 2003]. After fixing the bowed flanges and filter gaskets in the filter housing, the cab penetration on $0.3-\mu \mathrm{m}$ to $0.4-\mu \mathrm{m}$ particles was reduced to less than 1\% (a PF greater than 100) [Heitbrink et al. 2003]. Figure 5 shows the significant reduction in cab penetration for all the particle sizes measured when the filtration system leakage was addressed. 
$+\Delta p_{c}$, in wg

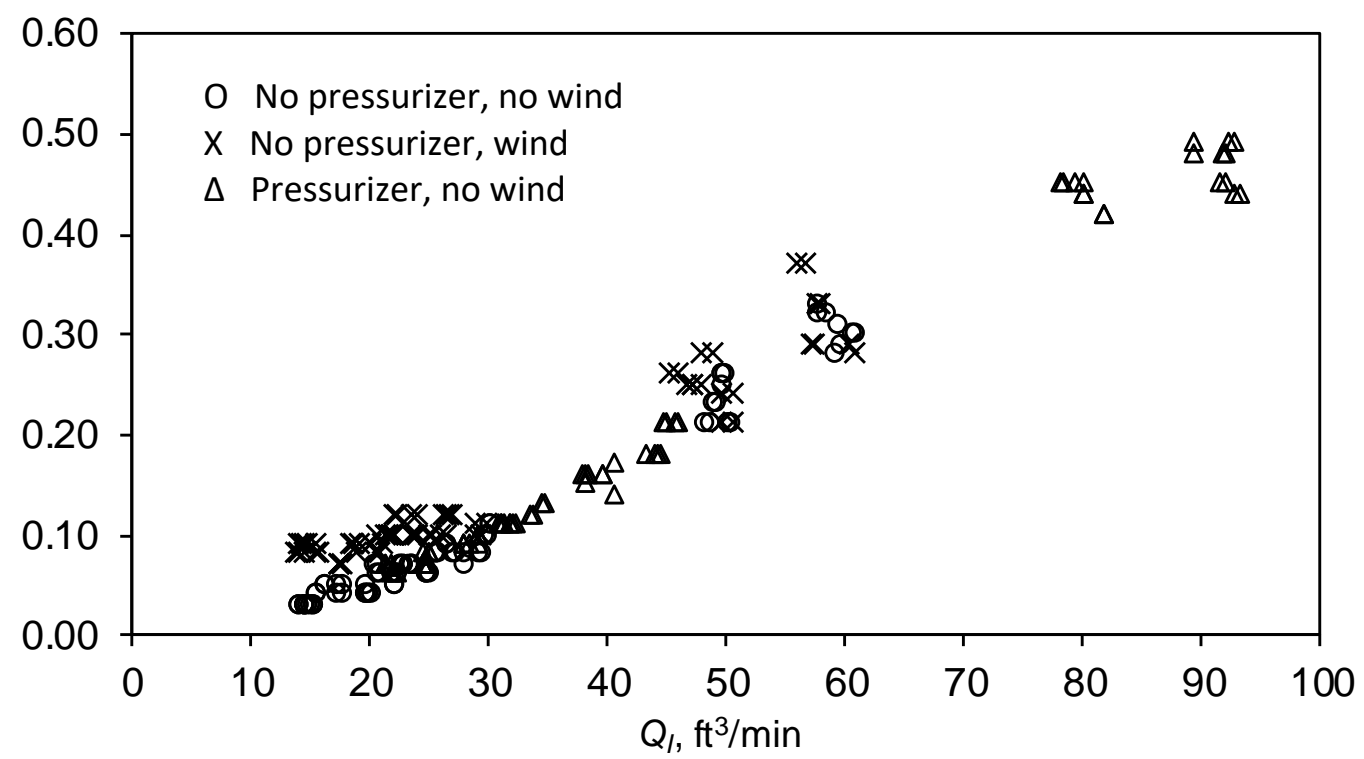

Figure 2. Relationship between cab differential pressure and intake airflow during laboratory experiments.

I, \% of $Q_{l}$

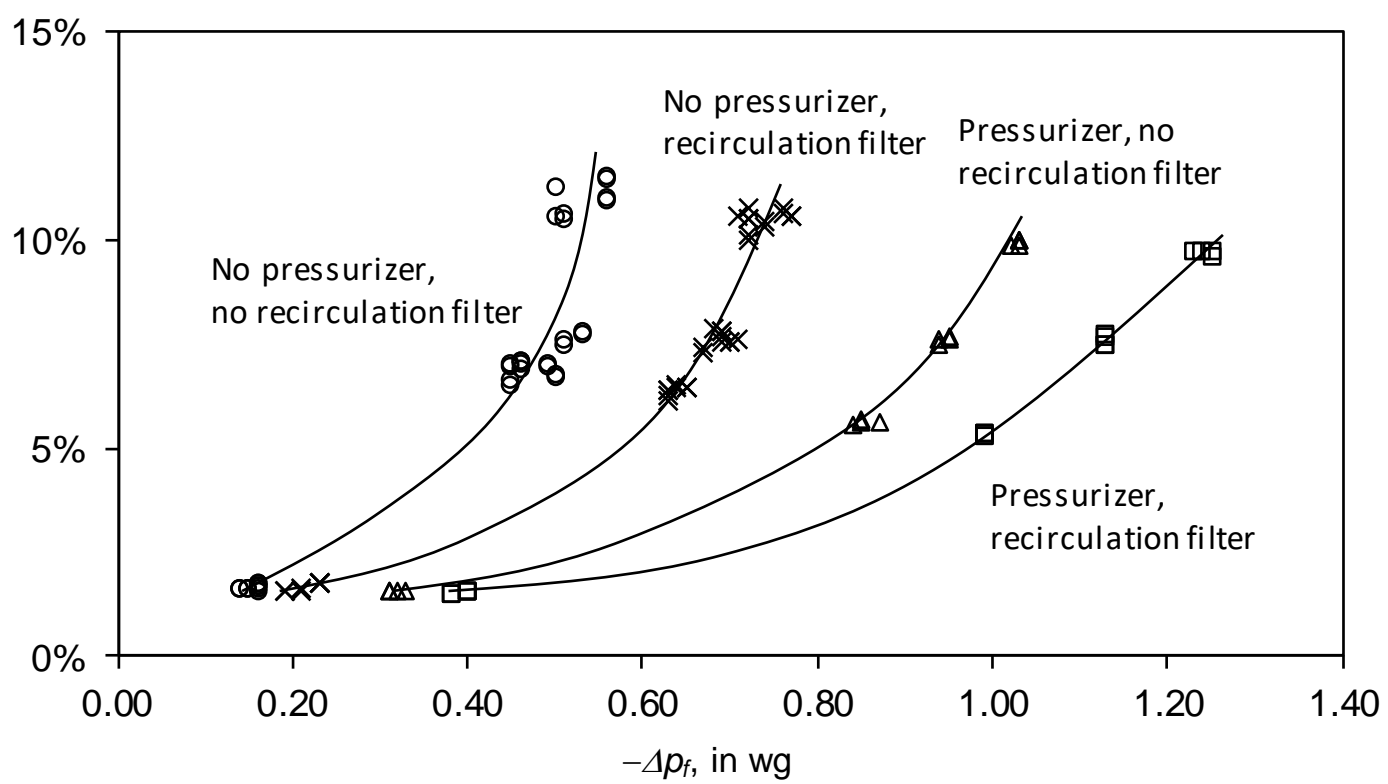

Figure 3. Relationship between intake leakage and differential pressure across the intake filter. 

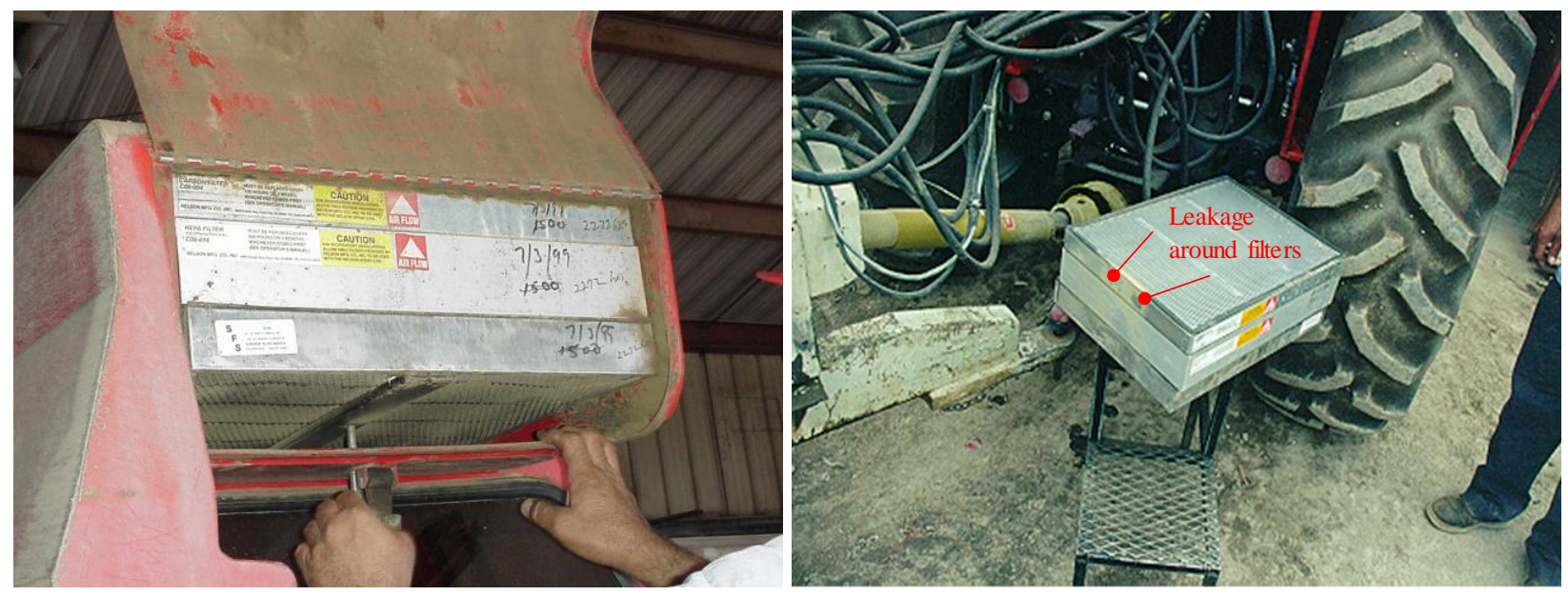

Figure 4. Filter housing using a contiguous series of pre-, HEPA, and charcoal panel filters (left); outside air leakage around filters on Nelson tractor cab (right).

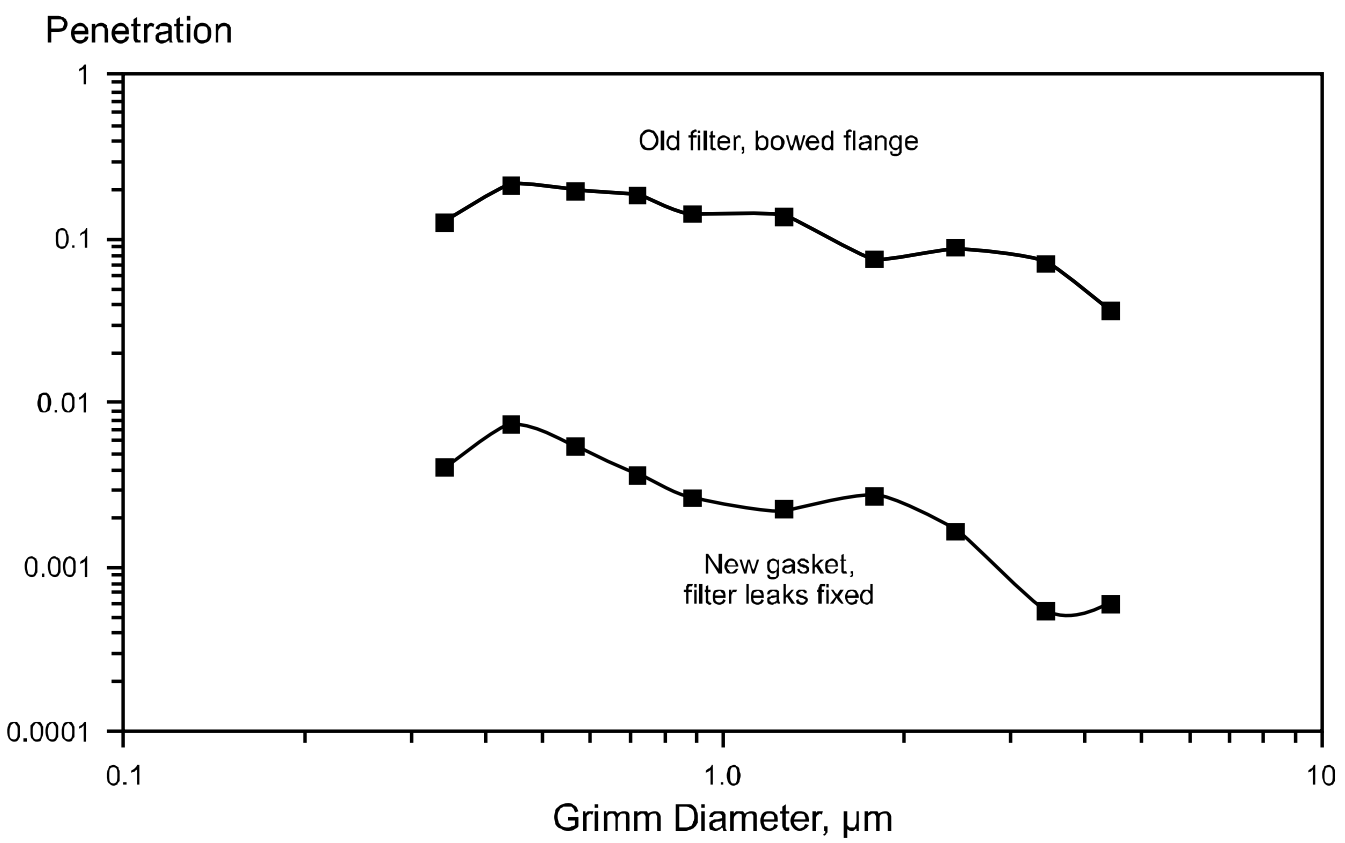

Figure 5. Nelson tractor cab test results before and after fixing filtration system air leakage.

\section{Providing effective respirable dust filtration on the enclosure's recirculated airflow}

Filtering the recirculated inside enclosure air significantly improves the enclosure's PF and reduces the time it takes to achieve the lowest steady state concentrations [NIOSH 2007a; Organiscak and Cecala 2008; NIOSH 2008b]. The laboratory test results averages presented in Table 2 show that the PF of the enclosure while using the recirculation filter was notably improved by 3.4 to 10.5 times more than with the intake filter alone. This notable enclosure PF improvement was achieved by using a recirculation filter that was $>70 \%$ efficient on submicron 
sized particles $(0.3-\mu \mathrm{m}$ to $1.0-\mu \mathrm{m})$. Also, this table shows that the average decay time (time to reach the lowest steady state inside concentrations after the door was closed) was noticeably lower when using the recirculation filter. Measured decay times ranged from 16 to 29 min without the recirculation filter and ranged from 6 to $11 \mathrm{~min}$ with the recirculation filter. The reason for this significant improvement in enclosure performance with the recirculation filter is that the enclosure's interior air is constantly drawn through the filter, thus continually re-filtering the dust out of the air [NIOSH 2007a; Organiscak and Cecala 2008; NIOSH 2008b].

These laboratory results demonstrate that a recirculation filter efficiency should be at least $>70 \%$ efficient on submicron particles $(0.3-\mu \mathrm{m}$ to $1.0-\mu \mathrm{m})$ in order to realize these significant enclosure PF improvements. The ASHRAE filter classification meeting this minimum specification is a MERV 14 or higher-rated filter as shown in Table 3. The MERV 14 filter specifications are $75 \%-84.9 \%$ capture efficiency on $0.3-\mu \mathrm{m}$ to $1.0-\mu \mathrm{m}$ particles and $>90 \%$ capture efficiency on respirable particles $>1.0 \mu \mathrm{m}$. These specifications were previously recommended by NIOSH as a minimum ASHRAE rating for a recirculation filter [Cecala et al. 2014].

Another method of providing very effective filtration of the enclosure's recirculated airflow is to use a final filter configuration within the system. NIOSH worked with an original equipment manufacturer (OEM) of mining equipment (J.H. Fletcher \& Co., Huntington, WV), an intake pressurizer/filter supplier (Sy-klone International, Inc., Jacksonville, FL), and an underground limestone mine (Sidwell Materials, Inc., Zanesville, $\mathrm{OH}$ ) to study the long-term performance of this type of filtration system design [Cecala et al. 2012; Cecala and Organiscak 2017]. Figure 6 shows the layout of the enclosed cab filtration system used on Fletcher's larger underground face drill cab enclosure $\left(160 \mathrm{ft}^{3}\right)$ as well as their smaller roof bolter cab enclosure $\left(75 \mathrm{ft}^{3}\right)$. As can be seen in this figure, the cab filtration system was configured to employ three filters: an intake, a recirculation, and a final filter.

Initial field testing of this system layout while using the small-panel recirculation filter (3-in width by 16-in length by 2 -in depth) at the Sidwell underground limestone mine showed that it quickly became loaded/restricted and had to be changed much more frequently than the other filters. Removal of this filter significantly increased recirculation airflow without a notable adverse effect on the cab PF [Cecala et al. 2012].

Long-term comparative field testing was further conducted using MERV 16 and HEPA filters at both the intake and final filter locations (shown in Figure 6) on these Fletcher equipment cabs which were deployed at a new underground limestone mine (Shelly Materials, Zanesville, $\mathrm{OH}$ ) [Cecala et al. 2016; Cecala and Organiscak 2017]. Subsequent particle count testing and airflow measurements on these enclosed cabs were conducted over a seven-month period with each type of filter on the highest HVAC fan setting, and these results are illustrated in Figure 7. This figure shows that the MERV 16 filter started off with a lower cab PF with higher airflows than the HEPA, but reached similar PFs with some filter loading. The long-term average PFs for the MERV 16 and HEPA filters on the face drill were 3,898 and 3,677, respectively, and were 573 and 681 on the roof bolter, respectively [Cecala et al. 2016]. There was no significant statistical difference between these PFs measured with MERV 16 and HEPA filters on each individual cab [Cecala et al. 2016]. The HEPA intake filter restricted the intake airflow quantity into the cab and was replaced more often [Cecala et al. 2016]. However, there was a significant statistical difference observed between the performance of these equipment enclosures, indicating that more outside air and contaminants must have leaked around the filtration system of the smaller 
roof bolter cab $\left(75 \mathrm{ft}^{3}\right)$ [Cecala et al. 2016]. Nevertheless, both of these enclosed cabs with this final filter design configuration had some of the highest PFs measured by NIOSH.

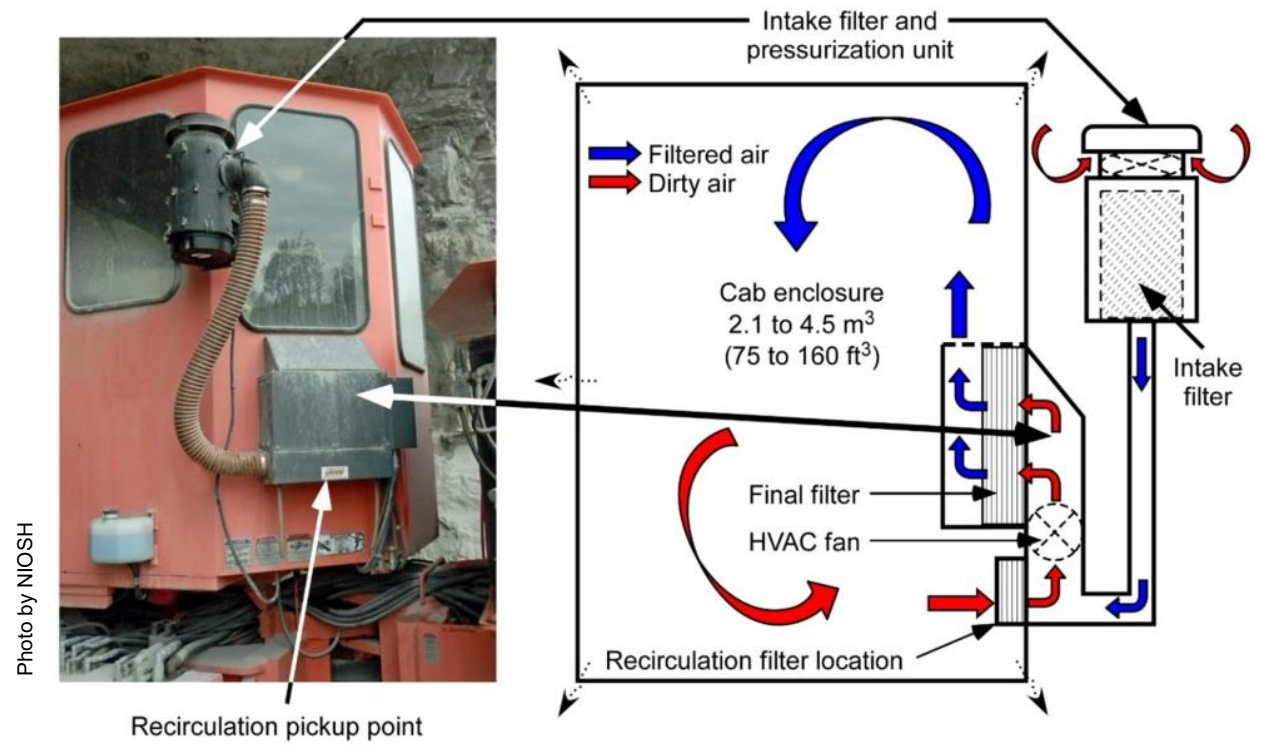

Figure 6. Final filter system configuration tested with MERV 16 and HEPA filters.

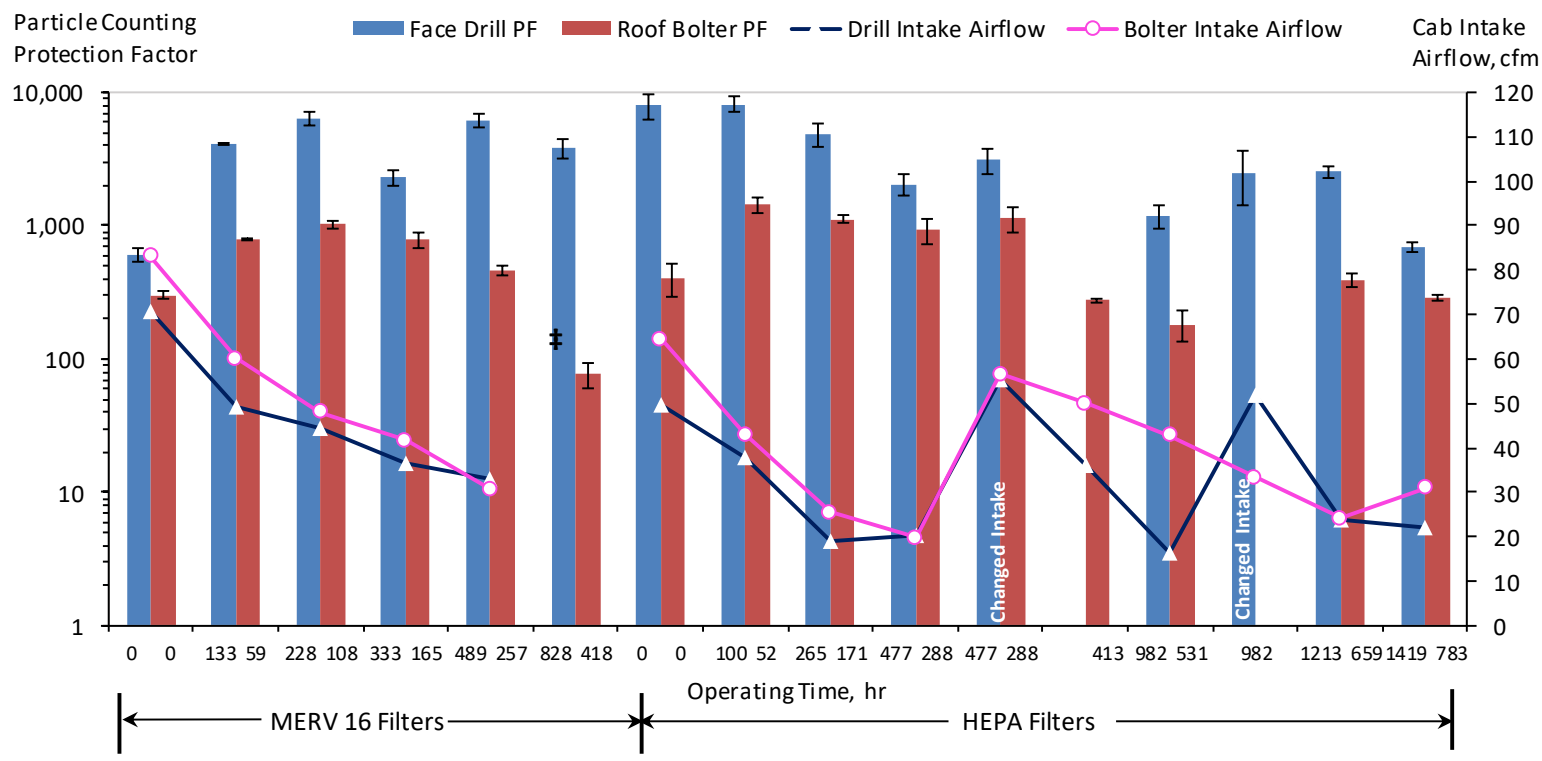

¥ Intake air readings not shown due to measurement anomalies.

Figure 7. Long-term field study test results of final filter system using MERV 16 and HEPA filters. 
Applying secondary enclosure design considerations for maintaining an effective filtration and pressurization system

Several secondary design considerations are recommended for maintaining the highest performance of environmental enclosures [NIOSH 2012a; Cecala et al. 2014]. These secondary considerations are described below.

Locating intake air inlet away from highest airborne contaminant generation sources

The air inlet to the cab filtration system should be located away from the highest potential sources of contaminant generation. Field dust sampling of several outside locations on Caterpillar (CAT) D11N and D10N bulldozers during overburden removal operations showed that the respirable dust levels near the cab intake inlet area beneath the cab and fuel tank $(6 \mathrm{ft}$ above the ground) were between 2 and 3 times higher than those up along the sides of the cab (about $11 \mathrm{ft}$ above ground level) [NIOSH 2001a]. These findings suggest that the cab filter loading rates can be reduced by these amounts by increasing the air inlet location further away from the ground level dust sources. Agricultural cabs used on tractors for pesticide spraying applications were observed to have their cab filtration system inlets located on top of the cabs [Hall et al. 2002]. The John Deere 7000 series tractor had the inlets on the top side of the cab and the Nelson spray cab on a Massy Ferguson 396 tractor had them on the top front of the cab, away from the typical spraying operations at the back of the tractors.

\section{Avoiding heaters, fans, or HVAC discharge vents at the floor level of the cab}

Any air blown across the floor of the environmental enclosure can aerosolize contaminants/dusts from the floor. During one field study, a drill cab enclosure had noticeably higher respirable dust levels inside the cab when the floor heater was being operated during the winter months. Further testing in the maintenance shop during a non-production shift confirmed that respirable dust concentrations inside the cab were $0.26 \mathrm{mg} / \mathrm{m}^{3}$ with the floor heater operating as compared to $0.01-0.03 \mathrm{mg} / \mathrm{m}^{3}$ without the floor heater operating [NIOSH 2001b; Cecala et al. 2001; Cecala et al. 2005].

Incorporating remote operator control of processes within enclosure to minimize the frequency of opening the enclosure to the outside

Doors and windows must be keep closed to maintain pressurization of the cleaned air inside the enclosure. A field study of a drill operator frequently opening the cab door to guide the joining of additional drill steels showed a 9-fold increase in dust levels inside the cab during the time when the door was opened [Cecala et al. 2007; NIOSH 2008a; Cecala et al. 2009]. Average respirable dust concentrations measured with a real-time dust monitor were $0.09 \mathrm{mg} / \mathrm{m}^{3}$ with the enclosure door closed and $0.81 \mathrm{mg} / \mathrm{m}^{3}$ with the door opened. Figure 8 (left) shows the drill operator opening the cab door for the last 30-45 sec of the 3-min process to add drill steels. The operator cab was closed for about the first two minutes of remotely maneuvering an additional section of drill steel from a rotating turret into place to be threaded. The visible airborne dust from operation drilling appeared to be dissipated by the time the operator opened the door to guide the jointing process of the additional drill steel; however, Figure 8 (right) shows that there were still notably higher respirable dust levels drawn into the cab when the door was opened as compared to when it was closed. This drill was the $4^{\text {th }}$ vehicle cab field tested in Table 1 , and had an average PF of 18 . The $5^{\text {th }}$ and $6^{\text {th }}$ cab vehicles field tested in Table 1 had higher PFs of 52 and 89, 
respectively, with all of their drill operations remotely controlled from inside the cab. Other field studies showed increases in respirable dust or DPM inside enclosures when pressurization was lost from opening doors or windows [Noll et al. 2011; Cecala et al. 2012; Noll et al. 2014a].

\section{Using mechanical filter media}

It is recommended to use filters having the mechanical type filter media rather than the electrostatic type filter media [NIOSH 2012a; Cecala et al. 2014]. Mechanical filters depend primarily on the capture processes of: 1) interception, where particles follow the airstream within one particle radius of the fabric fibers and adhere to them; 2) impaction, where particles diverge from the airstream and directly embed into one of the fibers; and 3) diffusion, where the smallest particles collide with gas molecules, which alters their flow path so they are captured by interception or impaction [NIOSH 2012a]. As the mechanical filters load, they tend to acquire a dust cake on the media and become more efficient. Continual loading of these filters increases their differential pressure or resistance to airflow to a point where they have to be changed. Electrostatic filters use fabric media that is able to sustain an electrostatic charge for primarily attracting the particles to adhere to the fabric fibers [NIOSH 2012a]. These filters tend to provide a lower resistance to airflow or pressure drop as compared to mechanical filters. However, electrostatic filter efficiency can be reduced with filter loading or when exposed to substances that can reduce the electrostatic charge on the filter fibers [Martin and Moyer 2000; Raynor and Chae 2004].
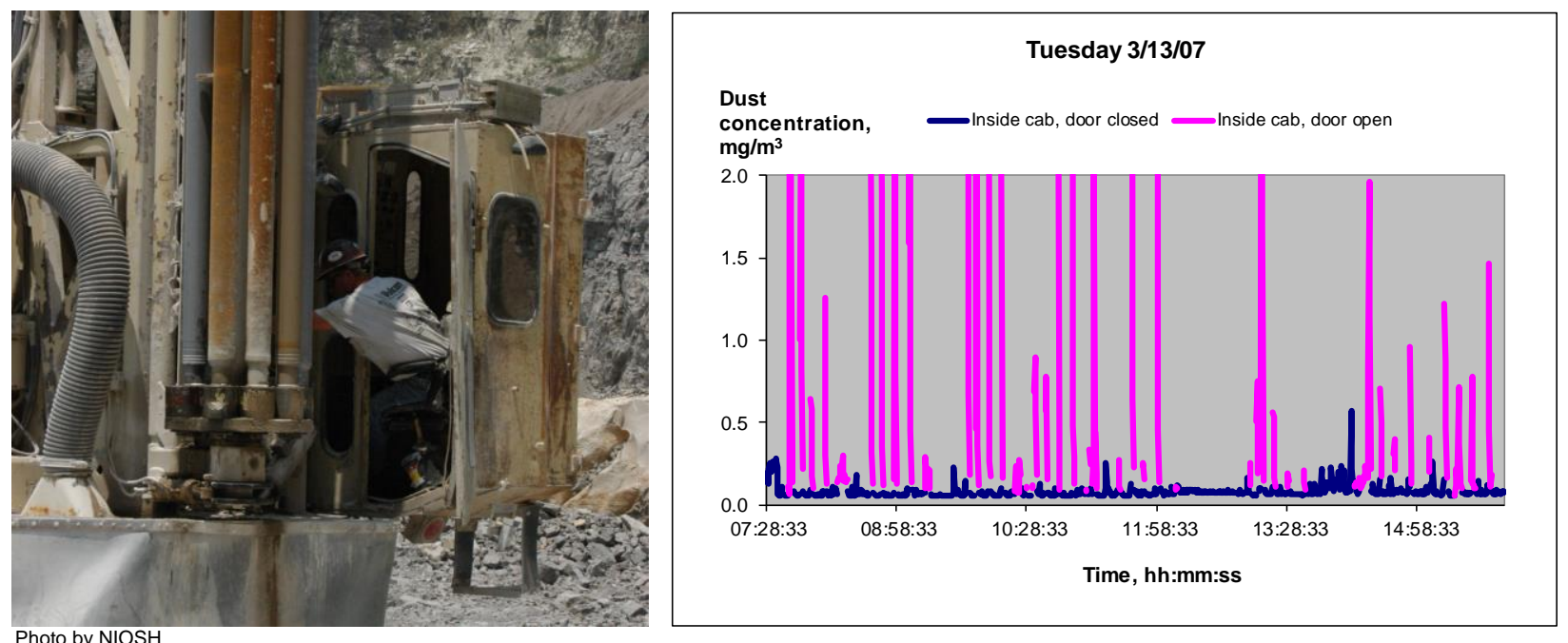

Figure 8. Drill operator opening door to guide drill steel (left); one shift of real-time respirable dust levels inside the cab with the door closed and open (right).

\section{Monitoring cab system performance with a cab pressure instrument}

Continually measuring enclosure pressurization shows when its status has notably changed. A measurable loss in pressure over time can indicate several possible developments to the system which include the reduction in intake airflow into the enclosure and/or a loss of enclosure integrity. The most likely cause of intake airflow loss into the enclosure is filter loading as discussed above [Cecala et al. 2016]. Other causes for intake airflow loss could be a missing recirculation filter, pressurizer fan failure, or HVAC fan failure. Another source of pressure loss 
is deterioration in enclosure seals to the outside (doors, windows, etc.). Therefore, continually measuring cab pressure can provide important feedback as to when the system needs to be inspected and requires maintenance - so as not to diminish the air cleaning performance of the environmental enclosure as previously discussed above.

Size and locate filter element(s) into the system to facilitate easy replacement and maintenance

Filter elements should be sized so that they can remove their intended contaminants over a reasonable time period of operation and should be located for easy access and replacement. Particulate or dust filter(s) should have enough filter media area to capture and retain ample amounts of dust while operating within a suitable filter pressure range to maintain adequate HVAC system airflow. Initial field testing of the Fletcher filtration systems (shown in Figure 6) showed that an inadequately sized small-panel recirculation filter became more quickly loaded/restricted and had to be changed approximately three times more often than the other filters in the system [Cecala et al. 2012]. These filters should also be located for easy accessibility to facilitate maintenance of their replacement and inspection. The easier a filter is to change, the less contamination should occur to the worker performing the task and to the work area. Securing filter elements and compression-sealing their gaskets are usually accomplished with screw-in fixtures, wingnuts, spring clips, etc. Figure 4 illustrates an example of easy access to the filter elements in the back of a pesticide sprayer tractor cab, secured with a screw-in pressure application bar. This figure further illustrates visible leakage caused by a bowed flange in the filter housing. After the bowed flange and filter gasket in the filter housing were fixed, cab penetration was reduced from $11 \%$ (a PF greater than 100) to less than 1\% (a PF greater than 100) [Heitbrink et al. 2003]. Finally, incorporating a protective screen into the design of a filter element can prevent media damage during its replacement, thereby increasing the cab enclosure's protection factor performance [Organiscak et al. 2013].

Use impermeable materials on interior enclosure surfaces for lower dust retention and easier housecleaning

When workers enter enclosures with muddy shoes and dusty clothes, this material can become an internal source of dust exposure. Using interior materials that retain less dust and are more easily cleaned can reduce dust generation inside the enclosure. For example, the use of vinyl seating and rubber floor mats as compared to fabric seats and carpeted floors can reduce dust generation. Limited field research has shown that applying sweeping compound for the working shift on the floor had a greater effect in reducing inside dust concentrations in cabs with rubber floor matting when compared to carpeted floors [NIOSH 2001c]. The sweeping compound and dirt on the floor is then swept out at the end of the working shift.

\section{Testing and Monitoring Environmental Enclosures}

Sampling of airborne contaminants (dusts, DPM, droplets, vapors) inside and outside of environmental enclosures is essential in determining the exposure of the occupants to these substances and the relative effectiveness of the enclosure on controlling these airborne contaminants. Control of outside contaminants is typically expressed as protection factor (PF), reduction efficiency $(\eta)$, or penetration (Pen) as shown below, using inside and outside enclosure concentrations (Equation 3 through Equation 5). Equation 6 shows how these measures are 
mathematically related and Table 4 compares these measures. As shown in the table, an enclosure with a PF of 25 has a reduction efficiency of $96 \%$ or a penetration of $4 \%$.

$$
\begin{aligned}
& P F=\frac{c}{x} \\
& \eta=1-\frac{x}{c} \\
& \text { Pen }=\frac{x}{c} \\
& P F=\frac{1}{1-\eta}=\frac{1}{P e n}
\end{aligned}
$$

where:

$$
\begin{aligned}
& P F=\text { protection factor, ratio, } \\
& \eta \quad=\text { reduction efficiency, fractional or expressed in percent, } \\
& P e n=\text { penetration, fractional or expressed in percent, } \\
& x \quad=\text { contaminant concentrations inside environmental enclosure, and } \\
& c \quad=\text { contaminant concentrations outside environmental enclosure. }
\end{aligned}
$$

Table 4. Comparison of environmental enclosure performance measures

\begin{tabular}{rrr}
\hline $\begin{array}{c}\text { Protection } \\
\text { Factor } \\
\text { (Ratio) }\end{array}$ & $\begin{array}{c}\text { Reduction Efficiency x 100 } \\
\text { (Percent) }\end{array}$ & \multicolumn{2}{c}{$\begin{array}{c}\text { Penetration x 100 } \\
\text { (Percent) }\end{array}$} \\
\hline 5 & 80 & 20 \\
10 & 90 & 10 \\
25 & 96 & 4 \\
50 & 98 & 2 \\
100 & 99 & 1 \\
1000 & 99.9 & 0.1 \\
\hline
\end{tabular}

Also, measuring environmental enclosure airflows and pressures is helpful in maintaining the system's optimum performance. Notable airflow and pressure changes to the environmental enclosure usually indicate filter loading and/or cab integrity maintenance issues that need to be addressed. 


\section{Respirable Dust}

Respirable dust is the one of most common aerosols sampled at mining and construction sites for industrial hygiene risk assessment of the work environment and worker exposures. Permissible exposure levels (PELs) for respirable dust and other airborne contaminants mandated by the U.S. government in mining and construction can be found in the Code of Federal Regulations (CFR) Titles 30 and 29, respectively [CFR 2016]. Other occupational exposure limits for airborne contaminants are threshold limit values (TLVs) published by the American Conference of Governmental Industrial Hygienists (ACGIH) and recommended exposure levels (RELs) published by NIOSH [ACGIH 2016; NIOSH 2007b].

\section{Gravimetric Respirable Dust Sampler}

The most common type of respirable dust sampler is gravimetric based. This sampler is usually comprised of a constant-flow personal sampling pump, a size-selective cyclone, and a filter cartridge. Figure 9 (left) shows the personal gravimetric sampler (Zefon International, Ocala, FL) approved for use in the metal/nonmetal mining industry. As part of the sampler depicted in Figure 9 (left), a 10-mm Dorr-Oliver cyclone separates the respirable fraction (dust with an aerodynamic diameter less than $10 \mu \mathrm{m}$ in size) from the oversize dust which is deposited into the grit pot at the bottom of the cyclone. The respirable fraction flows out of the top of the cyclone and is deposited on a pre-weighed filter cassette. The personal sampler pump flow rate specified for measuring respirable dust at metal/nonmetal mining operations with this approved sampler is 1.7 L/min. Some duty of care must be taken during sampling and handling of this personal sampler to keep the cyclone assembly in the upright position so that no oversized particles in the grit pot are deposited into the filter cassette. Other gravimetric sampler devices used for sampling airborne agents in different industries are specified by MSHA, OSHA, ACGIH, and NIOSH [CFR 2016; ACGIH 2016; NIOSH 2007b].

Once the filter cassette is removed from the cyclone assembly, it is post-weighed in a laboratory at nearly identical temperature and humidity conditions as the pre-weight measurement to determine the net weight gain of the respirable dust sample. The time-weighted average (TWA) dust concentration of the sample (typically for an 8-hr working shift) is determined by Equation 7 below. The deposited dust on the filter media can be further analyzed for its particular mineral content such as crystalline quartz by either NIOSH Method 7500 (X-ray diffraction or XRD) or NIOSH Method 7603 (infrared or IR absorption analysis) [NIOSH 2016].

Dust Concentration $\left(\mathrm{mg} / \mathrm{m}^{3}\right)=\frac{\text { Net Dust Wt. }(\mathrm{mg})}{\text { Sampling Time }(\mathrm{min}) \times \text { Pump Flow Rate }(\mathrm{L} / \mathrm{min})} \times \frac{1000(\mathrm{~L})}{1\left(\mathrm{~m}^{3}\right)}$

Table 1 shows the TWA gravimetric respirable dust concentrations measured for cab field studies at mining operations and their associated PFs. As observed from this table, the shift-toshift TWA dust concentrations and protection factors can vary notably for a particular cab because of operational and work practice variations. The lowest PF shown for each cab may also be a result of the outside concentrations not being high enough during some shifts to accurately ascertain the effectiveness of the cab. Outside dust concentrations must be one to two orders of magnitude higher than the inside concentrations to validate PFs from 10 to 100 [Organiscak et al. 2004; Organiscak et al. 2016]. 


\section{Nephelometer}

Given that the gravimetric respirable dust sampler only provides a TWA concentration during an operational sampling period, another type of instrument is needed to indicate the operational dust variations within a sampling period. A nephelometer is an electronic light-scattering instrument that detects real-time respirable concentrations. The nephelometer can be adjusted to a measured dust mass concentration to improve its accuracy. Figure 9 (right) shows a ThermoScientific Model 1000AN personal DataRam (pDR) (Thermo Fisher Scientific, Waltham, MA) lightscattering instrument commonly used by NIOSH in conjunction with personal gravimetric samplers during respirable dust studies. Used together, these instruments measure and record time-stamped dust levels for download to a personal computer. Adjacent sampling with both types of instruments allows the nephelometer to be specifically calibrated to the gravimetric concentration of the particular type of dust sampled. The gravimetric TWA dust concentration divided by the nephelometer TWA dust level is the multiplying factor used to calibrate the nephelometer dust level data to gravimetric concentrations [Listak et al. 2007]. This real-time dust data was used to examine the dust concentrations measured inside a drill cab with the door opened and closed as previously described and shown in Figure 8. Such real-time dust information allows for analysis of operational variables related to high respirable dust concentrations.
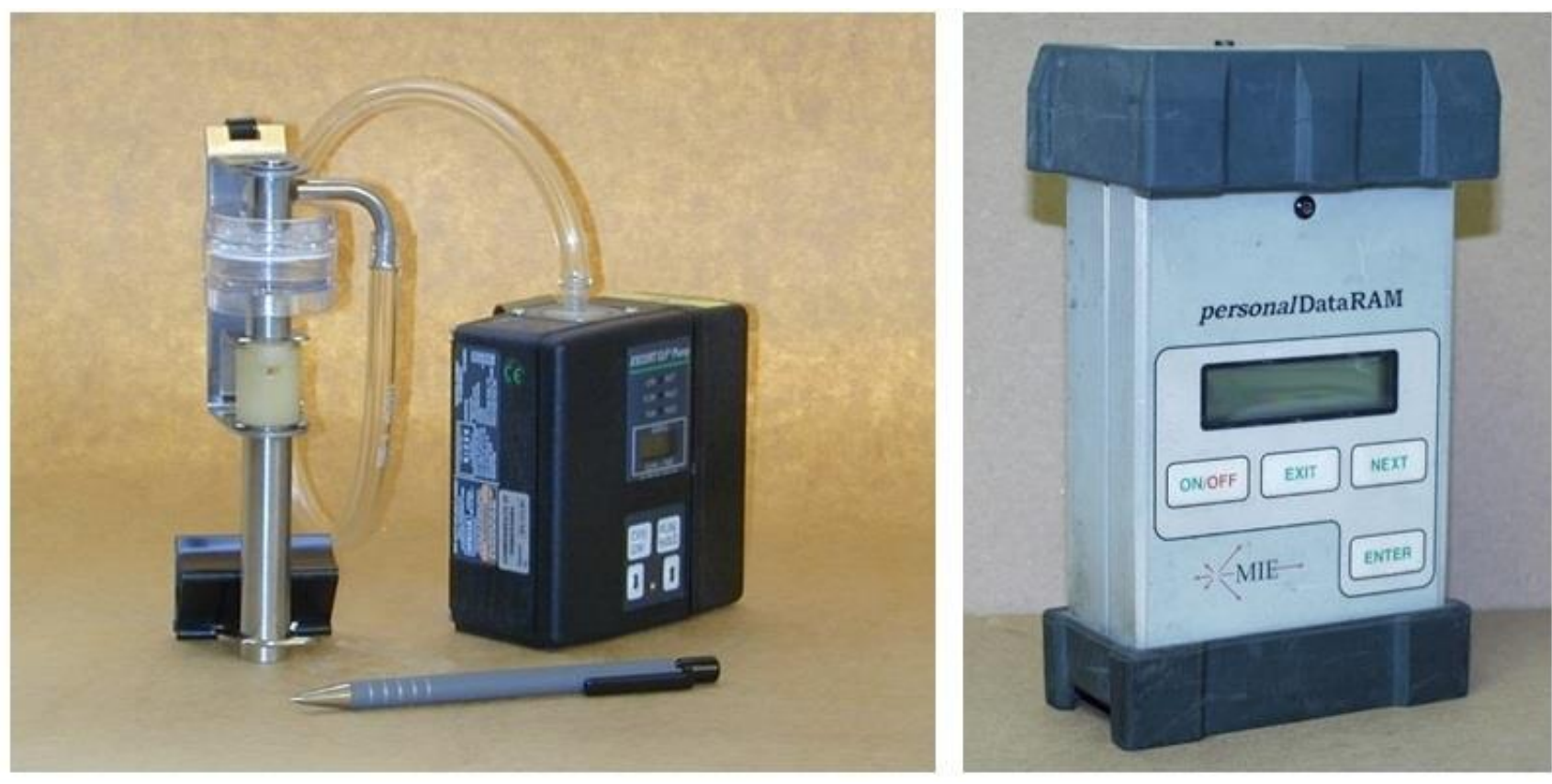

Figure 9. Personal gravimetric sampler (left); passive nephelometer

Photos by NIOSH light-scattering instrument (right). 


\section{Diesel Particulate Matter (DPM)}

Worker DPM exposure is regulated by the U.S. government for operating diesel vehicles in underground metal/nonmetal mines as described in CFR Title 30 [CFR 2016]. As shown in Figure 10 (left), a DPM sampler is comprised of a constant-flow sampling pump, a size-selective cyclone, and a DPM filter cartridge. This sampler is similar to the respirable gravimetric dust sampler in that it also uses a 10-mm SKC conductive cyclone (SKC Inc., Eighty Four, PA) operating at an airflow rate of $1.7 \mathrm{~L} / \mathrm{min}$ to separate the non-respirable from the respirable aerosols. The respirable-sized aerosols flow to a special SKC DPM cassette consisting of an internal 0.8 - $\mu \mathrm{m}$ cut-point impactor to remove the respirable dust before reaching the two tandem quartz fiber filters [Cauda et al. 2014]. The DPM aerosol is deposited on the first fiber filter with the second downstream filter used as a dynamic blank. These samples are analyzed for elemental carbon (EC) and total carbon (TC) by NIOSH Method 5040 [NIOSH 2016]. DPM concentrations measured by this method are TWA concentrations measured for the sampling period.

In order to measure changing DPM concentrations during the shift, NIOSH developed a realtime EC monitor using laser extinction [Noll et al. 2013; Noll and Janisko 2013; Noll et al. 2014b]. EC was used as the analyte because it makes up most of the DPM, it is not prone to interferences, and it is a proportional to laser extinction. This instrument was commercially developed into a portable personal real-time sampler unit for DPM sampling. Figure 10 (right) shows the Airtec diesel particulate monitor that is commercially available (FLIR Instruments, Boston, MA). This instrument uses a size-selective cyclone and a $0.8-\mu \mathrm{m}$ cut impactor cassette (without the quartz filters) to separate the dust from the DPM, which is drawn into the EC monitor. The Airtec measures and time-stamps short-term EC/DPM concentrations throughout the shift (5- , 10-, and 15-min moving averages recorded every minute) which can be downloaded to a computer for operational analysis.

Underground comparisons of the FLIR DPM sampler with the standard method of DPM exposures (NIOSH 5040 analytical method) showed no significant differences between the measurement methods, and the FLIR DPM instrument was found not to be affected by dust and humidity [Noll and Janisko 2013]. This instrument was used to document the effects of opening and closing a cab's door or window on EC (or DPM) concentrations measured on a face drill at an underground limestone mine (see Figure 11) [Noll et al. 2014a]. This figure illustrates that the inside cab EC concentrations similarly tracked the outside concentrations when the cab pressure was zero from an open window or door. Inside EC concentrations deviated from this trend and remained notably lower than outside concentrations only when positive cab pressures were achieved from blowing filtered intake air into the cab with the windows or doors closed. Opening a door or window clearly reduces the enclosed cab's pressure to zero and has a negative impact on controlling DPM inside the cab. 

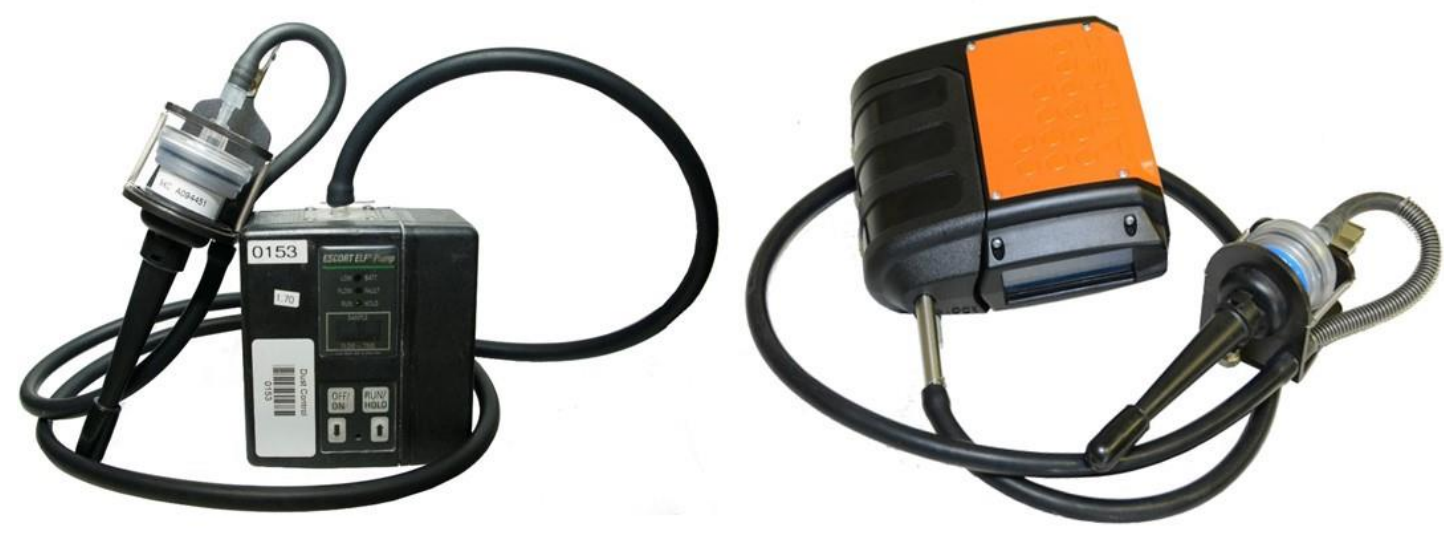

Photos by $\mathrm{NIOSH}$

Figure 10. DPM sampler (left); real-time EC/diesel particulate monitor (right).

\section{Particle Counting}

Particle counting is the measurement method used to quantify filtration performance with respect to the number and size of airborne particles removed. This measurement method is used by ASHRAE to classify air filter efficiency ratings in Table 3 [ASHRAE 1999]. ASAE also previously devised a consensus standard for field testing a cab's protection factor performance with particle counters, and specified a minimum 50:1 cab PF performance criteria on 3- $\mu \mathrm{m}$ diameter particles for pesticide applications. This procedure required two optical particle counters, one placed inside and the other outside the cab, to examine its protection factor on 2$\mu \mathrm{m}$ to $4-\mu \mathrm{m}$ particles on an end-use tractor as it drives along [ASAE 1997]. NIOSH examination of this test procedure indicated that inconsistent and low particle count data for the $2-\mu \mathrm{m}$ to $4-\mu \mathrm{m}$ particles outside the cab provided unreliable cab performance results. NIOSH recommended using smaller submicron particles as test media for cab filtration system performance, given the larger number of submicron particles present in the air [Heitbrink et al. 1998]. The advantage of particle counting as compared to gravimetric sampling for measuring filtration system performance is that a large number of smaller particles (submicron particles) are available at lower respirable dust mass concentrations, providing a better test medium for comparative performance testing of environmental enclosures [Organiscak et al. 2004; Organiscak et al. 2016]. 


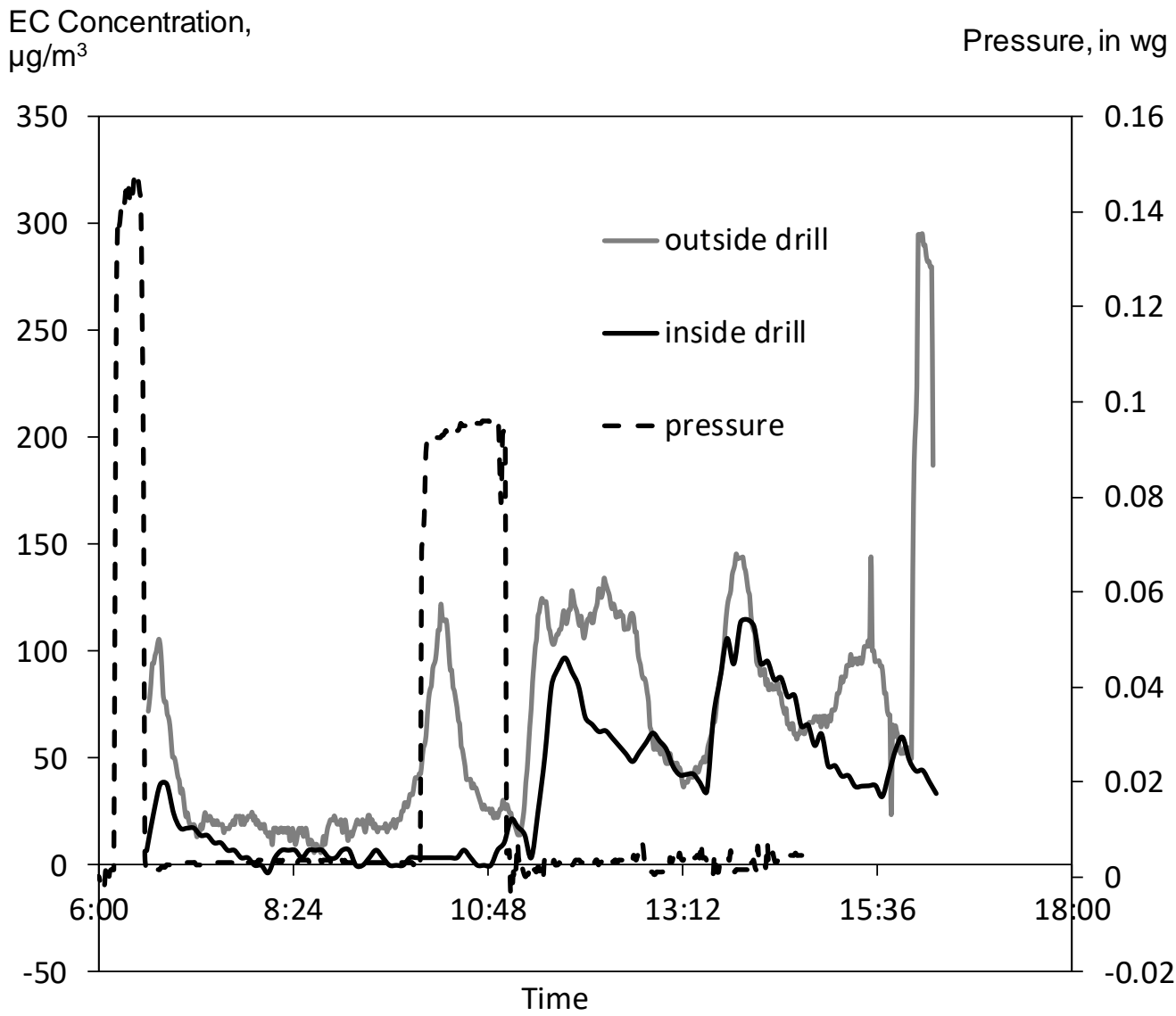

Figure 11. EC concentrations and cab pressure measurements made on an underground drill cab.

NIOSH laboratory and field testing of cab enclosures shows that the largest number of particles in the atmosphere are submicron, with the greatest number of particles detected in the instrument's smallest $0.3-\mu \mathrm{m}$ to $0.5-\mu \mathrm{m}$ size range [NIOSH 2008b; Organiscak et al. 2013]. High correlation $(r>0.98)$ was observed between the enclosures' PFs determined from the $0.3-\mu \mathrm{m}$ to $0.5-\mu \mathrm{m}$ particle size range and the accumulation of all the submicron particles size ranges $(0.3-$ $\mu \mathrm{m}$ to $1.0-\mu \mathrm{m})$. Figures 12 and 13 illustrate these high correlations along the unity line for the laboratory and field tests, respectively. These figures also show that lower correlations $(r<0.68)$ exist between the PFs measured with submicron particles $(0.3-\mu \mathrm{m}$ to $1.0-\mu \mathrm{m})$ and the larger particles $(>1.0-\mu \mathrm{m})$ because of fewer particles available at these larger size ranges in the ambient air for reliable enclosure performance testing. Therefore, NIOSH recommends using the submicron particle ranges such as $0.3-\mu \mathrm{m}$ to $0.5-\mu \mathrm{m}$ or $0.3-\mu \mathrm{m}$ to $1.0-\mu \mathrm{m}$ for enclosure performance testing, because these size ranges are where the largest portion of particles are available in the ambient air and are the most challenging to be removed by the enclosure's filtration system. 


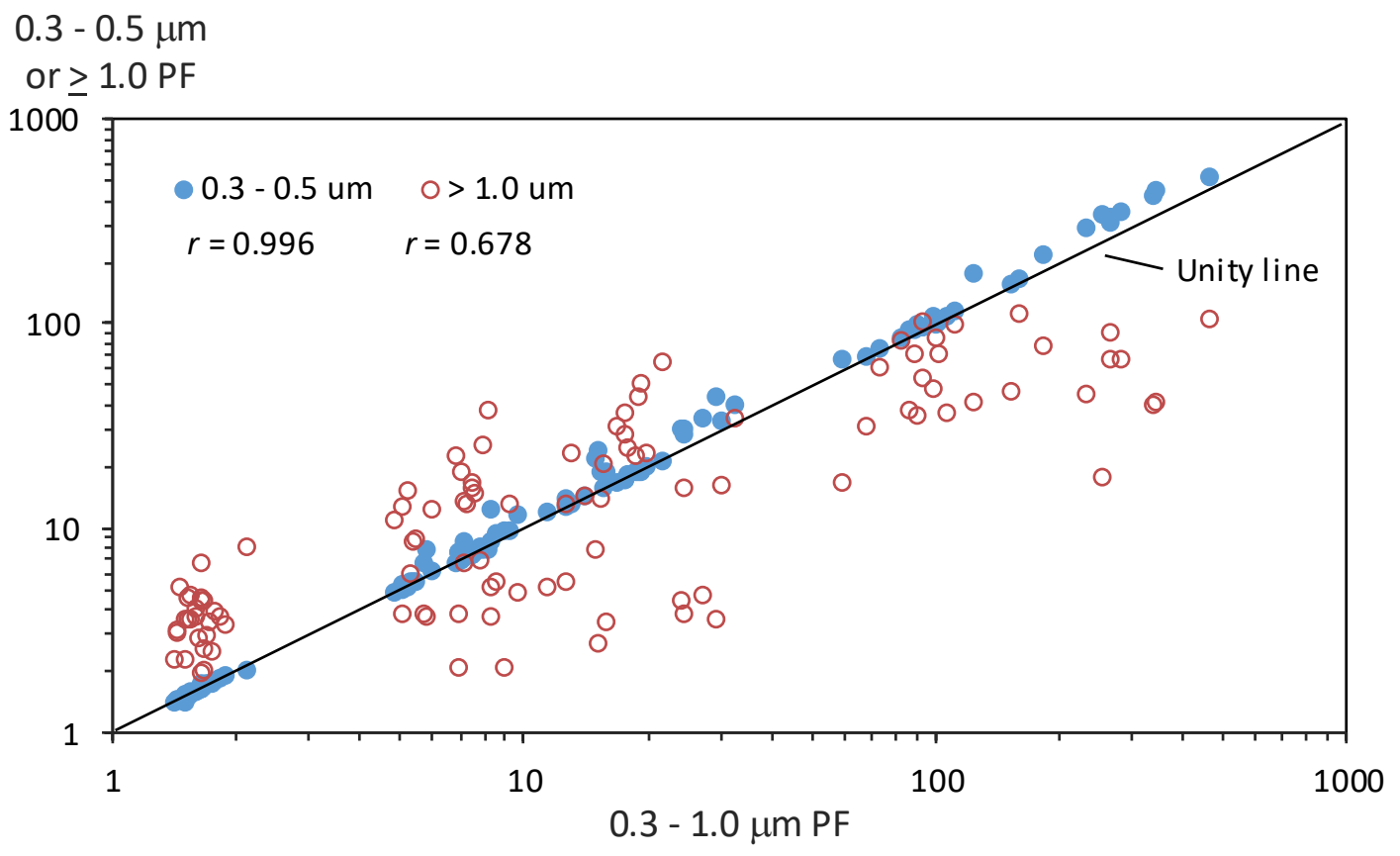

Figure 12. Particle size-related enclosure PFs measured in the laboratory.

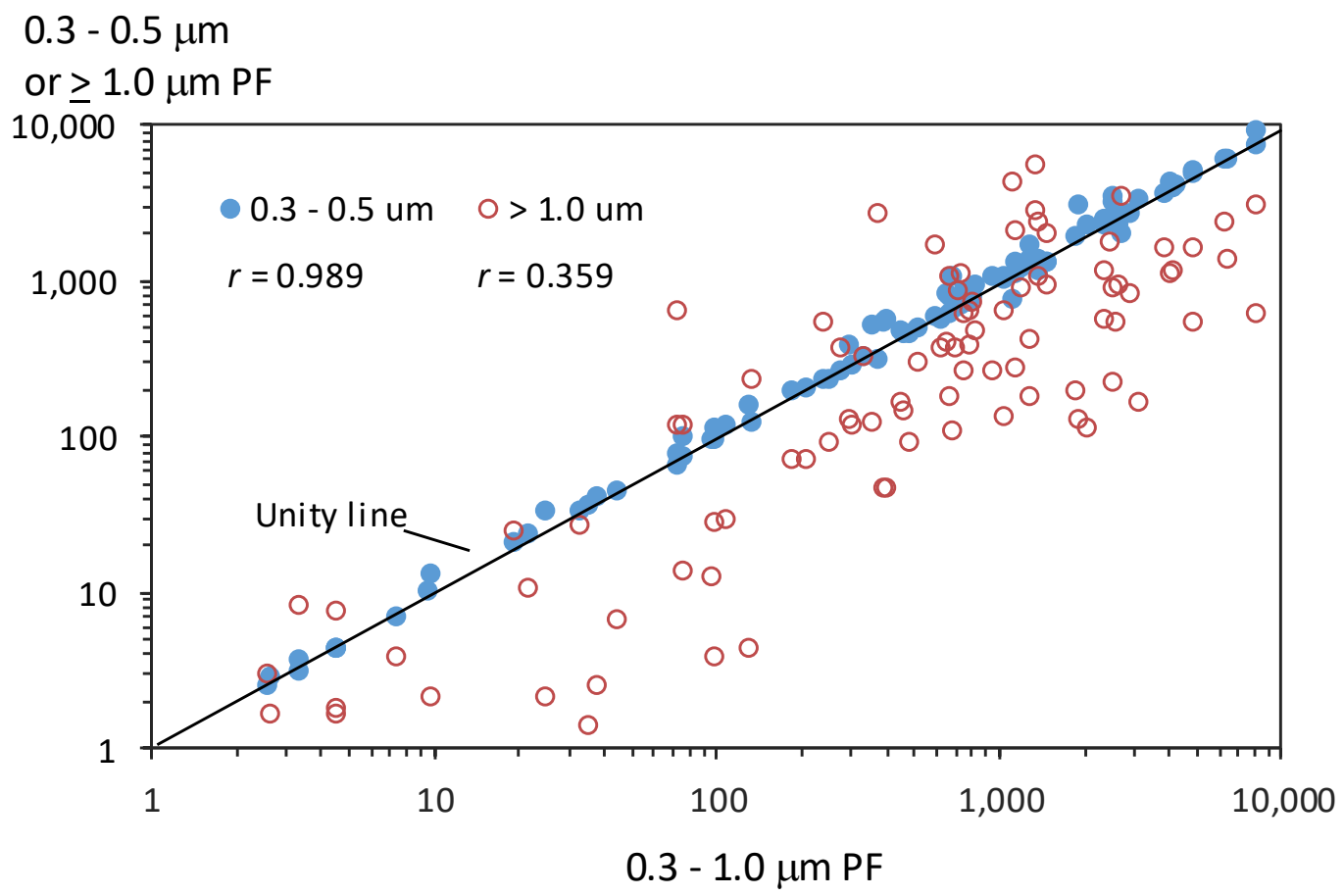

Figure 13. Particle size-related enclosure PFs measured during field studies. 
Optical particle counters are available with different performance specifications and userselectable configurations. They operate by detecting the physical relationship between the forward scatter of a laser beam and particle diameter in a sample volume of air. Many of the instruments available can measure down to submicron particle sizes of $0.3-\mu \mathrm{m}$ to $0.5-\mu \mathrm{m}$. The more costly instruments provide a user-selectable and larger number of particle size ranges, while the lower cost instruments usually have a lower number of defined particle size ranges. Most instruments have data logging capabilities with user-selected sampling periods or sample volumes.

Figure 14 (left) shows TSI optical particle sizer model 3330 desktop instrument (TSI Incorporated, Shoreview, MN) used by NIOSH with up to 16 user-selectable size ranges. This instrument is capable of operating in aerosol concentrations up to 3,000,000 particles/L with 5\% coincidence error. Coincidence error is primarily the undercounting of particles hidden behind other particles as particle concentrations increase. Figure 14 (right) shows a handheld Met One model HHPC-6 instrument (Met One Instruments, Grants Pass, OR) used by NIOSH with six fixed particle size ranges of $0.3-\mu \mathrm{m}$ to $0.5-\mu \mathrm{m} ; 0.5-\mu \mathrm{m}$ to $0.7-\mu \mathrm{m} ; 0.7-\mu \mathrm{m}$ to $1.0-\mu \mathrm{m} ; 1.0-\mu \mathrm{m}$ to $3.0-\mu \mathrm{m} ; 3.0-\mu \mathrm{m}$ to $5.0-\mu \mathrm{m}$, and $>5.0-\mu \mathrm{m}$. It is capable of counting up to 70,670 particles/L with $5 \%$ coincidence error. The higher grade TSI instrument is about 4 times the cost of the handheld Met One and could be used in higher dust/particle concentrations during production operations. The lower cost Met One instrument is more suitable for static testing cab enclosures with the particles in the ambient air under nonproduction settings.

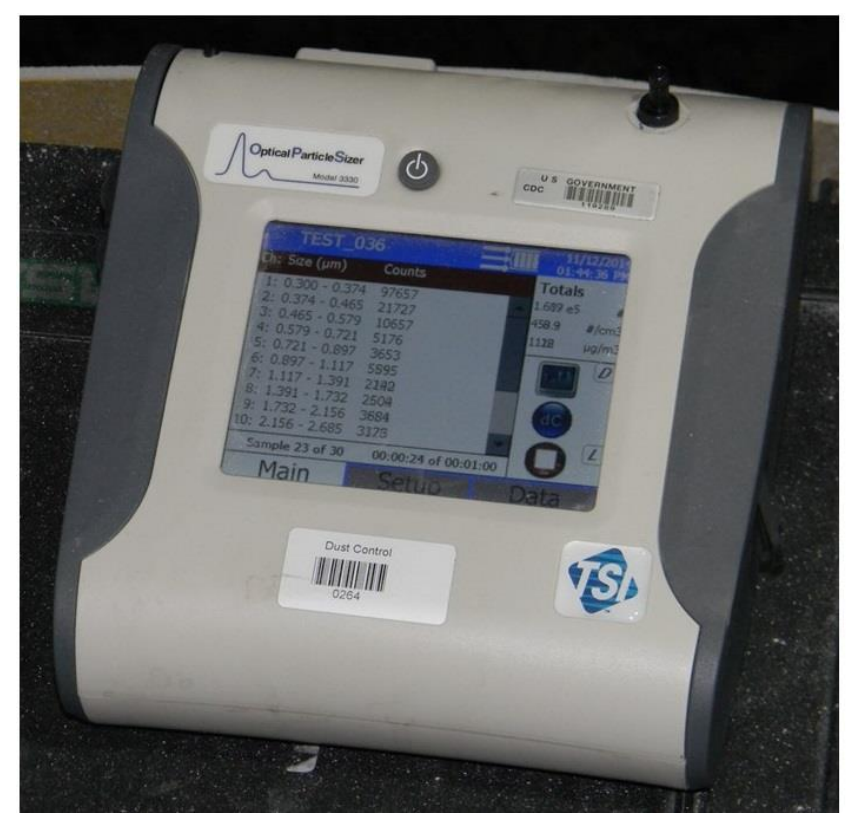

Figure 14. Desktop size selectable optical particle counter (left); handheld fixed-size optical particle counter (right).

Particle counting performance testing of enclosures can use either a one- or two-instrument sampling methodology. Ideally this type of testing should be performed at or near steady state concentration conditions. A steady state enclosure condition is the point in time where the interior contaminant concentrations reach their optimum lowest achievable concentrations 
provided by the filtration system. A two-instrument sampling methodology simultaneously measures upstream and downstream of the filtration system and introduces individual instrument biases into the experimental error, so it is recommended that the instruments be rotated between the sampling locations an equal number of times to average out these biases. The two-instrument methodology was specified for mobile testing of a cab by ASAE and was primarily used by NIOSH in laboratory and field studies [ASAE 1997; Heitbrink et al. 1998; Hall et al. 2002; Heitbrink et al. 2003; NIOSH 2008b; Organiscak and Cecala 2008; Cecala et al. 2012; Organiscak et al. 2013; Cecala et al. 2016; Organiscak et al. 2016]. To evaluate optimum performance, enclosure filtration effectiveness should be determined from the particle count data when the inside enclosure concentrations are at their lowest steady state conditions.

The sampling time period needed to collect sufficient stable interior data may be shorter or longer, depending on the enclosure volume and airflow quantity of the filtered air. The time to reach near steady state conditions after the enclosure is closed off from the outside contaminants can be roughly estimated by using the ventilation dilution equation for the enclosure volume (Equation 8, assuming no interior generation) [ACGIH 2010]. The time estimate to achieve a $95 \%$ enclosure interior concentration reduction near steady state conditions is calculated by using 0.05 for $\mathrm{x} / \mathrm{x}_{\mathrm{o}}$ ratio in the dilution equation, yielding a time period of 3 times the ratio of enclosure volume to airflow quantity as show in Equation 9. A time estimate to achieve a $99 \%$ enclosure interior concentration reduction near steady state conditions is calculated by using 0.01 for $\mathrm{x} / \mathrm{x}_{\mathrm{o}}$ ratio in the dilution equation, yielding a time period of 4.6 times the ratio of enclosure volume to airflow quantity as shown in Equation 10. As can be seen from these equations, the time is directly related to enclosure volume and indirectly related to airflow quantity. The airflow quantity used in these equations should be the airflow quantity that is filtered. Intake airflow rate should be used if it is the only air filtered, or total airflow rate should be used if both intake and recirculated air are filtered.

$$
\begin{aligned}
\Delta t & =-\frac{V}{Q} \ln \left(x / x_{o}\right) \\
\Delta t & =\frac{3 V}{Q} \\
\Delta t & =\frac{4.6 \mathrm{~V}}{Q}
\end{aligned}
$$

where:

$$
\begin{aligned}
\Delta t= & \text { time to reach enclosure interior concentration, } \\
V= & \text { volume of enclosure, } \\
Q= & \text { airflow quantity of filtered air into enclosure, } \\
x_{o}= & \text { starting concentration inside environmental enclosure, } \\
x= & \text { concentration reached inside the enclosure after dilution with } \\
& 100 \% \text { contaminant-free air, and } \\
x / x_{o}= & \text { proportional concentration ratio inside the enclosure from contaminant-free } \\
& \text { ventilation; use } 0.05 \text { for } 95 \% \text { concentration dilution to steady state } \\
& \text { conditions or } 0.01 \text { for } 99 \% \text { concentration dilution to steady state conditions. }
\end{aligned}
$$


When performing this type of enclosure testing, particle concentrations should be continuously measured to detect when they reach their lowest and most stable interior levels for comparison with the outside concentrations for the same time period. In NIOSH laboratory and field testing, researchers typically conducted enclosure testing for 45 minutes when using only an intake filter and for 30 minutes when using both an intake and recirculation filter [NIOSH 2008b; Organiscak and Cecala 2008; Cecala et al. 2012; Organiscak et al. 2013; Cecala et al. 2016; Organiscak et al. 2016]. The most stable and last 15 minutes of data for these test periods were used for the data analysis.

Laboratory enclosure results have shown that identical filter test configurations were repeatable on different days of testing with different ambient submicron $(0.3-\mu \mathrm{m}$ to $1.0-\mu \mathrm{m})$ particle count concentrations outside the enclosure. Figure 15 illustrates some of the laboratory test results when using a high-efficiency intake filter with and without recirculation filter and wind. PFs were found to be relatively consistent when outside particle count concentrations were above 20,000 counts per liter and also above the instrument's 5\% coincidence error level of 70,670 particles/L. Although the enclosure's PF performance may have been slightly reduced in some of the tests when coincidence levels of the outside particle counter instrument were exceeded, these laboratory results indicate that enclosure performance was still adequately quantified under less than ideal test conditions [NIOSH 2008b; Organiscak et al. 2013]. A significant improvement in enclosure PF was attained by using a recirculation filter, and the wind was found to primarily have an adverse impact on particulate penetration into the enclosure when no recirculation filter was used. Finally, this particle counting method was also used in field studies for examining the performance of a three-filter system and a long-term comparison of MERV 16 and HEPA filters on cab filtration system performance [Organiscak et al. 2013; Cecala et al. 2016].

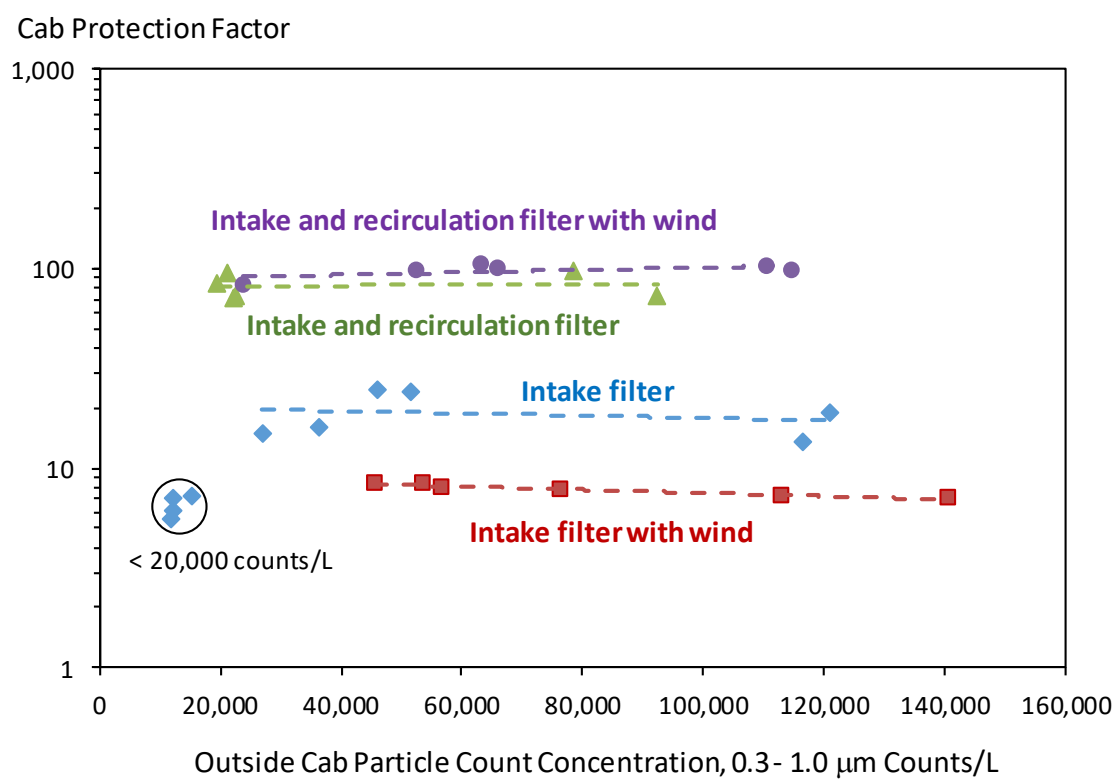

Figure 15. Laboratory particle counting test replicates for the high-efficiency intake filter configuration with and without a recirculation filter and wind. 
A single-instrument sampling methodology removes instrument bias from the testing, but it does not continuously measure both sampling locations for a more thorough examination of testing variability or experimental error. To perform this type of sampling, equal lengths of sample tubing are routed to the inside of the cab and outside of the cab near the intake airflow inlet. The particle counter should be initially used to monitor the inside of the cab until it reaches the lowest steady state conditions, and then be alternated for several minutes between the inside and outside sampling locations. When alternating the instrument between sampling locations, the sample lines should be purged for at least the first minute and the data collected after the line was purged should be used for the data analysis. Sampling inside and outside the enclosure should be replicated at least twice and may require additional replicates if the outside concentrations are highly variable during testing. This procedure was used to quantify cab PFs of at least 50:1 (outside to inside particle concentrations) for a pesticide spraying company after refurbishing and performing maintenance on 13 tractor cabs [Moyer et al. 2005]. ASABE specifies a minimum of four 10 -minute sampling replicates on $0.3-\mu \mathrm{m}$ to $0.5-\mu \mathrm{m}$ size particles outside and inside the cab enclosure using the single-instrument sampling method [ASABE 2017a].

\section{Gases, Vapors, and Liquid Droplets}

Many gases can be measured continuously with direct reading electronic instruments that use electrochemical, infrared, photoacoustic, etc. principles of detection. Vapors and gases can also be sampled by being collected in sorbent tubes using an air sampling pump for subsequent laboratory analysis. These sampling methods can be used to monitor environmental enclosures when suspected gas or vapor contaminants could be present from the outside environment.

NIOSH conducted some pesticide droplet sampling to help address concerns over the size of pesticides aerosols generated during air blast spay operations. Pesticide size distributions were measured at a site on an orchard in California's central valley near Visalia. During this study, the air blast sprayer directed a pesticide solution containing chlorpyrifos at two instruments used to evaluate the particle size distribution. One of the instruments was an aerodynamic particle sizer (APS Model 33b, TSI, St. Paul, MN), which sizes particles based on the transit time as they are accelerated between two laser beams within the instrument. As particles are passed through the two laser beams, scattered light is detected by two photomultiplier tubes and the time difference between these two events is measured - thus the particles are sized based upon transit time.

The other instrument used in this study was the micro-orifice uniform deposit impactor (MOUDI, MSP Corporation, St. Paul, MN). The MOUDI is an eight-stage cascade impactor that was operated at a flow rate of $30 \mathrm{~L} / \mathrm{min}$. This impactor is unique in that each stage rotates, which allows the collected material to uniformly deposit on the filters. In this study, the pesticide spray mist (liquid droplets) was collected on aluminum substrates that were coated in PAM vegetable oil (Conagra Brands, Chicago, IL). The 50 percent cut diameters for the MOUDI are: 18- $\mu \mathrm{m}, 10-$ $\mu \mathrm{m}, 6.2-\mu \mathrm{m}, 3.2-\mu \mathrm{m}, 1.8-\mu \mathrm{m}, 1.0-\mu \mathrm{m}, 0.32-\mu \mathrm{m}$, and $0.18-\mu \mathrm{m}$. The last stage of the impactor was not used in this study, and the stages were backed up with a $0.8-\mu \mathrm{m}$ mixed cellulose ester membrane filter. The impactor stages and back-up filter were then analyzed for pesticide chlorpyrifos by a modification of NIOSH Manual of Analytical Methods 5600 [Hall et al. 2002].

During this study, the particle size measurements were not made at the same time with the APS and the MOUDI. The instruments both sampled air through a custom sampling train that had an omnidirectional inlet from a $\mathrm{PM}_{10}$ sampler (Anderson-Grasby). The design flow for the $\mathrm{PM}_{10}$ 
sampler is $17 \mathrm{~L} / \mathrm{min}$ and the design flow for the MOUDI is $30 \mathrm{~L} / \mathrm{min}$. Therefore, the sampling train had to be designed so that $17 \mathrm{~L} /$ min could be pulled through the $\mathrm{PM}_{10}$ sampler, and an additional $13 \mathrm{~L} / \mathrm{min}$ of sheath air was added after the sample inlet to supply a total of $30 \mathrm{~L} / \mathrm{min}$ to the MOUDI. In addition, the MOUDI was enclosed in a positive pressure container to eliminate the possibility of small aerosols (generated from the blast air sprayer) leaking between the sample stages. The PM10 sampler was also used in the sampling train with the APS. The APS operated at a design flow rate of $5 \mathrm{~L} / \mathrm{min}$. Therefore, to pull air at the PM10 sampler designed flow rate $(17 \mathrm{~L} / \mathrm{min})$, an additional pump had to be used for the APS sample train. The APS and the additional pump pulled air through the $\mathrm{PM}_{10}$ sampling inlet, and the sampling train was designed so that the APS would collect isokinetic samples [Hall et al. 2002].

The measured distributions from this study indicated that there is a noticeable mass of aerosols in sizes less than $3 \mu \mathrm{m}$. This may be surprising, because most of the literature on this subject indicates that pesticide spray is typically larger than $100 \mu \mathrm{m}$. However, for this study the spray concentration was 1.5 gallons of concentrate in 500 gallons of water. The concentrate was 50 percent petroleum distillate. When the water evaporates from this spray droplet solution, a 100$\mu \mathrm{m}$ spray droplet will become an $11-\mu \mathrm{m}$ particle. ${ }^{5}$ This indicates that pesticide spray that does not deposit on the crop or on the ground could become a much smaller particle due to evaporation, thus explaining the generation of particles smaller than $3 \mu \mathrm{m}$ [Hall et al. 2002]. The results of this study indicated that a range of 3 percent to 23 percent of the chlorpyrifos aerosol mass was smaller than $3 \mu \mathrm{m}$. However, the mass concentration for these particles was less than the ACGIH TLV for chlorpyrifos at the time of the study [Hall et al. 2002].

Also, NIOSH has examined some direct reading carbon dioxide $\left(\mathrm{CO}_{2}\right)$ measurements to demonstrate that the quantity of intake airflow delivered into an environmental enclosure was more than adequate for human respiration for multiple people. A minimum recommended intake airflow quantity per person inside a cab enclosure is between 15 and $25 \mathrm{ft}^{3} / \mathrm{min}$ [ASAE 1997; ASABE 2013a; ASHRAE 2007; CEN 2009a]. Eighty to $118 \mathrm{ft}^{3} / \mathrm{min}$ delivered into a larger control room $\left(1,440 \mathrm{ft}^{3}\right.$ of volume) typically had less than $1,100 \mathrm{ppm}$ of $\mathrm{CO}_{2}$ concentrations, which was more than adequate for human respiration by multiple people inside the enclosure [Noll et al. 2015].

NIOSH furthermore conducted research on using $\mathrm{CO}_{2}$ gas sampling at comparative locations inside and outside an unoccupied cab enclosure using a special $\mathrm{CO}_{2}$ intake filter to quantify air leakage around the enclosure's filtration system. This research was conducted under a NIOSH CRADA with Clean Air Filter Company (CAF) to develop an expedient, simple, quantitative, and reliable field test method for measuring air leakage into enclosed cab filtration systems. This method was developed as an alternate to particle counting environmental enclosures, and removes enclosure measurement interferences from internal particulate generation such as dirty floors, interior surfaces, and abraded blower motor brushes [Cecala et al. 2005; Heitbrink and Collingwood 2005].

Several application approaches were investigated for the air leakage measurement method. A time decay model of inside enclosure concentration was developed (see Equation 11 below) for a timed concentration decay test, with a single instrument for determining if the enclosure is

\footnotetext{
${ }^{5}$ The dried droplet size is proportional to the cube root of the mass fraction of the nonvolatiles (spherical diameter) left over after all the water is evaporated from the pesticide droplet solution.
} 
meeting a particular air leakage target [Organiscak and Schmitz 2006]. This test is relatively easy to perform in that the monitor can be placed outside the enclosure for several minutes to measure ambient $\mathrm{CO}_{2}$ concentrations, and then put inside the enclosure to start the decay test with a stopwatch. However, the time calculation for comparison with the observed time to reach a particular concentration requires accurate knowledge of intake air quantity $(Q)$, enclosure volume $(V)$, and filter efficiency $(\eta f)$.

This test approach was demonstrated in the laboratory because the enclosure parameters and filter efficiency could be accurately measured, but would be quite challenging to measure accurately in the field [Organiscak and Schmitz 2006]. Steady state testing (represented by Equation 12 below) with two $\mathrm{CO}_{2}$ instruments similar to the particle counting testing (previously described above) was also examined in the laboratory, and researchers found that this testing reasonably quantified the leakage, but that instrument biases and reduced $\mathrm{CO}_{2}$ filter efficiency over time could diminish the accuracy of this approach [Organiscak and Schmitz 2006].

$$
\begin{aligned}
& \Delta t=-\frac{V}{Q} 1 n \frac{c Q\left(1-\eta_{f}+l \eta_{f}\right)-x Q}{c Q\left(1-\eta_{f}+l \eta_{f}\right)-x_{o} Q} \\
& P e n=\frac{x}{c}=1-\eta_{f}+l \eta_{f} \\
& l=\frac{x-i}{c-i}
\end{aligned}
$$

where:

$$
\begin{aligned}
& \Delta t=\text { time to reach enclosure interior concentration, } \\
& V=\text { volume of enclosure, } \\
& Q=\text { intake airflow quantity into enclosure, volume per time, } \\
& \eta_{f}=\text { intake filter efficiency, fractional, }(1-i / c) \\
& l=\text { proportion of cab intake air leakage, fractional, } \\
& x_{o}=\text { starting concentration inside environmental enclosure, } \\
& x=\text { concentration reached inside the enclosure, } \\
& c \quad=\text { concentration outside environmental enclosure, } \\
& i \quad=\text { immediate concentration after the filter, and } \\
& \text { Pen }=\text { enclosure penetration, ratio, } x / c
\end{aligned}
$$

In order to negate instrument bias, frequent instrument calibration in the field, and changing filter efficiency over time, another simpler single instrument assessment was examined to determine air leakage. This method measures relative $\mathrm{CO}_{2}$ concentration differences inside and outside the $\mathrm{cab}$ filtration system using the same instrument at or near steady state cab conditions. Equation 13 shown above was derived from Equation 12 to quantify air leakage around the $\mathrm{CO}_{2}$ intake test 
filter by measuring $\mathrm{CO}_{2}$ concentrations inside the cab, immediately after the intake filter, and outside the cab by using the same instrument. ${ }^{6}$

Figure 16 shows good agreement between the test results for a Sable CA-10a $\mathrm{CO}_{2}$ instrument (Sable Systems International, Las Vegas, NV) and two Vaisala GM70 $\mathrm{CO}_{2}$ instruments (Helsinki, Finland) simultaneously rotated between these three sampling locations as compared to a mass flowmeter measured air leakage conducted on CAF's laboratory cab test stand. Table 5 shows the data collected on a John Deere tractor cab while simultaneously using a Sable and Vaisala 1 instrument, and illustrates the consistent measurement biases between the two instruments at the sampling locations. However, each instrument measured comparable air leakages because their relative $\mathrm{CO}_{2}$ concentration differences in the cab filtration system were used to calculate leakage. This "Method for Leak Testing an Environmental Enclosure" has been patented in Australia, Canada, the United States, and the European Union [Organiscak and Schmitz 2009; Organiscak and Schmitz 2010a; Organiscak and Schmitz 2010b; Organiscak and Schmitz 2016].

Table 5. $\mathrm{CO}_{2}$ measurements on the John Deere tractor cab

\begin{tabular}{|c|c|c|c|c|}
\hline Instrument & $\begin{array}{r}\text { Cab } \\
\text { Concentration, } \\
\text { ppm }\end{array}$ & $\begin{array}{r}\text { Filter } \\
\text { Concentration, } \\
\text { ppm }\end{array}$ & $\begin{array}{r}\text { Outside } \\
\text { Concentration, } \\
\text { ppm }\end{array}$ & $\begin{array}{r}\text { Cab Leakage, } \\
\text { percent }\end{array}$ \\
\hline \multirow[t]{3}{*}{ Sable } & 19 & 14 & 420 & 1.2 \\
\hline & 18 & 13 & 405 & 1.2 \\
\hline & 17 & 13 & 429 & 1.0 \\
\hline \multirow[t]{3}{*}{ Vaisala 1} & 47 & 43 & 441 & 0.8 \\
\hline & 50 & 46 & 432 & 1.1 \\
\hline & 52 & 42 & 438 & 2.5 \\
\hline
\end{tabular}

${ }^{6}$ The instrument sample airline to each of these locations should be purged for a minute or two after it is switched to the new location before measuring $\mathrm{CO}_{2}$ concentrations. Air leakage is defined as the fractional amount (or percentage) intake air that bypasses the intake $\mathrm{CO}_{2}$ filter and is unfiltered. 


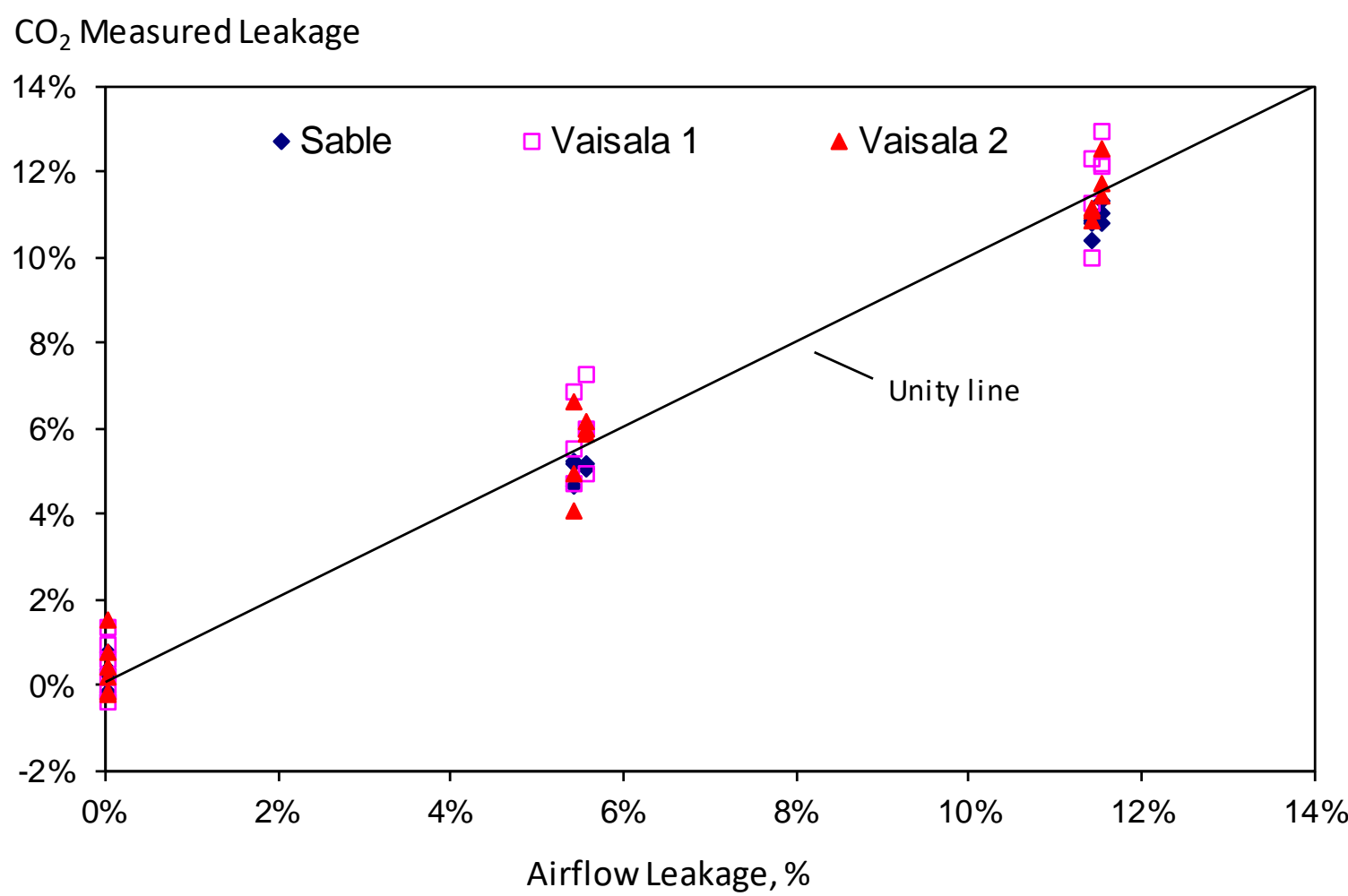

Figure 16. Air leakage test measurements made on Clean Air Filter (CAF) Company's test stand.

\section{Airflow and Pressure Measurements}

In addition to the methods outlined above, taking airflow and pressure measurements within environmental enclosures are other means of monitoring and maintaining desired filtration system performance. Figure 17 (left) shows digital pressure instrumentation that can be electronically data logged (top) or monitored via an analog gauge (bottom) that can be visually observed by the enclosure occupant. Continuous pressure monitoring of an environmental enclosure showed pressure decreases for filter dust loading and pressure increases from filter replacement and enclosure integrity repairs, thereby enhancing timely maintenance actions [Patts et al. 2017]. Figure 17 (right) shows a hotwire measurement of intake airflow being taken through a straight, smooth section of pipe attached to the cab enclosure. This measurement directly indicates when intake airflow decreases below a desired minimum and the filter needs to be replaced [Cecala et al. 2016, Patts et al. 2017].

Recirculation airflow in many cases has to be measured with a vane anemometer traversing the recirculation inlet area. Sometimes the total airflow blown back into the enclosure at the discharge outlet has to be measured to determine either the intake or recirculation airflow by subtraction. Although some of these airflow measurements may not be made under ideal conditions as recommended in ACGIH's industrial ventilation practices, consistency in measurement procedures and locations is important for examining changes to a particular HVAC/filtration system [ACGIH 2010]. 
Intake and recirculation airflows were measured during field studies to benchmark filters as they were loaded with dust and to determine when they needed to be replaced. Recirculation filters were replaced when their airflow dropped below the intake airflow into the enclosure [Cecala et al. 2012; Organiscak et al. 2013]. Intake HEPA filters were replaced when intake air quantity dropped below $25 \mathrm{ft}^{3} / \mathrm{min}$, which corresponded to cab pressure reductions below $0.05 \mathrm{in} \mathrm{wg}$ [Cecala et al. 2016]. Another source for pressure loss is deterioration in enclosure seals to the outside (doors, windows, etc.) as was observed in the case with one cab having an increase in intake airflow with a corresponding loss of cab pressure [Organiscak et al. 2013].
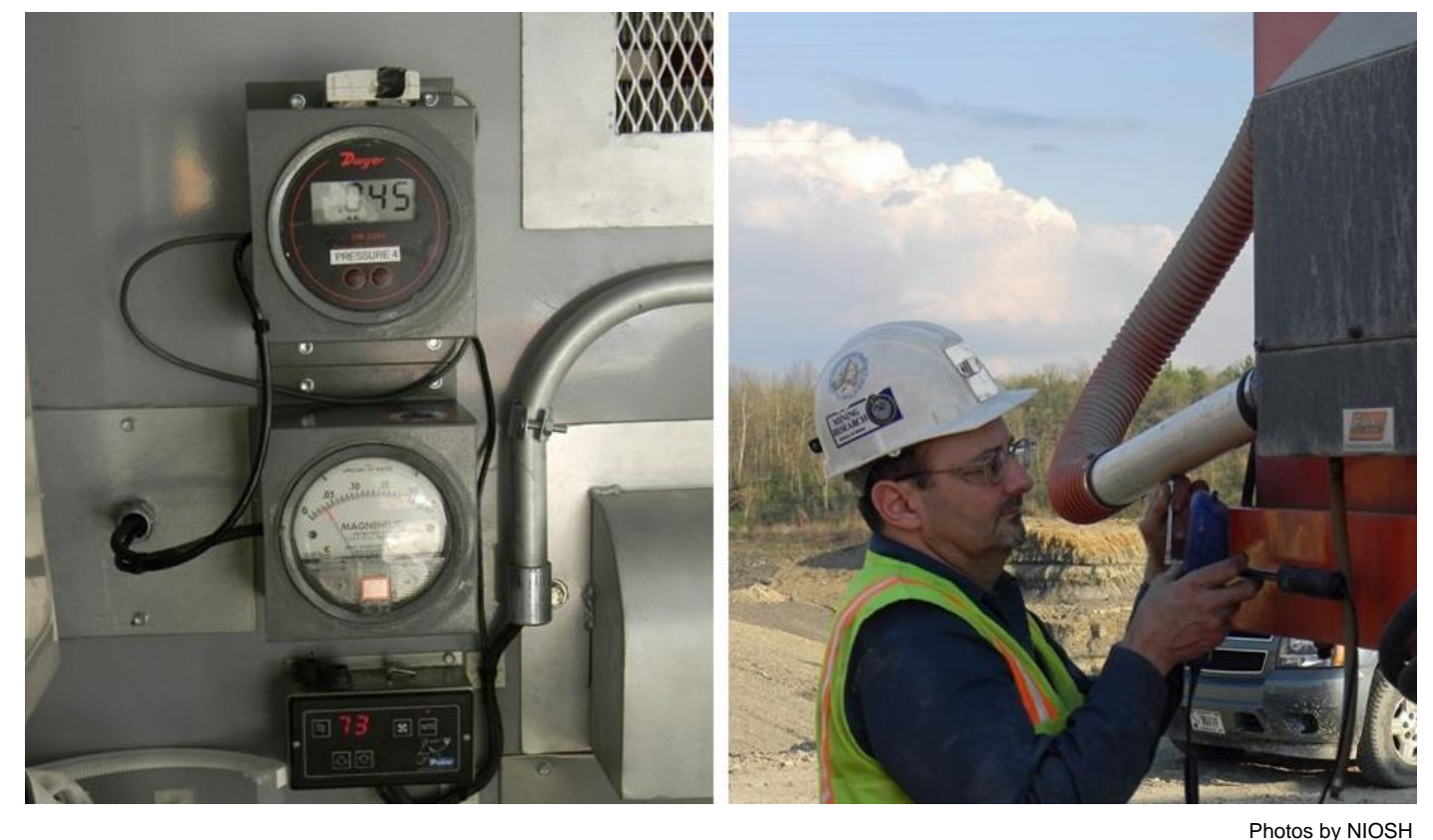

Figure 17. Digital (top) or analog (bottom) enclosure pressure monitoring (left); hot wire anemometer measurement (right).

\section{Enhanced Video Analysis of Dust Exposures (EVADE) software}

Video exposure monitoring of an employee's work environment is a valuable tool for examining their dustiest job tasks and control methods to reduce their exposures while performing these tasks. "Helmet-CAM" is a system developed by NIOSH and Unimin Corporation to record worker activities and contaminant exposure levels corresponding to those activities. This system can be used in enclosed cabs, operator compartments, and control rooms to provide a simple and relatively inexpensive method to assess worker respirable dust exposures in these areas [Cecala et al. 2013, Cecala et al, 2015]. This system consists of a lightweight video camera and an instantaneous dust monitor that are worn by a worker as normal work duties are conducted. Once the video and dust data are obtained, the information is downloaded to a computer and the 
NIOSH-developed EVADE software merges the video and dust data to assess the areas, tasks, and functions that impacted the individual's respirable dust exposure ${ }^{7}$ [NIOSH 2014].

There are many different types of commercially available video cameras that can be used to provide the video component for this assessment technology. The primary requirements for the camera are that it can record video for one to two hours, and that it outputs the video file in avi, mp4, or wmv formats. The video unit most frequently used by NIOSH since the initial development of this technology was the POV (point-of-view) camera by V.I.O. design (Extreme Technologies, LLC, Minneapolis, MN). This system employs a video lens that was originally attached to the worker's hardhat using a commercially available flashlight clip or other methods, with duct tape being the most common technique. This POV camera uses a thin cable approximately 18 inches long to connect the video lens to the digital video recording portion of the device, and creates two digital video files — with an "avi" and a "thm" extension — which are then processed by the EVADE software.

The second component of the Helmet-CAM system for dust monitoring is the instantaneous respirable dust monitor. For its testing, NIOSH used the Thermo Fisher Scientific pDR-1500 Aerosol Monitor (personal DataRAM) (Thermo Fisher Scientific, Waltham, MA). This instrument was chosen because it is an active sampler using an internal pump to collect the dust sample [Reed et al. 2012]. The unit was slightly modified so that a 3-ft section of conductive tubing could be connected to the 10-mm Dorr-Oliver cyclone, which is the normal pre-classifier device used for respirable dust sampling in the metal/nonmetal mining industry. The pDR-1500 was also set to a 1.7-liter/min flow rate, which is the required flow rate used for compliance respirable dust sampling by MSHA for the metal/nonmetal mining industry [MSHA 1990].

When the Helmet-CAM assessment analysis was performed, a 10-mm Dorr-Oliver cyclone was placed on the miner's lapel and within the individual's breathing zone, identical to the method used for a compliance-type dust sample. The 3-ft length of conductive tubing was used to connect the cyclone to the main body of the pDR-1500 monitor, and the instrument was configured to integrate samples over a two-second period for this testing. The worker would typically wear the dust monitor and video recording unit in a backpack so as not to interfere with work tasks. The worker was then asked to perform his or her normal job duties for an approximate pre-determined time period - normally between 90 minutes and 2 hours. Afterwards, the video and respirable dust exposure data files were downloaded using the instrument's output functions to perform the respirable dust assessment using the EVADE software.

In addition to monitoring a worker's personal dust exposure, the Helmet-CAM system has proven to be effective for use in enclosed cabs of mobile equipment or in operator booths and control rooms [Cecala and O'Brien 2014]. The one major difference in these types of applications is instead of the worker wearing the system, it is statically positioned in the cab, booth, or room. In these applications, the backpack is normally attached to the back of the operator's seat or chair so as to not impact the worker's ability to comfortably sit and perform normal duties. In enclosed cabs, the video camera lens is normally duct taped somewhere within

\footnotetext{
${ }^{7}$ Since its original creation as a software to help monitor dust exposure, EVADE has been enhanced significantly in its features, including its ability to help monitor exposure of multiple contaminants simultaneously. The EVADE version 2.0 software is available at NIOSH's website at http://www.cdc.gov/niosh/mining/Works/coversheet1867.html.
} 
the cab or on the dashboard to provide the video footage of the vehicle's location and task, as shown in Figure 18. This particular video segment illustrates that the truck cab dust concentrations noticeably increased when it drove into the loading area of the mining pit. For operator booths or control rooms, the video camera should be positioned to provide footage of ingress or egress to the area as well as individuals within the enclosure and their activities.

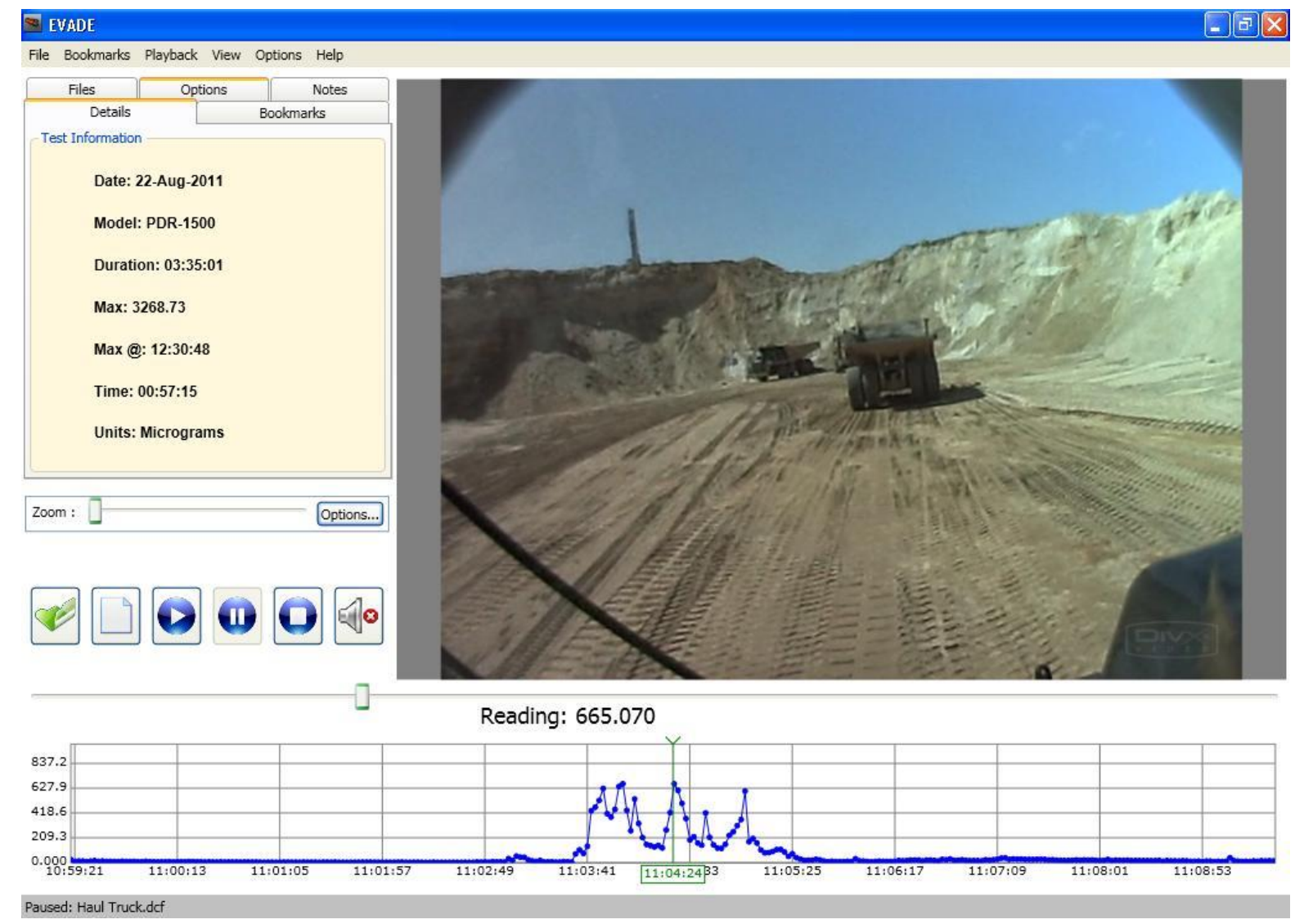
Figure 18. Helmet-CAM technology used in the enclosed cab of haul truck for assessment of truck driver's respirable dust exposure relevant to the truck location as viewed by the video.

\section{Data Analysis of Environmental Enclosure Performance}

Data from testing environmental enclosures needs to be analyzed into useful information for optimizing long-term performance. This can be primarily accomplished through graphical representation of the performance measurements made on the environmental enclosure. Timerelated graphical information can provide visual observations of enclosure performance trends for determining inspection and maintenance intervals. Data averaging and error analysis is also useful for examining the level of statistical uncertainty for the evaluation of significant enclosure performance factors. A description of these analytical methods is discussed below. 


\section{Graphical Analysis}

Graphical representation of data is one of the most useful analytical methods for examining environmental enclosure performance. Graphing time-related data of multiple performance measurements is very helpful for observing corresponding changes to the environmental enclosure. This type of observational analysis has already been discussed above and is particularly illustrated by Figure 7. This figure shows the time history of the long-term MERV 16 and HEPA filter benchmarking comparisons on a Fletcher face drill and roof bolter machine at the Shelly limestone mine. This figure illustrates cab enclosure protection factors (PFs) and intake airflow changes observed during the study. It shows that the cab intake airflows were higher for the MERV 16 filters and that the HEPA intake filter had to be replaced more often without any observed long-term benefit to cab PF [Cecala et al. 2016]. This figure also shows the 95\% confidence intervals determined for the measured PFs and that the face drill PFs were significantly higher than the roof bolter PFs during this study. Confidence intervals can be determined by several statistical methods and are discussed below.

Figure 19 is an additional time-history performance graph of the Fletcher roof bolting machine at

the Shelly mine while initially using the small recirculation filter in the three-filter cab filtration system design [Organiscak et al. 2013]. This figure indicates that the cab PF increased with filter loading over time and that the recirculation filter airflow dropped quickly and was restored to its original airflow when it was replaced twice at 106 and 337 hours. After the recirculation filter was removed at 526 hours, the recirculation airflow was increased to levels slightly higher than with a new recirculation filter (by $11 \mathrm{ft}^{3} / \mathrm{min}$ ) with a corresponding drop-off in intake airflow (by $22 \mathrm{ft}^{3} / \mathrm{min}$ ). This change initially reduced the cab enclosure PF from 745 to 247 , then steadily increased to a PF of 2,451 after an additional 263 hours of operation. Recirculation airflow, intake airflow, and cab enclosure PF simultaneously decreased after 789 hours of operation, with the testing concluded at 842 hours of operation with new filters installed.

This graph illustrates that the recirculation filter capacity was undersized in this three-filter system, and removing it did not diminish its PF performance over the long term [Cecala et al. 2012]. This figure additionally shows the $95 \%$ confidence intervals determined for the measured PFs, and indicates that the filtration system changed significantly with filter loading over the time history of this study. This roof bolting machine was later used during the long-term MERV 16 and HEPA filter comparisons.

\section{Normal Distribution Error Analysis of Sample Data}

Performance variables measured during environmental enclosure testing can be examined for measurement errors or uncertainty involved with the testing. Descriptive statistical measures typically associated with sampling a variable include a mean, standard deviation, relative standard deviation, sample size, standard error, and confidence intervals of these measurements. These descriptive statistics are shown below in Equation 14 through Equation 20 [Johnson 2005].

$$
\begin{aligned}
& \bar{x}=\frac{\sum_{i=1}^{n} x_{i}}{n} \\
& S=\sqrt{\frac{\sum_{i=1}^{n}\left(x_{i}-\bar{x}\right)^{2}}{n-1}}
\end{aligned}
$$




$$
\begin{aligned}
& R S D=\frac{s}{\bar{x}} \\
& S E=\frac{s}{\sqrt{n}} \\
& E_{\text {two-tailed }}=t_{n-1, \alpha / 2} \cdot S E \\
& E_{\text {one-tailed }}=t_{n-1, \alpha} \cdot S E \\
& C I=\bar{x} \pm E_{\text {two-tailed }}=\bar{x}+\text { or }-E_{\text {one-tailed }}
\end{aligned}
$$

where:

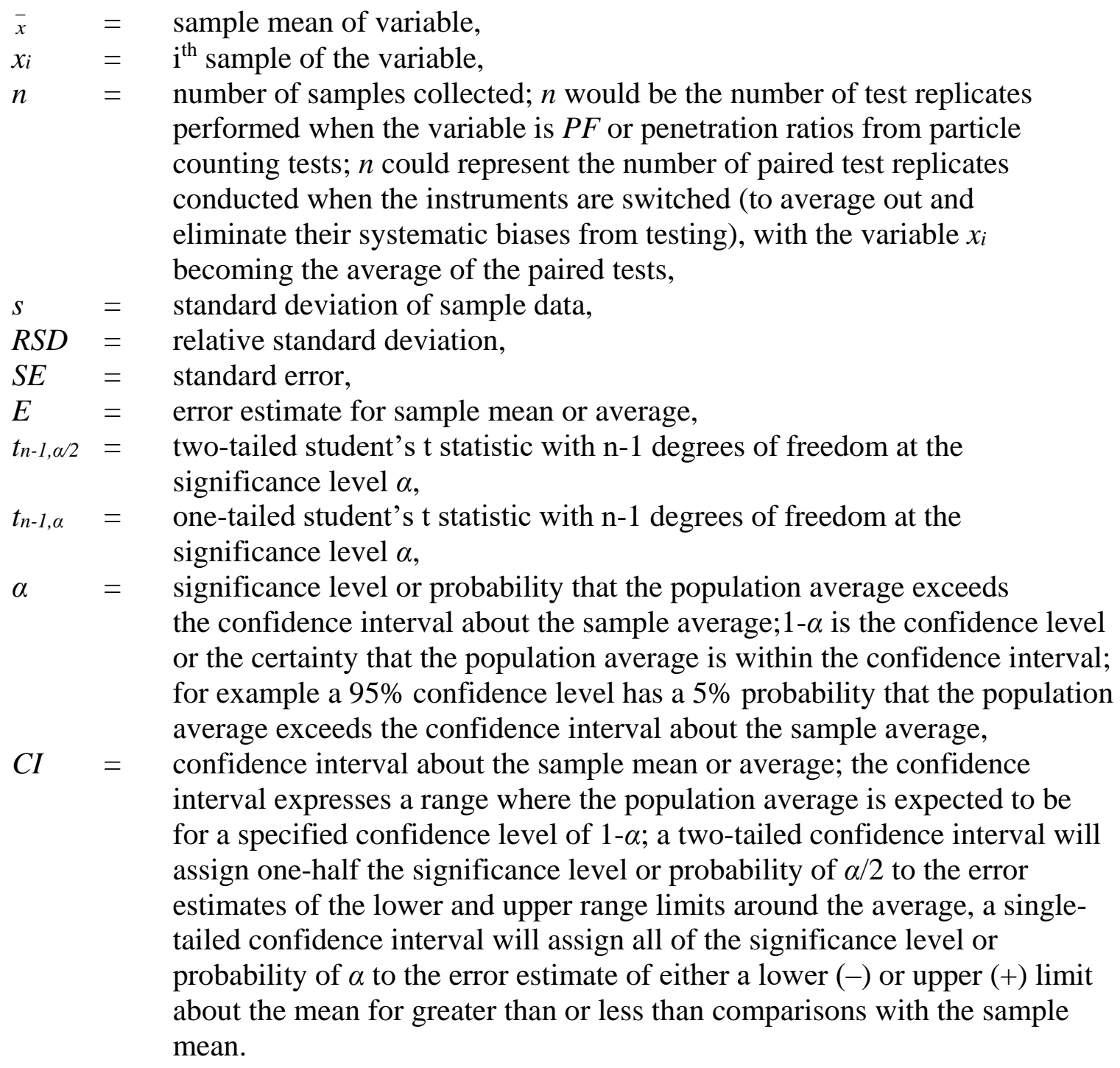




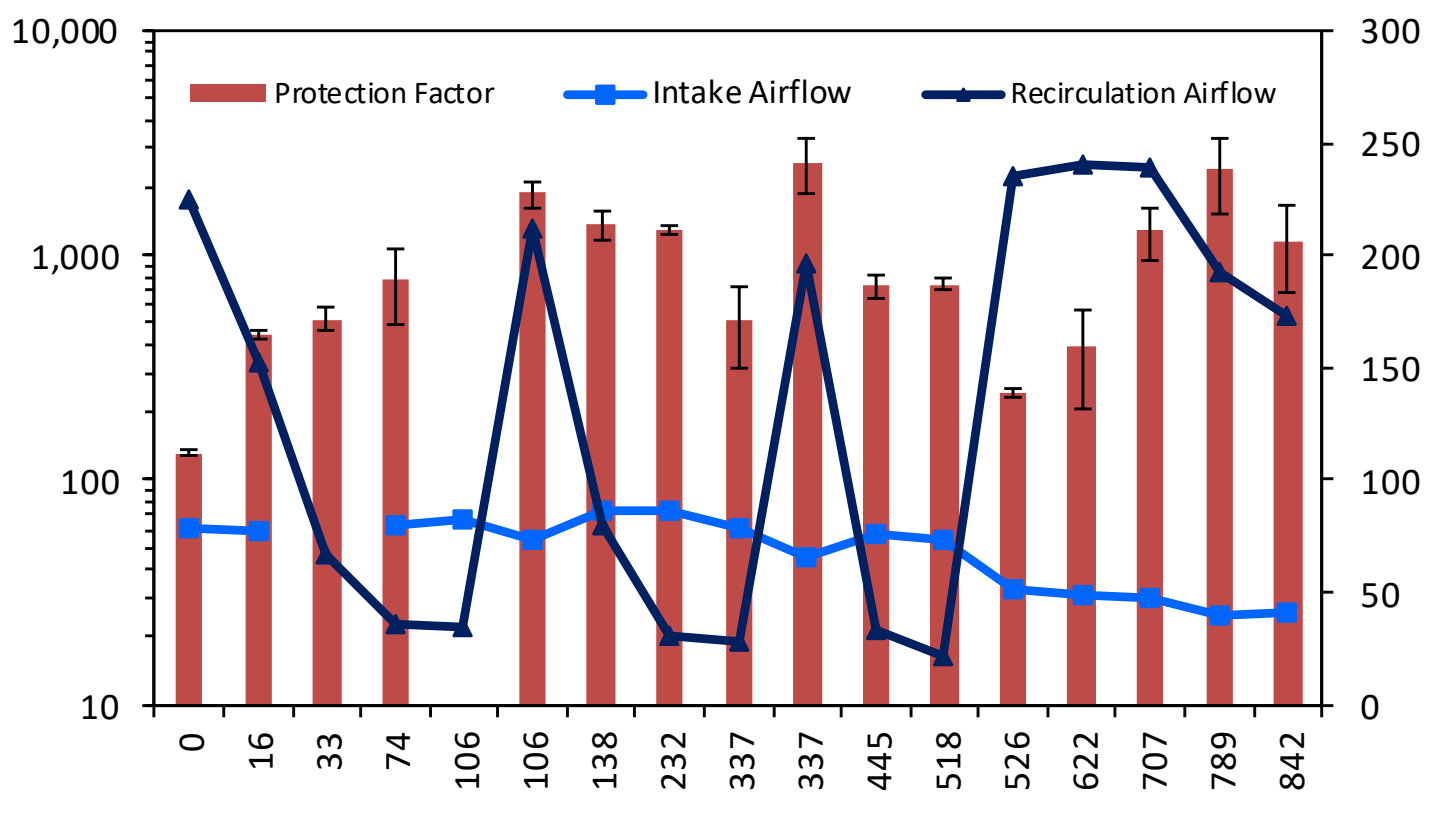

Roof Bolter Operating Time, hrs.

\section{Figure 19. Graphical information of long-term field study of roof bolter using a three-filter configuration.}

These statistics were used to calculate the confidence intervals for comparison of the average cab PFs for the MERV 16 and HEPA filters during the long-term field study. Table 6 shows the PF data collected (illustrated in Figure 7) and statistics calculated for similar face drill and roof bolter cab filtration systems with the MERV 16 and HEPA filters. As can be seen from this table, the two-tailed CI values overlap between the MERV 16 and HEPA filters test comparisons on each cab. However, the two-tailed CI values do not overlap when comparing the face drill and roof bolter cab PFs, indicating that the performances of the cab filtration systems are significantly different although their design appears to be the same. These differences are likely due to the change/variation in the air leakage around the filters between these two seemingly identical filtration systems for the face drill and roof bolter [Cecala et al. 2016]. Furthermore, the one-tailed lower CI values for the face drill show that its PF sample means are significantly greater than 1,000 (at the 95\% confidence level), while the roof bolter one-tailed higher $C I$ values show that its PF sample means are significantly less than 1,000 (at the 95\% confidence level). These normal distribution sampling statistics allow examination of measurement uncertainty from environmental enclosure performance testing, assuming that the sampling is random, independent, and approximates a normal distribution. 
Table 6. Calculation of statistics for MERV 16 and HEPA filter comparisons on face drill and roof bolter cabs

\begin{tabular}{|c|c|c|c|c|}
\hline 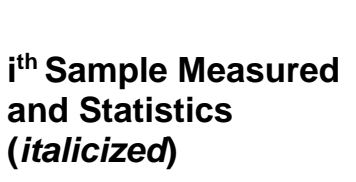 & $\begin{array}{r}\text { Face Drill } \\
\text { Cab PF }^{\star} \text { for } \\
\text { MERV } 16 \\
\text { Filters }\end{array}$ & $\begin{array}{r}\text { Face Drill } \\
\text { Cab PF for } \\
\text { HEPA Filters }\end{array}$ & $\begin{array}{r}\text { Roof Bolter } \\
\text { Cab PF for } \\
\text { MERV } 16 \\
\text { Filters }\end{array}$ & $\begin{array}{r}\text { Roof Bolter } \\
\text { Cab PF } \\
\text { for HEPA } \\
\text { Filters }\end{array}$ \\
\hline 1 & 612 & 8,036 & 300 & 400 \\
\hline 2 & 4,106 & 8,133 & 790 & 1,425 \\
\hline 3 & 6,337 & 4,853 & 1,021 & 1,116 \\
\hline 4 & 2,301 & 2,028 & 783 & 923 \\
\hline 5 & 6,227 & 3,116 & 465 & 1,129 \\
\hline 6 & 3,807 & 1,178 & 77 & 274 \\
\hline 7 & $\mathrm{NA}^{\dagger}$ & 2,509 & NA & 182 \\
\hline 8 & NA & 2,550 & NA & 390 \\
\hline 9 & NA & 685 & NA & 290 \\
\hline $\bar{x}$ & 3,898 & 3,667 & 573 & 681 \\
\hline$s$ & 2,226 & 2,763 & 353 & 465 \\
\hline$n$ & 6 & 9 & 6 & 9 \\
\hline$R S E$ & 0.571 & 0.753 & 0.616 & 0.683 \\
\hline$S E$ & 909 & 921 & 144 & 155 \\
\hline Significance Level $\alpha$ & 0.05 & 0.05 & 0.05 & 0.05 \\
\hline Confidence Level 1- $\alpha$ & 0.95 or $95 \%$ & 0.95 or $95 \%$ & 0.95 or $95 \%$ & 0.95 or $95 \%$ \\
\hline Two-tailed $t_{n-1,0.025}$ & 2.571 & 2.306 & 2.571 & 2.306 \\
\hline$E_{\text {two-tailed }}$ & 2,336 & 2,124 & 371 & 357 \\
\hline$C I$ & 1,562 to 6,234 & 1,543 to 5,791 & 202 to 944 & 324 to 1038 \\
\hline One-tailed $t_{n-1,0.05}$ & 1.943 & 1.860 & 1.943 & 1.860 \\
\hline$E_{\text {one-tailed }}$ & 1,766 & 1,713 & 280 & 288 \\
\hline Lower CI & 2,132 & 1,954 & 293 & 393 \\
\hline Upper CI & 5,664 & 5,380 & 853 & 969 \\
\hline
\end{tabular}

*Cab PFs are the averages of alternated instrument paired test replicates

'NA-not available 


\section{Propagation of Error Analysis of Protection Factor Ratios}

A propagation of error analysis approach can be used when the ratios of variables measured are not random, independent, and may not approximate the normal distribution. These conditions can occur when environmental enclosure testing is not conducted at steady state conditions and the inside concentrations are dependent on the changing outside concentrations. Furthermore, a small sample size of 2 to 4 tests adds to the level of uncertainty to the testing that is not quite at steady state conditions, and typically occurs during field testing of the environmental enclosure [Organiscak et al. 2013].

The propagation of error analysis approach was used to estimate the measurement uncertainty of cab PFs (PF = outside/inside, particles counted) measured during shop and field testing of underground face drills, a scaling machine, and a roof bolter [Organiscak et al. 2013]. Since multiple one-minute particle count samples were collected inside and outside the cab during a test, their sample averages were used to calculate the cab PF (ratio) for the test. The cab's protection factor was determined from the average of the test replicates, and its measurement uncertainty would typically be estimated from the standard deviation of the test replicates. Conducting a two-replicate cab test procedure in the field would generally be considered too small a sample size for determining the measurement uncertainty. An alternative approach for estimating the cab PF measurement uncertainty is to determine the standard error for each test replicate by using the propagation of error analysis of the sample data for a two-variable ratio [Bevington 1969]. The standard errors of the individual test replicates can be further combined (or pooled) by using Satterthwaite's standard error approximation, which assumes unequal variance between the test replicates [Satterthwaite 1946]. This approach uses the variation from the one-minute samples collected during each test replicate to estimate the measurement uncertainty of the average cab PF for the test.

Equation 21 shows how to determine the standard error of estimate for a PF ratio of a particle counting test [Bevington 1969]. This equation assumes that there are an equal number of outside and inside samples $(n)$ collected during the test [Bevington 1969]. Covariance can be ignored in the equation if the variables are independent or there are insufficient pairs of data for a good estimate. Since outside and inside cab sample data are not independent outside of steady state conditions, covariance was used in the standard error of estimate calculations for 15 pairs of concurrent sampling data analyzed per test replicate at near steady state sampling conditions. This PF (ratio) propagation of error analysis, shown in Equation 21, could also be used for the penetration (ratio) into the environmental enclosure.

$$
\frac{s_{P F}}{\sqrt{n}}=\frac{P F}{\sqrt{n}} \sqrt{\left(\frac{s_{o}}{o}\right)^{2}+\left(\frac{s_{i}}{i}\right)^{2}-2 \frac{s_{o i}^{2}}{o i}}=\frac{P F}{\sqrt{n}} \sqrt{R S D_{o}^{2}+R S D_{i}^{2}-2 r_{o i} \frac{s_{o} s_{i}}{o i}}
$$

where:

$$
\begin{aligned}
& o=\text { mean of outside particle counts or concentrations, } \\
& S_{o}=\text { standard deviation of outside particle counts or concentrations, } \\
& R S D_{o}=\text { relative standard deviation of outside particle counts or concentrations, } s_{o} / o, \\
& i \quad=\text { mean of inside particle counts or concentrations, } \\
& S_{i}=\text { standard deviation of inside particle counts or concentrations, } \\
& R S D_{i}=\text { relative standard deviation of inside particle counts or concentrations, } s_{i} / i,
\end{aligned}
$$




$$
\begin{aligned}
& s_{o i}^{2}=\text { covariance between outside and inside particle counts or concentrations, } \\
& P F=\text { protection factor, } o / i, \\
& S_{P F}=\text { standard deviation of protection factor, } \\
& r_{o i}=\text { correlation coefficient between outside and inside particle count data, and } \\
& n=\text { equal number of particle count samples taken inside and outside the cab. }
\end{aligned}
$$

Equation 22 illustrates the method for Satterthwaite's standard error approximation for multiple test replicates, assuming unequal variances between test replicates [Satterthwaite 1946].

Equation 23 shows how to determine the degrees of freedom for Satterthwaite's approximation [Satterthwaite 1946].

$$
\begin{gathered}
s e_{p}=\sqrt{\frac{s_{1}^{2}}{n_{1}}+\frac{s_{2}^{2}}{n_{2}}+\cdots+\frac{s_{k}^{2}}{n_{k}}} \\
d f=\frac{\left(\frac{s_{1}^{2}}{n_{1}}+\frac{s_{2}^{2}}{n_{2}}+\cdots+\frac{s_{k}^{2}}{n_{k}}\right)^{2}}{\left(n_{1}-1\right)^{-1}\left(\frac{s_{1}^{2}}{n_{1}}\right)^{2}+\left(n_{2}-1\right)^{-1}\left(\frac{s_{2}^{2}}{n_{2}}\right)^{2}+\cdots+\left(n_{k}-1\right)^{-1}\left(\frac{s_{k}^{2}}{n_{k}}\right)^{2}}
\end{gathered}
$$

where:

$$
\begin{aligned}
& s e_{p}=\text { Satterthwaite's standard error approximation, } \\
& s k=\text { standard deviation of the kth test replicate, } \\
& n_{k}=\text { number of samples in the kth test replicate, } \\
& k=\text { number of test replicates, and } \\
& d f=\text { degrees of freedom. }
\end{aligned}
$$

The confidence intervals for the PF of similar test replicates can be determined by multiplying the Satterthwaite's standard error approximation (Equation 22) by the student's t-statistic for the calculated degrees of freedom (Equation 23). This uncertainty analysis uses the particle count sample data during each test replicate to estimate the confidence level of the average PF for the replicates. Table 7 illustrates the particle count information and standard error calculations for four test replicates conducted with two particle counting instruments on the initial underground drill cab filtration system design with a HEPA final filter at the manufacturing shop facility [Organiscak et al. 2013]. The test information in Table 7 shows the particle count concentrations measured for the $0.3-\mu \mathrm{m}$ to $1.0-\mu \mathrm{m}$ size range. 


\section{Table 7. Initial cab filtration system particle counting test results using the HEPA final filter}

\begin{tabular}{l|r|r|r|r}
\hline \multicolumn{1}{c|}{ Test Information } & Test Replicate 1 & Test Replicate 2 & Test Replicate 3 & Test Replicate 4 \\
\hline Outside Average* $^{*}$ & 99,266 & 128,649 & 91,065 & 94,022 \\
Outside Std. Dev $^{*}$ & 19,192 & 17,478 & 6314 & 10,129 \\
Inside Average* $^{*}$ & 1,301 & 1,668 & 1,114 & 1,074 \\
Inside Std. Dev $^{*}$ & 230 & 211 & 93 & 83 \\
Covariance $^{*}$ & $4,142,231$ & $3,162,488$ & 498,549 & 758,239 \\
No. of Samples & 15 & 15 & 15 & 15 \\
Protection Factor & 76.3 & 77.1 & 81.7 & 87.5 \\
Standard Error & 1.32 & 1.41 & 0.93 & 1.14 \\
\hline
\end{tabular}

*0.3- $\mu \mathrm{m}$ to $1.0-\mu \mathrm{m}$ sized particle count per liter

$\dagger$ Outside average $\div$ inside average

ॠStandard error determined from Equation 21

The Protection Factor (PF) for test replicate 1 would be calculated as follows:

$$
P F=\frac{99,266}{1,301}=76.3
$$

The PF standard error of estimate for test replicate 1 would be calculated as follows:

$$
\frac{S_{P F}}{\sqrt{n}}=\frac{76.3}{\sqrt{15}} \times \sqrt{\left(\frac{19,192}{99,266}\right)^{2}+\left(\frac{230}{1,301}\right)^{2}-2 \times\left(\frac{4,142,231}{99,266 \times 1,301}\right)}=1.32
$$

The PFs and standard error of estimates for the other test replicates would be similarly calculated. The Satterthwaite's standard error approximation for all the test replicates would be the square root of the summation of the standard errors squared by using Equation 22, as shown below for the four test replicates in Table 7.

$$
s e_{p}=\sqrt{1.32^{2}+1.41^{2}+0.93^{2}+1.14^{2}}=2.43
$$


The degrees of freedom for the Satterthwaite's standard error approximation would be calculated by Equation 23, and is shown below for the four test replicates. To be conservative, the degree of freedom calculation was rounded down to the nearest whole number, which would be 51 .

$$
d f=\frac{\left(1.32^{2}+1.41^{2}+0.93^{2}+1.14^{2}\right)^{2}}{\frac{1.32^{4}}{(15-1)}+\frac{1.41^{4}}{(15-1)}+\frac{0.93^{4}}{(15-1)}+\frac{1.14^{4}}{(15-1)}}=51.6
$$

The average cab PF would be calculated by taking the sample mean of the test replicates (Equation 14). The two-tailed error for this mean PF (at the $95 \%$ confidence level) is determined by multiplying the Satterthwaite's standard error approximation by the student's t-statistic for the calculated 51 degrees of freedom. The two-tailed confidence interval (at the $95 \%$ confidence level) from this analysis would be $80.6 \pm 4.8$ (two-tailed $E=1.96 \times 2.43$ ).

By comparison, the calculation of the standard deviation and standard error from the PFs of the four test replicates using Equation 15 and Equation 17 would yield the following results of 5.15 and 2.58, respectively. Although the 2.58 standard error is similar to the Satterthwaite's standard error approximation of 2.43, its two-tailed confidence interval (at the $95 \%$ confidence level) would be larger at $80.6+8.2$ (two-tailed $\mathrm{E}=3.182 \times 2.58$ ) because of the greater uncertainty in the Student's t-statistic for three degrees of freedom. This greater uncertainty also includes all experimental errors within the testing, whereas the propagation of error analysis has the covariance element of the testing errors removed (subtracted out) from the standard error estimate.

Given the additional measurement uncertainty expected with conducting only two cab test replicates during the field studies, the alternate propagation of error analysis and Satterthwaite's error approximation procedures were used in determining the PFs confidence intervals for the field study results shown in Figures 7 and 19. This analysis uses all the available sampling data collected during the two test replicates. The confidence levels of the cab PF test results shown in these figures illustrate that the cab enclosures' performance significantly changed during these long-term studies because of filter loading and airflow changes in the filtration system [Organiscak et al. 2013].

\section{Poisson Distribution Error Analysis of Particle Counting Data}

Error analysis of microscopic particle classification on filter media (sizing and counting particles) was developed using the Poisson distribution to ensure that enough particles were counted to evaluate the certainty or uncertainty of the test results [Leith and First 1976]. This method can also be applied to optical particle counters, and was referred to as an alternate method for particle counting error analysis of cabs in the previous ASAE Standard S525-1.1 [ASAE 1997; Heitbrink et al. 1998]. Based on the Poisson distribution, the relative standard deviation associated for the average particle count concentration is equal to the square root of the reciprocal of the total number of particles counted as shown in Equation 24 below [Leith and First 1976]. The average particle count concentration is equal to the mean number of particles counted in representative samples within a volume of air. Confidence intervals for these average particle concentrations are also shown below in Equation 25 for a two-tailed t-statistic and in Equation 26 for a one-tailed t-statistic. The t-statistic approximates the normal distribution for sample sizes greater than 30 [Johnson 2005]. 
When computing ratios from two concentrations such as PF of an environmental enclosure, the confidence intervals for the ratios incorporate the propagation of error from both sampling locations and are shown below in Equation 27 and Equation 28 for a two-tailed t-statistic and a one-tailed t-statistic, respectively [Leith and First 1976]. These PF error equations can also be applied to filter penetration or environmental enclosure penetration ratios. For the normal distribution to serve as a reasonable approximation of the Poisson distribution for these cab performance ratio comparisons, it is suggested that a total of 50 particle counts should be measured inside the enclosure [ASAE 1997; Heitbrink et al. 1998].

$$
\begin{aligned}
& \frac{\sigma_{p}}{P}=\sqrt{\frac{1}{N}} \\
& C I=P \pm t \alpha / 2 \cdot P \sqrt{\frac{1}{N}} \\
& C I=P+\text { or }-t_{\alpha} \cdot P \sqrt{\frac{1}{N}} \\
& C I=P F \pm t \alpha / 2 \cdot P F \sqrt{\frac{1}{N_{o}}+\frac{1}{N_{i}}} \\
& C I=P F+\text { or }-t_{\alpha} \cdot P F \sqrt{\frac{1}{N_{o}}+\frac{1}{N_{i}}}
\end{aligned}
$$

where:

$$
\begin{aligned}
& P=\text { average particle count concentration, } \\
& \sigma_{p}=\text { standard deviation of particle count concentration samples, } \\
& N=\text { total number of particles counted to determine the concentration, } \\
& N_{o}=\text { total number of particles counted outside the environmental enclosure, } \\
& N_{i}=\text { total number of particles counted inside the environmental enclosure, } \\
& P F=\text { protection factor of environmental enclosure; the ratio of the average } \\
& \text { outside to inside concentrations, and if these concentrations are determined } \\
& \text { from the same volume of air the total outside and inside counts can also } \\
& \text { be used to determine the } P F \text {, } \\
& t_{\alpha / 2}=\text { two-tailed student's } \mathrm{t} \text { statistic with infinite degrees of freedom at the } \\
& \text { significance level } \alpha \\
& t_{\alpha}=\text { one-tailed student's t statistic with infinite degrees of freedom at the } \\
& \text { significance level } \alpha \text {, } \\
& \alpha=\text { significance level or probability that the population average exceeds } \\
& \text { the confidence interval about the sample average; } 1-\alpha \text { is the confidence level is } \\
& \text { or the certainty that the population average is within the confidence interval: } \\
& \text { for example a } 95 \% \text { confidence level has a } 5 \% \text { probability that the population } \\
& \text { average exceeds the confidence interval about the sample average, }
\end{aligned}
$$


$C I=$ confidence interval about the sample mean or average; the confidence interval expresses a range where the population average is expected to be for a specified confidence level of 1- $\alpha$; a two-tailed confidence interval will assign one-half the significance level or probability of $\alpha / 2$ to the error estimates of the lower and upper range limits around the average, a singletailed confidence interval will assign all of the significance level or probability of $\alpha$ to the error estimate of either a lower (-) or upper (+) limit about the mean for a greater than or less than comparisons with the sample mean.

An example on how to apply this error analysis can be conducted with the particle count data previously presented in Table 7. Shown below is the PF calculation based on the average of the outside and inside concentrations. The two-tailed confidence interval for a 95\% confidence level is calculated by using the total number of particles counted outside and inside. The total number of particles outside and inside are determined by multiplying their average concentrations (particles/liter) by the sampling airflow rate $(2.83 \mathrm{liters} / \mathrm{min})$ times the total sampling time for the testing ( $15 \mathrm{~min} \times 4=60 \mathrm{~min}$ ). The slight difference in this average $\mathrm{PF}$ as compared to the previous average calculated above is due to rounding errors in averaging the individual PFs of each replicate. However, the confidence intervals for the Poisson distribution analysis are noticeably smaller than the previous ones calculated above, because this analysis only accounts for the errors in particle counting and not the experimental errors included during these particular test replicates (which deviated from steady state conditions), which are included in the normal and propagation of error analysis methods performed above. The Poisson distribution analysis is more applicable for error analysis of lower particle counts and/or lower sample volumes when there is less data to compute errors from the other analysis.

$$
\begin{gathered}
P F=\frac{\frac{99,266+128,649+91,065+94,022}{4}}{\frac{1,301+1,668+1,114+1,074}{4}} \cdot=\frac{103,250.5}{1,289.25}=80.1 \\
C I=80.1 \pm 1.96 \times 80.1 \sqrt{\frac{1}{103,250.5 \times 2.83 \times 60}+\frac{1}{1,289.25 \times 2.83 \times 60}}=80.1 \pm 0.3
\end{gathered}
$$

This Poisson distribution error analysis approach is more suitable for particle count data collected over short time periods (several minutes of sampling) and at lower concentrations, given that the same sample volumes are measured outside and inside the enclosure. The error analysis can be performed with either the one-particle or two-particle counter sampling methods, alternated between inside and outside locations with the enclosure at near steady state conditions. As an example, an $80 \mathrm{PF}$ can be quantified with average particle count concentrations of 100 particles/L inside and 8,000 particles/L outside the environmental enclosure for two-minute sampling intervals replicated twice at each location with a $2.83-\mathrm{L} / \mathrm{min}$ sampling rate. The calculation of two-tailed confidence interval at the $95 \%$ confidence level for this example is shown below. 


$$
C I=80 \pm 1.96 \times 80 \sqrt{\frac{1}{8,000 \times 2.83 \times 4}+\frac{1}{100 \times 2.83 \times 4}}=80 \pm 4.7
$$

As can be seen from this calculation, the PF confidence interval increased dramatically from 80.1 \pm 0.3 to $80 \pm 4.7$ when a smaller sample size, air volume, or particle count was used. If a lower $(-)$ or higher $(+)$ one-tailed confidence interval about the average is to be calculated, then a $t$ value of 1.645 instead of 1.96 is used.

\section{Mathematical Modeling of Environmental Enclosure Filtrations Systems}

Mathematical modeling of environmental enclosure filtration systems was advanced by NIOSH to examine the key design parameters influencing enclosure protection factor $(\mathrm{PF})$ performance. The first mathematical modeling exercise was conducted in conjunction with laboratory testing to validate its usefulness in examining filtration system design parameters on cab enclosure penetration or PF. The key filtration system design parameters tested in the laboratory were intake filter efficiency, air leakage around the intake filter, intake filter loading, recirculation filter usage, and wind infiltration [NIOSH 2008b]. This first mathematical model formulation was based on a time-dependent mass balance model of airborne substances within a control volume [NIOSH 2008b]. This model was a differential equation that was converged to a steady state solution for ease of use [NIOSH 2008b; Organiscak and Cecala 2009]. To simplify mathematical derivation of other filtration system models, a node analysis technique was utilized to illustratively assist with the algebraic formulation of these models at steady state conditions [Organiscak et al. 2014].

Figure 20 shows the node analysis diagram for one- (intake filter) and two-filter (with a recirculation filter) filtration systems. The model formulations are based on the mass balance of incoming and outgoing contaminants (dust, particles, etc.) at the interior cab node. Equation 29 and Equation 30 were developed for the one- and two-filter systems, respectively. These models are dimensionless and show that the enclosure PF or penetration (Pen) are related to the intake filter efficiency, intake airflow, intake air leakage, recirculation filter efficiency, recirculation airflow, and wind quantity infiltration. If adequate environmental enclosure positive pressurization is achieved to resist wind infiltration (as previously discussed), the wind airflow quantity $\left(Q_{w}\right)$ would be zero in the model. Figure 21 shows the results of the model predictions compared to the laboratory testing results (previously presented in Table 2). As illustrated in this graph, there is good positive correlation (correlation coefficient, $r=0.995$, at significance level $p$ $<0.02$ ) along the unity line between the measured and modeled cab PFs. A notable difference in PFs was also observed between the two intake filters tested (filter efficiencies, $\eta_{I}<40 \%$ and $\eta_{I}>$ $99 \%$ ) and when the recirculation filter ( $\eta_{R}=72 \%$ efficiency) was added to the filtration system. Therefore, mathematical models can be used for examination of environmental enclosure filtration system design parameters on PF or Pen performance. 


$$
\begin{aligned}
& P F=\frac{c}{x}=\frac{Q_{I}+Q_{W}}{Q_{I}\left(1-\eta_{I}+l \eta_{I}\right)+Q_{W}}=\frac{1}{\text { Pen }} \\
& P F=\frac{c}{x}=\frac{Q_{I}+Q_{R} \eta_{R}+Q_{W}}{Q_{I}\left(1-\eta_{I}+l \eta_{I}\right)+Q_{W}}=\frac{1}{\text { Pen }} \\
& P F=\frac{c}{x}=\frac{Q_{I}+Q_{R}\left(\eta_{R}+\eta_{F}-\eta_{R} \eta_{F}\right)+Q_{W}}{Q_{I}\left(1-\eta_{I}+l \eta_{I}\right)\left(1-\eta_{F}\right)+Q_{W}}=\frac{1}{P e n}
\end{aligned}
$$

where:

$$
\begin{aligned}
& c=\text { outside contaminant concentration penetrating the filtration system, } \\
& x=\text { inside cab contaminant concentration (interior cab node), } \\
& \eta=\text { filter reduction efficiency, fractional, } \\
& 1-\eta=\text { filter penetration, fractional, } \\
& Q=\text { airflow quantity, } \\
& l=\text { intake air leakage, fractional, }
\end{aligned}
$$

with the following filter efficiency and air quantity subscripts:

$$
\begin{array}{ll}
I- & \text { intake, } \\
F- & \text { final, } \\
R- & \text { recirculation, and } \\
W- & \text { wind. }
\end{array}
$$

A mathematical model for a three-filter system design studied on several underground limestone equipment cabs was also formulated. This model was developed to examine the cab system's operational parameters with respect to field study performance measurements [Organiscak et al. 2014]. Figure 6 shows the intake, recirculation, and final filter locations within the HVAC system. Figure 22 shows the node layout of this system and Equation 31, above, represents the model formulated for this system [Organiscak et al. 2014]. Note that if zeros are used for the final filter efficiency, Equation 31 reduces down to Equation 30, which is the two-filter system. Similarly, putting in zero for the recirculation filter efficiency of equation 30 reduces it down to equation 29 , which is the single-filter system.

The initial three-filter systems tested in the field were on cabs of an underground face drill and roof bolter machine. A MERV 16 final filter was used on both cabs with a $>95 \%$ filter efficiency on respirable-sized particulates. The face drill used unrated intake and recirculation filters and did not use a separate intake pressurizer. The roof bolter used a MERV 16 intake filter/pressurizer unit with an unrated recirculation filter similar to the face drill. Particle counting, airflows, and cab pressures were measured on these cabs during a non-production time period. New and used unrated intake and recirculation filters were taken back to the Pittsburgh Mining Research Division's (PMRD) laboratory and particle count tested for their filter efficiency. The measured respirable-sized particle efficiency (on $0.3-\mu \mathrm{m}$ to $1.0-\mu \mathrm{m}$ particles) of the unrated new and used intake filters were $22.8 \%$ and $98.4 \%$, respectively. Recirculation filter efficiencies (on $0.3-\mu \mathrm{m}$ to $1.0-\mu \mathrm{m}$ particles) of the unrated new and used recirculation filters were $11.9 \%$ and $76.1 \%$, respectively. 


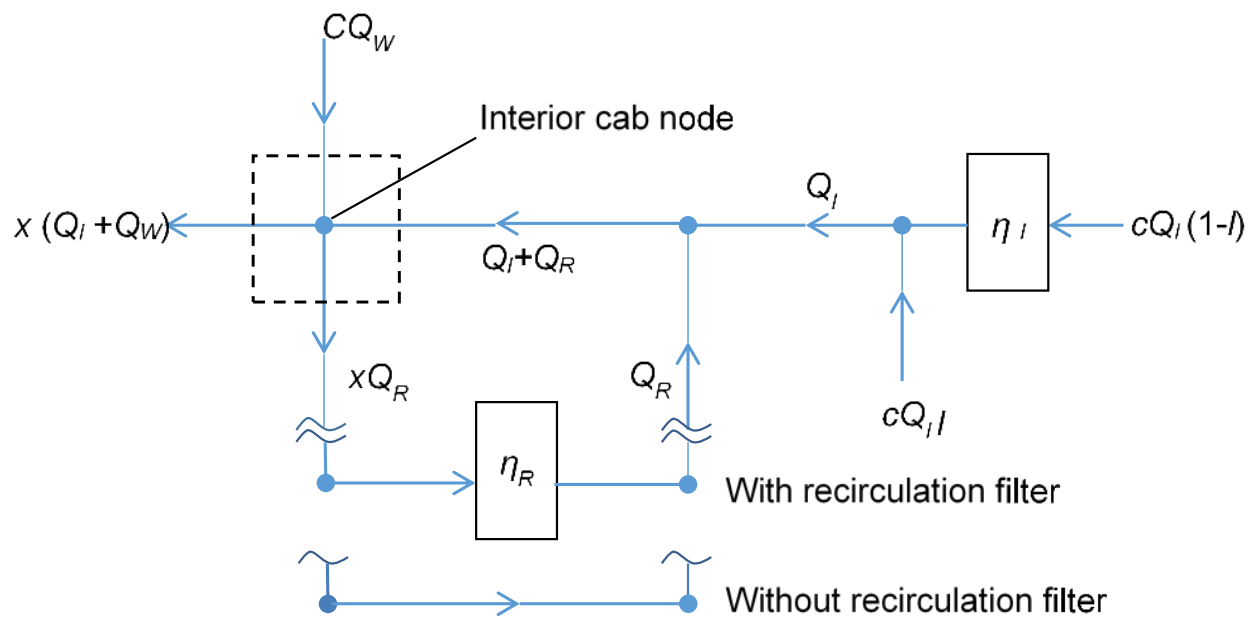

Figure 20. Two- and single-filter cab systems with and without a recirculation filter, respectively ( $Q$ 's denote air quantities, $x$ 's \& $c$ 's denote contaminant concentrations, and $\eta$ 's denote filter efficiencies).

Modeled Protection Factor

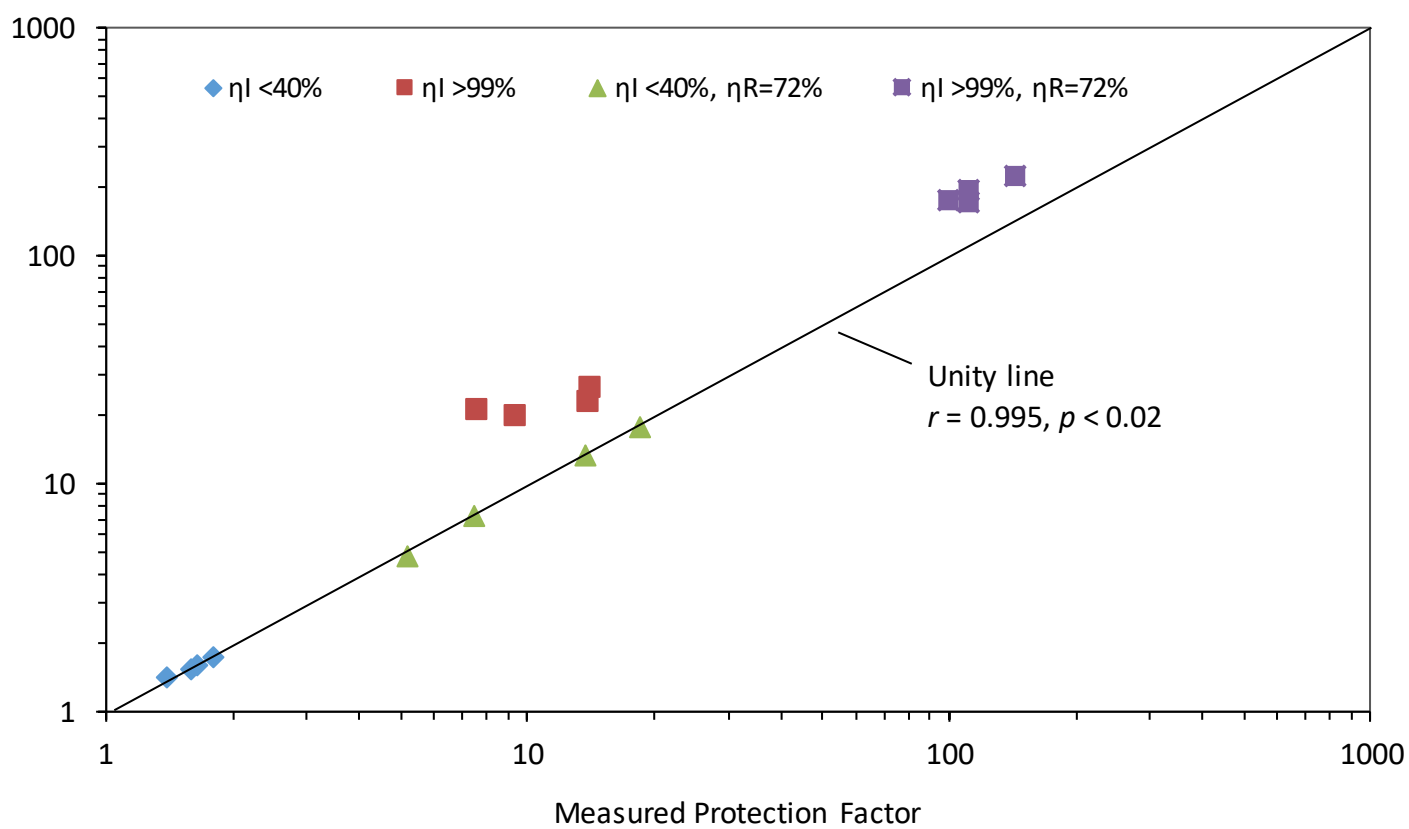

Figure 21. Comparison of laboratory measured cab protection factors to the modeled protection factors. 
Figure 23 shows the cab PFs measured during the field studies (data points) as compared to the expected lower (blue solid) and upper (green solid) operating ranges modeled with the new and used filters, respectively. Twenty-nine out of $33 \mathrm{PF}$ measurements were found to be within the modeled operating ranges (curves) expected from these cab filtration systems. The cab-measured points were spread out between the lower and upper model curves because the filter efficiencies and airflows were changing due to dust loading over the seven-month sampling period [Cecala et al., 2012; Organiscak et al. 2014]. The outlying points can be accounted for simply by slightly increasing or decreasing the model's filter collection efficiencies or intake leakage values by $1 \%$ to $2 \%$, which may be caused by filter product variations, filter airflow efficiency variations, and diverse dust loading conditions experienced between cabs during mining.

Operating the roof bolter filtration system without the recirculation filter (open points in Figure 23) increased the recirculation-to-intake airflow ratio while maintaining comparable PFs with the three-filter system. This particular two-filter system arrangement performed well because the high-efficiency final filter cleans both the filtered intake air and unfiltered recirculation air before it is discharged into the cab. Finally, modeling one- and two-MERV 16 filter systems (intake and recirculation filter systems) illustrated in Figure 23 for the same recirculation to intake airflow ratios shows that their performance would have been inferior as compared to the final filter systems modeled and tested [Organiscak et al. 2014].

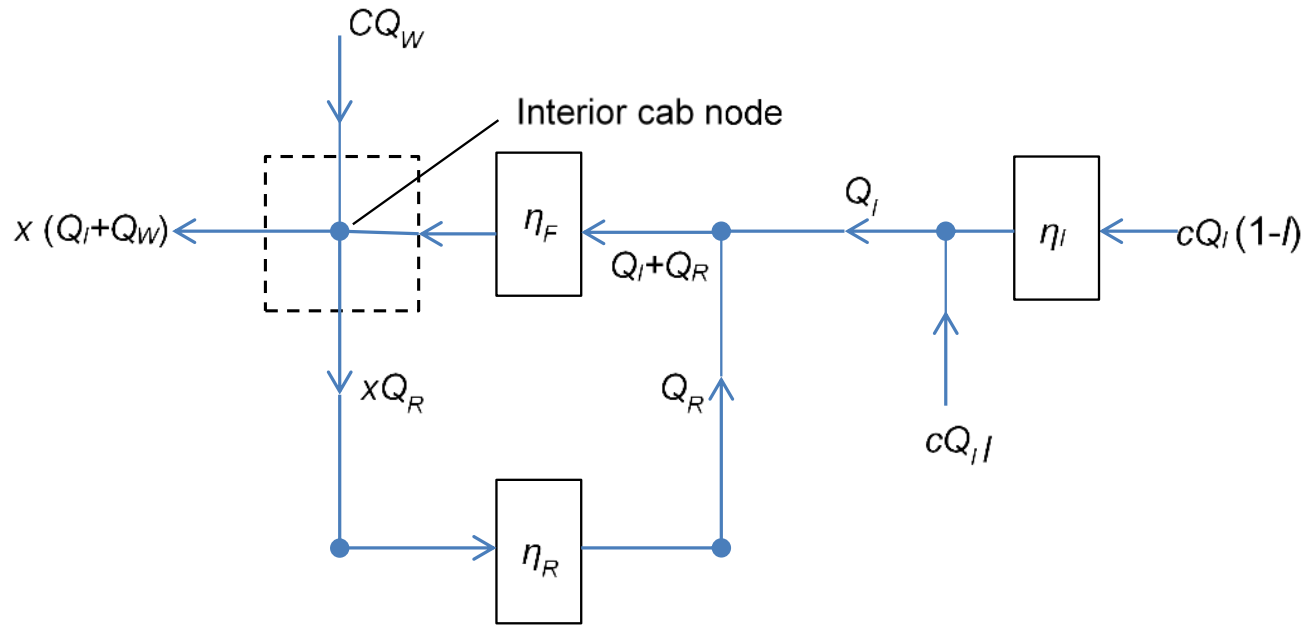

Figure 22. Three-filter cab system with final filter downstream of intake
and recirculation filters ( $Q$ 's denote air quantities, $x^{\prime} s \& c^{\prime} s$ denote
contaminant concentrations, and $\eta$ 's denote filter efficiencies).

Additional modeling and testing was conducted on these two cabs during a long-term field study of MERV 16 versus HEPA filters. New intake pressurization filtration units were first added to the cabs and the MERV 16 and HEPA filters were successively installed at the intake and final filter locations (see Figure 6) over comparative seven-month periods. These field study results were previously discussed and are shown in Figure 7 and Table 6. Although no significant longterm PF difference was observed between the MERV 16 filters and the HEPA filters used in each cab, a significant difference was observed between the roof bolter and the face drill when using the identical filters. This difference is speculated to be the result of sealing or integrity deviations between the mechanical structures of the two identical HVAC/filtration systems. Additional 
evidence to this effect was observed early in the testing of the MERV 16 filters on the roof bolter, when particle count measurements were taken with several extra filter combinations to examine the mathematical modeling of these filtration system changes. The filter combinations tested included adding a used recirculation filter to the system and removing the final filter from the system. Applying the final filter model (Equation 31) to represent these filtration system changes indicated that a greater than $65 \%$ intake air leakage was needed to conform the modeled results to the measured cab test results [Cecala et al. 2016]. Examination of the HVAC systems during filter changes indicated that dust deposits were not only forming downstream of the intake filter but downstream of the final filters (see Figure 24), indicating multiple leaks in the HVAC system around the filters. Air leakage around other filters in the system can be modeled by multiplying the portion of airflow passing through the filter $(Q(1-l))$ by the filter penetration (1 $-\eta)$, plus the portion of unfiltered airflow leaking around the filter $(Q l)$. A more refined cab filtration system model with these additional leaks was formulated by node analysis and is shown in Figure 25 [Cecala et al., 2016].

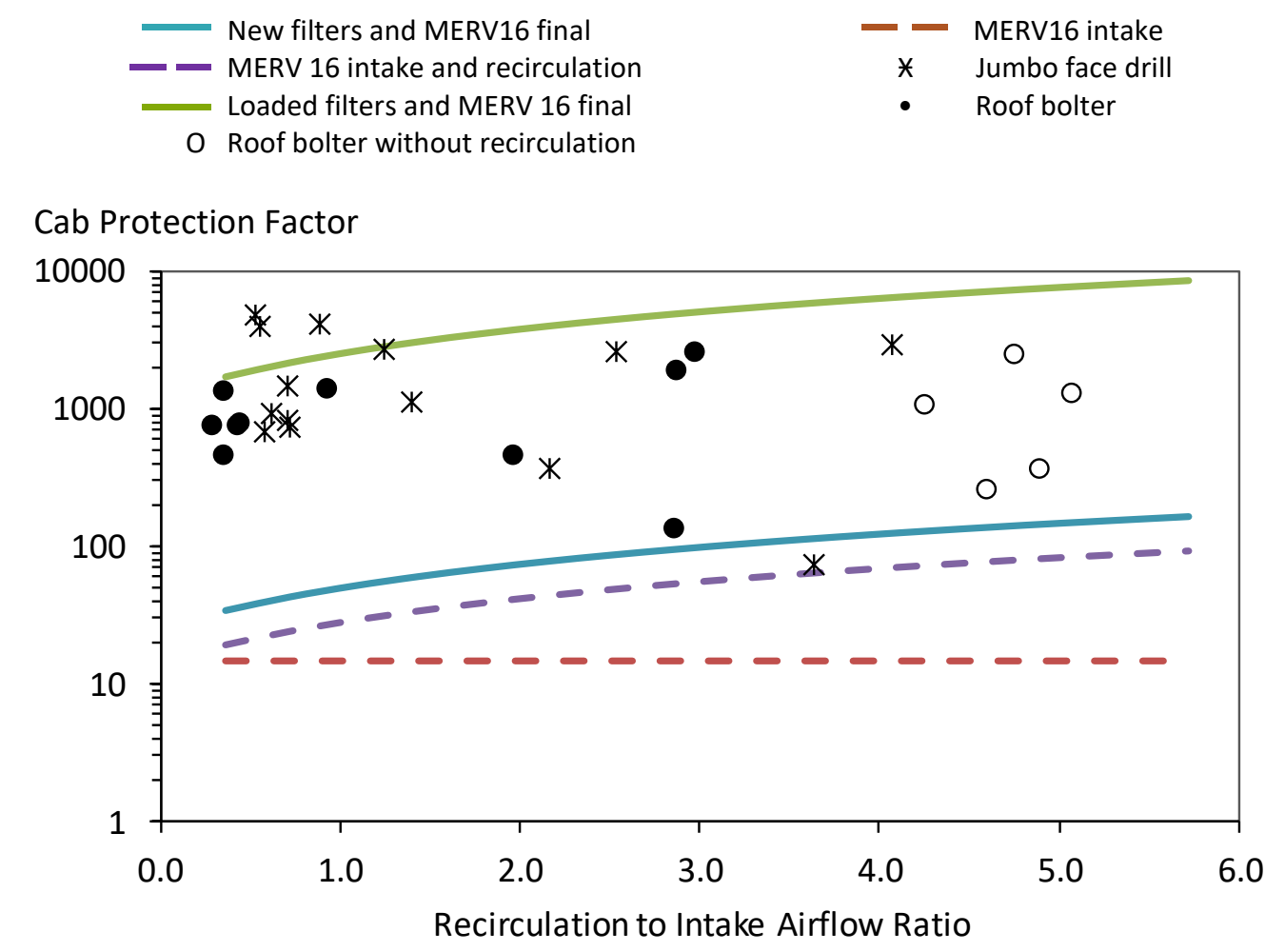

Figure 23. Field-measured protection factors shown with modeled ranges. 

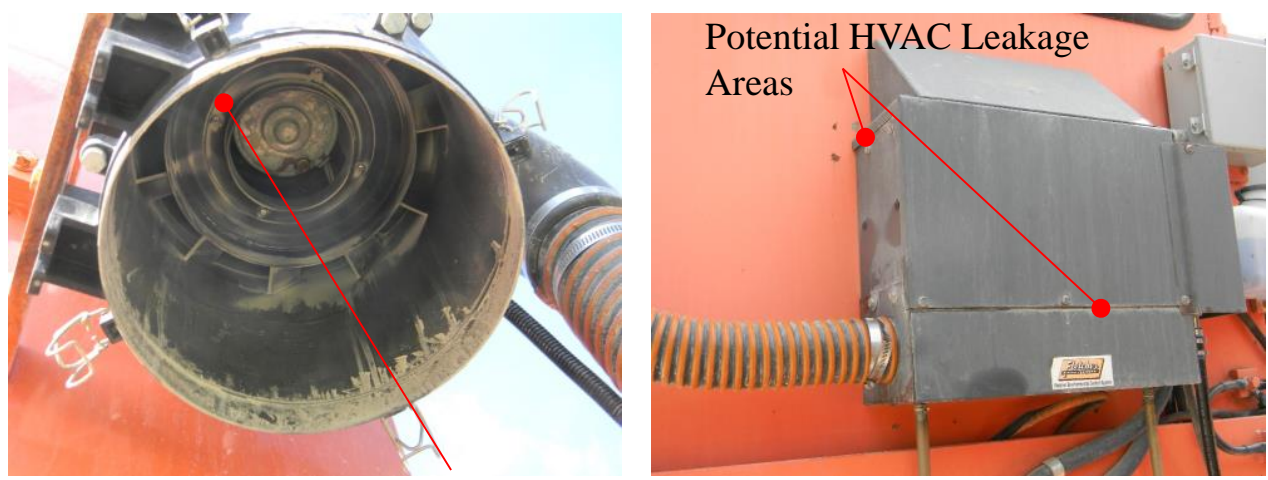

Leakage around filters
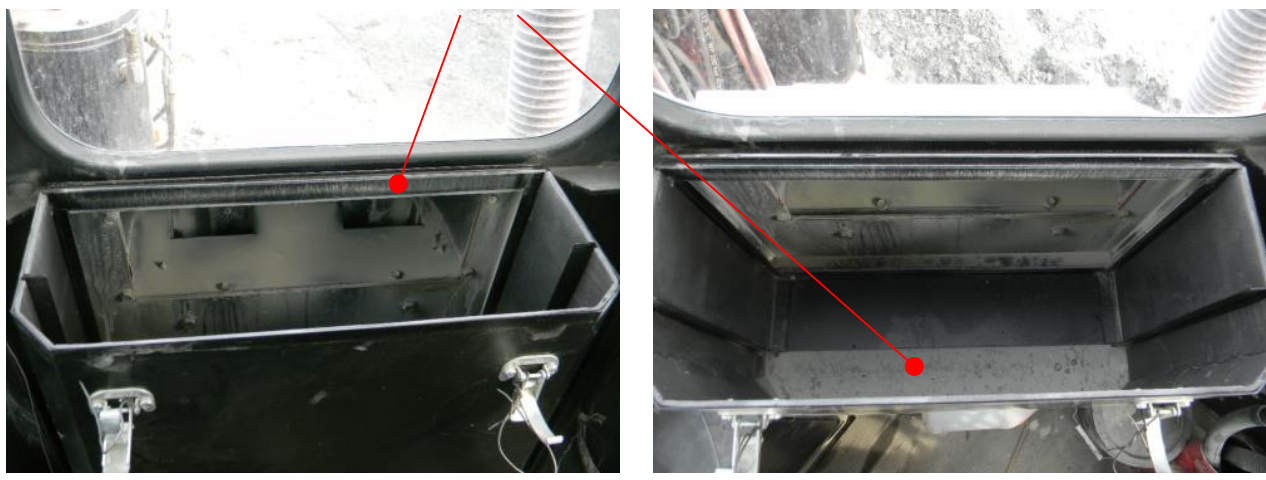

Photos by NIOSH

Figure 24. Visual observation of multiple air leaks within the air filtration system. Red circles represent some areas with evidence of leakage.

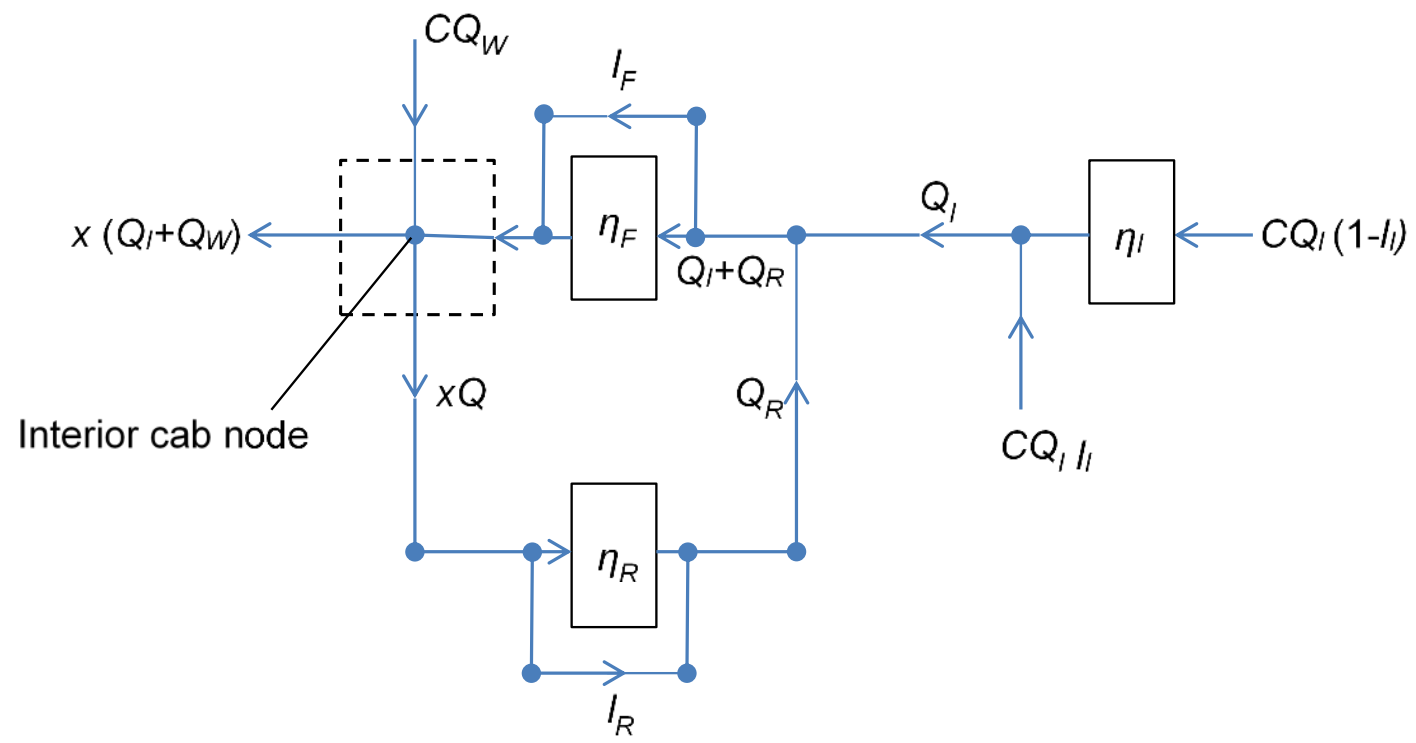

Figure 25. Three-filter cab system with potential leaks around the filters ( $Q$ 's denote air quantities, $x$ 's \& c's denote contaminant concentrations, and $\eta$ 's denote filter efficiencies). 
Figure 25 illustrates this node analysis of the three-filter system with the addition leaks around the filters. As shown in this diagram, the final filter is downstream of the intake and recirculation filters. Outside contaminants enter into the filtration system circuit through the intake filter, leakage around the intake filter, and direct penetration into the cab enclosure openings when wind velocity pressure exceeds cab pressure. Other air leaks in the system can occur around the recirculation and final filters. Some of the filtered interior cab air is pushed outside by the intake airflow and any outside wind penetration, while the remaining portion of the cab air is recirculated through the recirculation and final filters. The filtration system model is formulated as an equality of the incoming contamination mass to the exiting contamination mass at the interior cab node while assuming steady state conditions, as shown by Equation 32:

$$
\text { Mass }_{\text {in }}=\text { Mass }_{\text {out }}
$$

The incoming mass is what penetrates the cab filtration system and the outgoing mass is what leaves the cab interior and is recirculated through the filtration system, as shown in Equation 33 using the same variable designations and subscripts as defined above:

$$
\begin{aligned}
& {\left[c Q_{I}\left(1-l_{I}\right)\left(1-\eta_{I}\right)+c Q_{I} l_{I}+x Q_{R}\left(1-l_{R}\right)\left(1-\eta_{R}\right)+x Q_{R} l_{R}\right] \times} \\
& {\left[\left(1-l_{F}\right)\left(1-\eta_{F}\right)+l_{F}\right]+c Q_{W}=x\left(Q_{I}+Q_{W}\right)+x Q_{R}}
\end{aligned}
$$

The bracketed intake, recirculation, and final filter terms are multiplied and rearranged:

$$
\begin{aligned}
& {\left[c Q_{I}\left(1-\eta_{I}+l_{I} \eta_{I}\right)\left(1-\eta_{F}+l_{F} \eta_{F}\right)\right]+\left[x Q_{R}\left(1-\eta_{R}+l_{R} \eta_{R}\right)\left(1-\eta_{F}+l_{F} \eta_{F}\right)\right]+c Q_{W}=} \\
& x\left(Q_{I}+Q_{W}\right)+x Q_{R}
\end{aligned}
$$

The outside and inside concentration terms are rearranged to opposing sides in Equation 35:

$$
\begin{aligned}
& {\left[c Q_{I}\left(1-\eta_{I}+l_{I} \eta_{I}\right)\left(1-\eta_{F}+l_{F} \eta_{F}\right)\right]+c Q_{W}=} \\
& x\left(Q_{I}+Q_{R}+Q_{W}\right)-\left[x Q_{R}\left(\left(1-\eta_{R}+l_{R} \eta_{R}\right)\left(1-\eta_{F}+l_{F} \eta_{F}\right)\right]\right.
\end{aligned}
$$

Next, we solve for protection factor $(\mathrm{PF})$ ratio or penetration $(P e n=1 / P F)$. Equation 36 below was solved for protection factor and can be easily inverted to determine penetration:

$$
P F=\frac{c}{x}=\frac{Q_{I}+Q_{R}-\left[Q_{R}\left(1-\eta_{R}+l_{R} \eta_{R}\right)\left(1-\eta_{F}+l_{F} \eta_{F}\right)\right]+Q_{W}}{\left[Q_{I}\left(1-\eta_{I}+l \eta_{I}\right)\left(1-\eta_{F}+l_{F} \eta_{F}\right)\right]+Q_{W}}=\frac{1}{P e n}
$$

This equation provides a more sensible proportioning of air leakages observed throughout the filtration system. Additional two- and three-filter system combinations-intake filter with final and/or recirculation filter; MERV 16 and HEPA filters; new and used-were also tested on both cabs throughout this long-term study and were modeled using their measured airflow quantities with assumed proportional air leakages. Face drill air leakages modeled bypassing the new 
intake, recirculation, and final filters were 4\%, 2\%, and 2\%, respectively, and were doubled when modeling used filters at these locations. Roof bolter air leakages used in the model were further doubled over those used for the face drill, given its significantly lower cab PF field measurements. For the two-filter systems, zero efficiency was used in the equation for the missing filter, thereby removing its air filtering effect from the model.

Shown below is an example of the filtration system model PF calculation for the roof bolter with new MERV 16 filters (95\% efficiency or 0.95) installed at the intake and final filter locations, and with measured intake and recirculation airflows of 83 and $246 \mathrm{ft}^{3} / \mathrm{min}$, respectively. Since the cab was adequately pressurized, we can assume $0 \mathrm{ft}^{3} / \mathrm{min}$ of wind infiltration for the model. The calculated cab PF with these cab parameters is shown below to be 334 as compared to the measured PF of 300 (particle counting at near steady state conditions). Other filter combinations tested in the field were similarly measured and modeled.

$$
P F=\frac{83+246-[246 \times(1-0+(0 \times 0)) \times(1-0.95+(0.04 \times 0.95))]+0}{[83 \times(1-0.95+(0.08 \times 0.95)) \times(1-0.95+(0.04 \times 0.95))]+0}=334
$$

Figure 26 shows the comparison of the measured cab PFs and the modeled cab PFs, with reasonable agreement along a unity line. The spread in the data is presumed to be primarily a result of the actual unknown field leakage deviations from the assumed modeled leakages specified above. This figure also shows that the lowest PFs were measured and modeled when no final filter was used. Additionally, the opening points in the figure show there was no observable cab PF benefit to adding the recirculation filter into the system when using the final filter. Adding the recirculation filter into the system significantly reduced the recirculation airflow and cab PF [Cecala et al. 2016]. A negative aspect of not having the recirculation filter in the system is that dirt and dust from inside the cab would get drawn into and deposited in the HVAC system, thereby increasing maintenance issues. An alternative solution to improving this cab filtration system would be to increase the size of the recirculation filter to increase its airflow capabilities. Finally, multiple leakages in the HVAC/filtration system can have a significant impact on cab PFs, as shown when comparing the measured and modeled PFs of the two vehicle cabs. Therefore, the cab HVAC/filtration system needs to be well-sealed to extract the benefits of using high-efficiency dust filters. 


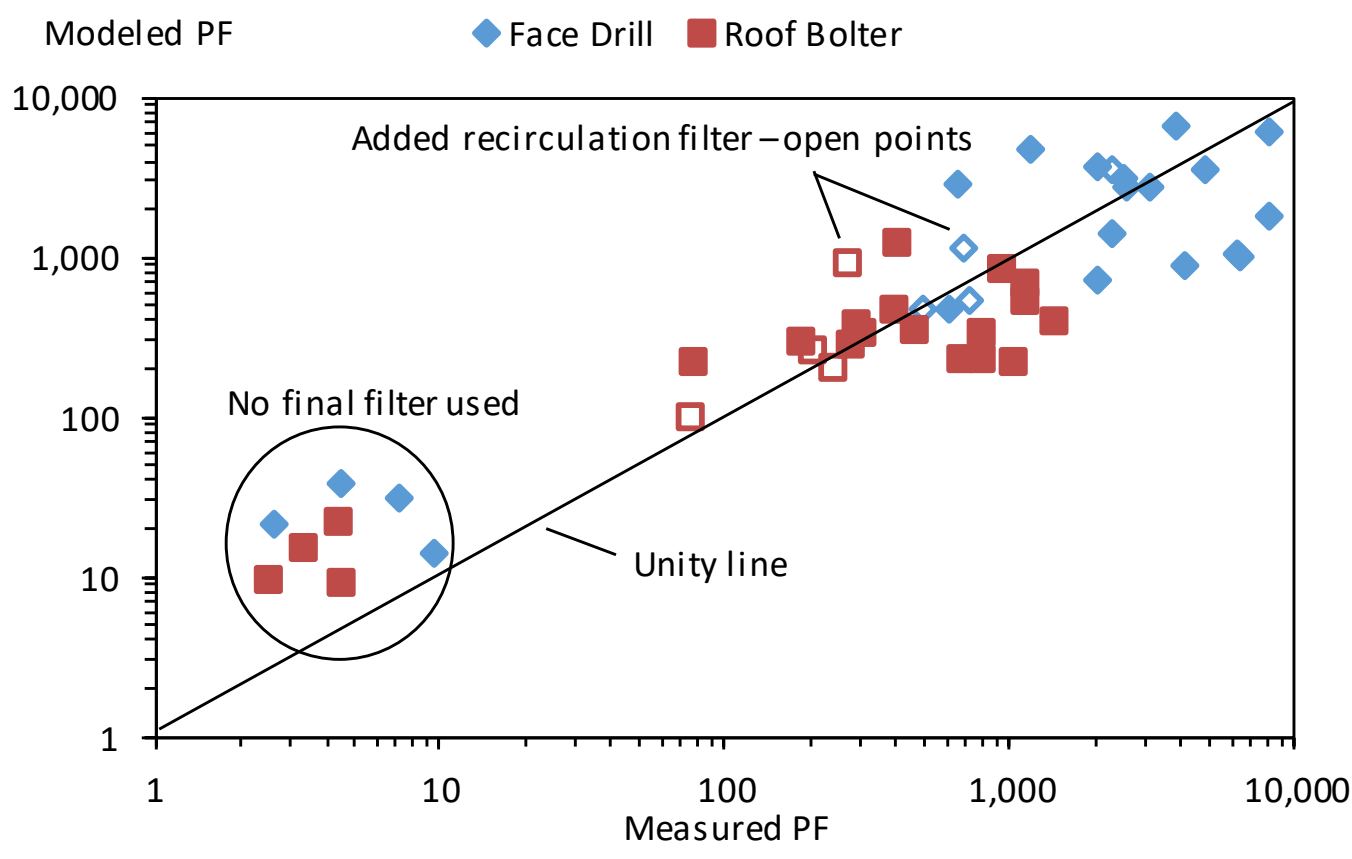

Figure 26. Measured and modeled PFs of the face drill and
roof bolter during the filter field study.

\section{Conclusions}

Two key elements of an effective environmental enclosure are a good filtration system and an enclosure with good integrity (sealed isolation from the outside environment). A good filtration system should include filtering out at least $95 \%$ or greater of airborne respirable aerosols (dust, diesel particulate matter, liquid droplets, etc.) from the outside intake air with an additional recirculation filtering component for the inside air. A separate intake air pressurizing fan (booster fan) is recommended as good practice to ensure adequate intake airflow into the enclosure irrespective of the HVAC fan speed operation. Good enclosure integrity is needed to achieve positive pressure to prevent wind penetration into the enclosure and to minimize air leakage around the filtration system. Air leakage around high-efficiency filters was found to have a detrimental effect on environmental enclosure protection factor (PF) performance, and air leakage around the filters increases with filter loading. Therefore, the proper seals around the filters and maintenance/change-out schedules for the filters are needed. Wind penetration into the enclosure was only a noticeable factor if the environmental enclosure's positive interior static pressure was less than the outside wind velocity pressure exerted on the enclosure, and if the filtration system did not have a recirculation filtering component to continuously re-filter the enclosure's interior air. Finally, adding a final filtering element downstream of both the intake and recirculation filtering circuits significantly increased the enclosure PF performance, because of the additional level of filtration added onto the total airflow of the environmental enclosure's filtration system. Both laboratory and field testing confirmed these design guidelines. 
Testing, monitoring, and mathematical modeling of environmental enclosures are also beneficial to quantifying and optimizing filtration system designs as well as maintaining optimum PF performance for enclosure occupants. Particle counting the outside and inside air quality of environmental enclosures was found to be one of the best test methods for determining relative effectiveness in removing airborne contaminants. Occupational exposure sampling (gravimetric, dust, DPM, etc.), enclosure airflow measurements, and enclosure pressurization measurements are also useful in assessing the operational effectiveness of environmental enclosures. Long-term monitoring programs or benchmarking is very valuable for historically examining environmental enclosure maintenance needs and for optimizing performance such as filter change intervals. Analytical techniques can be used on measurement data to determine the certainty of environmental enclosure changes with respect to operating parameters.

Node analysis techniques were utilized to develop mathematical models of environmental enclosure filtration systems. These models were advanced to examine the filtration system design effects of filter placement, filter efficiency, airflow quantities, air leakage, and wind penetration on the environmental enclosure's air cleaning performance. Mathematical modeling comparisons with laboratory and field testing results illustrate their usefulness for optimizing enclosure filtration system performance parameters.

\section{References}

ACGIH [2010]. Industrial ventilation: a manual of recommended practice for design. $27^{\text {th }}$ ed. Cincinnati, $\mathrm{OH}$ : American Conference of Governmental Industrial Hygienists.

ACGIH [2016]. 2016 Threshold limit values for chemical substances and physical agents and biological exposure indices. Cincinnati, $\mathrm{OH}$ : American Conference of Governmental Industrial Hygienists

ASABE [2013a]. Tractors and self-propelled machinery for agriculture - air quality systems for cabs, Part 2: cab and HVAC design [Standard S613-2.1]. St. Joseph, Michigan: American Society of Agricultural and Biological Engineers.

ASABE [2013b]. Tractors and self-propelled machinery for agriculture - air quality systems for cabs, Part 3: filters for environmental cab HVAC systems [Standard S613-3]. St. Joseph, Michigan: American Society of Agricultural and Biological Engineers.

ASABE [2017a]. Tractors and self-propelled machinery for agriculture - air quality systems for cabs, Part 4: performance test of a cab [Standard S613-4]. St. Joseph, Michigan: American Society of Agricultural and Biological Engineers.

ASABE [2017b]. Tractors and self-propelled machinery for agriculture - air quality systems for cabs, Part 4: air filter element test [ASABE/ISO 14269-4]. St. Joseph, Michigan: American Society of Agricultural and Biological Engineers.

ASAE [1997]. Agricultural cabs environmental air quantity, Part 1: definitions, test methods, and safety practices [Standard S525-1.1]. St. Joseph, Michigan: American Society of Agricultural Engineers. 
ASHRAE [1999]. Methods of testing general ventilation air-cleaning devices for removal efficiency by particle size [Standard 52.2]. Atlanta, Georgia: American Society of Heating, Refrigerating and Air-Conditioning Engineers.

ASHRAE [2007]. Ventilation for acceptable indoor air quality [Standard 62.1]. Atlanta, Georgia: American Society of Heating, Refrigerating and Air-Conditioning Engineers.

Bémer D, Fismes J, Subra I, Blachère V, Protois J [2007]. Pesticide aerosol characteristics in the vicinity of an agricultural vehicle cab during application. J Occup Environ Hyg 4:476-482.

Bevington PR [1969]. Data reduction and error analysis for the physical sciences. New York: McGraw-Hill pp. 60-64.

Cauda E, Sheehan M, Gussman R, Kenny L, Volkwien J [2014]. An evaluation of sharp cut cyclones for sampling diesel particulate matter aerosol in the presence of respirable dust. Ann Occup Hyg 58(8): 995-1005.

Cecala AB, Organiscak JA, Heitbrink WA [2001]. Dust underfoot-enclosed cab floor heaters can significantly increase operator's respirable dust exposure. Rock Products 104:39-44.

Cecala AB, Organiscak JA, Heitbrink WA, Zimmer JA, Fisher T, Gresh RE, Ashley JD II [2004]. Reducing enclosed cab drill operator's respirable dust exposure at surface coal operations with a retrofitted filtration and pressurization system. Littleton, Colorado: (SME) Society for Mining, Metallurgy, and Exploration, 2003 Transactions 314:31-36.

Cecala AB, Organiscak JA, Zimmer JA, Heitbrink WA, Moyer ES, Schmitz M, Ahrenholtz E, Coppock CC, Andrews EH [2005]. Reducing enclosed cab drill operator's respirable dust exposure with effective filtration and pressurization techniques. J Occup Environ Hyg 2:54-63.

Cecala AB, Organiscak JA, Zimmer JA, Moredock D, Hillis MS [2007]. Closing the door to dust when adding drill steels. Rock Products 110(10):29-32.

Cecala AB, Organiscak JA, Zimmer JA, Hillis MS, Moredock D [2009]. Maximizing air quality inside enclosed cabs with a unidirectional filtration and pressurization system. Littleton, Colorado: (SME) Society for Mining, Metallurgy, and Exploration, 2009 Transactions 326:7178.

Cecala AB, Organiscak JA, Noll JD [2012]. Long-term evaluation of cab particulate filtration and pressurization performance. Littleton, Colorado: (SME) Transactions of the Society for Mining, Metallurgy, and Exploration, 332:521-531.

Cecala AB, Reed WR, Joy GJ, Westmoreland SC, O'Brien AD [2013]. Helmet-CAM: tool for assessing miners' respirable dust exposure, Min Eng 65(9):78-84.

Cecala AB, O'Brien, AD [2014]. Here comes the Helmet-CAM: a recent advance in technology can improve how miner operators investigate and assess respirable dust. Rock Products 117(10):26-30. 
Cecala AB, Organiscak JA, Noll JD, Rider JP [2014]. Key components for an effective filtration and pressurization system for mobile mining equipment. Min Eng 66(1):44-50.

Cecala AB, Azman A, Bailey K [2015]. Assessing noise and dust exposure. Agg Manager 20(9):32-37.

Cecala AB, Organiscak JA, Noll JD, Zimmer JA [2016]. Comparison of MERV 16 and HEPA filters for cab filtration of underground mining equipment. Min Eng 68(8):50-56.

Cecala AB, Organiscak JA [2017]. Partnership helps all breathe a little easier: a metal/nonmetal underground mining crew partners with NIOSH to study air quality in enclosed cabs and improve worker health. Agg Manager 22(2):30-37.

CEN [2009a]. Agricultural tractors and self-propelled sprayers-protection of the operator (driver) against hazardous substances - part 1: cab classification, requirements and test procedures [Standard CEN-EN 15695-1]. European Committee for Standardization, Management Centre: Avenue Marnix 17, B-1000, Brussels.

CEN [2009b]. Agricultural tractors and self-propelled sprayers-protection of the operator (driver) against hazardous substances - part 2: filters, requirements and test procedures [Standard CEN-EN 15695-2]. European Committee for Standardization, Management Centre: Avenue Marnix 17, B-1000, Brussels.

Chekan GJ, Colinet JF [2003]. Retrofit options for better dust control cab filtration, pressurization systems prove effective in reducing silica dust exposures in older trucks. Agg Manager 8(9):9-12.

CFR [2016]. Code of Federal Regulations. Washington, DC: US Government Printing Office, Office of the Federal Register.

Hall RM, Heitbrink WA, Reed LD [2002]. Evaluation of a tractor cab using real-time aerosol counting instrumentation. Appl Occup Environ Hyg 17:47-54.

Heitbrink WA, Hall RM, Reed LD, Gibbons D [1998]. Review of ambient aerosol test procedures in ASAE standard 525. J Agric Saf Health 4(4):255-266.

Heitbrink WA, Thimons ED, Organiscak JA, Cecala AB, Schmitz M, Ahrenholtz E [2000]. Static pressure requirements for ventilation enclosures. In: Proceedings of the Sixth International Symposium on Ventilation for Contaminant Control, Helsinki, Finland, June 2000, pp. 97-99.

Heitbrink WA, Moyer ES, Jensen, PA, Watkins DS, Martin SB [2003]. Environmental agricultural tractor cab filter efficiency and field evaluation. AIHA J 64:394-400.

Heitbrink WA, Collingwood S [2005]. Aerosol generation by blower motors as a bias in assessing aerosol penetration into cab filtration systems. J Occup Environ Hyg 2(1):45-53. 
ISO [2011]. High-efficiency filters and filter media for removing particles in air-part 1: classification, performance testing and marking [Standard 29463-1]. ISO Central Secretariat Chemin de Blandonnet 8 CP 401 - 1214 Vernier, Geneva, Switzerland: International Organization for Standardization.

Johnson RA [2005]. Miller and Freund's probability and statistics for engineers. Upper Saddle River, NJ: Pearson Prentice Hall, Pearson Education, Inc.

Leith D, First MW [1976]. Uncertainty in particle counting and sizing procedures. Am Ind Hygiene Assoc J 37(2):103-108.

Listak JM, Chekan GJ, Colinet JF, Rider JP [2007]. Performance of a light scattering dust monitor at various air velocities: results of sampling in the active versus the passive mode. Int $\mathbf{J}$ Miner Res Eng 12(1):35-47.

Martin SB, Moyer ES [2000]. Electrostatic respirator filter media: filter efficiency and most penetrating particle size effects. Appl Occup Environ Hyg 15(8):609-617.

Moyer ES, Heitbrink WA, Jensen, PA [2005]. Test for the integrity of environmental tractor cab filtration systems. J Occup Environ Hyg 2:516-523.

MSHA 1990. Mine Safety and Health Administration metal, nonmetal health procedures manual (PH90-IV4), Chapter D, Arlington, Virginia.

Nieuwenhuijsen MJ, Kruize H, Schenker MB [1998]. Exposure to dust and its particle size distribution in California agriculture. Am Ind Hygiene Assoc J 58:34-38.

NIOSH [2001a]. Improved cab air inlet location reduces dust levels and air filter loading rates. By Organiscak JA, Page SJ. Pittsburgh, PA: U.S. Department of Health and Human Services, Centers for Disease Control and Prevention, National Institute for Occupational Safety and Health, Technology News 485.

NIOSH [2001b]. Floor heaters can increase operator's dust exposure in enclosed cabs. By Cecala AB, Organiscak JA. Pittsburgh, PA: U.S. Department of Health and Human Services, Centers for Disease Control and Prevention, National Institute for Occupational Safety and Health, Technology News 486.

NIOSH [2001c]. Sweeping compound application reduces dust from soiled floors within enclosed operator cabs. By Organiscak JA, Page SJ, Cecala AB. Pittsburgh, PA: U.S. Department of Health and Human Services, Centers for Disease Control and Prevention, National Institute for Occupational Safety and Health, Technology News 487.

NIOSH [2007a]. Recirculation filter is key to improving dust control in enclosed cabs. By Organiscak JA, Cecala AB. Pittsburgh, PA: U.S. Department of Health and Human Services, Centers for Disease Control and Prevention, National Institute for Occupational Safety and Health, DHHS (NIOSH) Publication No. 2008-100. 
NIOSH [2007b]. NIOSH pocket guide to chemical hazards ( $3^{\text {rd }}$ printing with minor technical revisions). U.S. Department of Health and Human Services, Centers for Disease Control and Prevention, National Institute for Occupational Safety and Health, DHHS (NIOSH) Publication No. 2005-149.

NIOSH [2008a]. Minimizing respirable dust exposure in enclosed cabs by maintaining cab integrity. By Cecala AB, Organiscak JA. Pittsburgh, PA: U.S. Department of Health and Human Services, Centers for Disease Control and Prevention, National Institute for Occupational Safety and Health, DHHS (NIOSH) Publication No. 2008-147.

NIOSH [2008b]. Key design factors of enclosed cab dust filtration systems. By Organiscak JA, Cecala AB. Pittsburgh, PA: U.S. Department of Health and Human Services, Centers for Disease Control and Prevention, National Institute for Occupational Safety and Health, DHHS (NIOSH) Publication No. 2009-103.

NIOSH [2012a]. Dust control handbook for industrial minerals mining and processing. By Cecala AB, O'Brien AD, Schall J, Colinet JF, Fox WR, Franta RJ, Joy J, Reed WR, Reeser PW, Rounds JR, Schultz MJ. Pittsburgh, PA: U.S. Department of Health and Human Services, Centers for Disease Control and Prevention, National Institute for Occupational Safety and Health, DHHS (NIOSH) Publication No. 2012-112.

NIOSH [2012b]. A new leak test method for enclosed cab filtration systems. By Organiscak JA, Schmitz M. Pittsburgh, PA: U.S. Department of Health and Human Services, Centers for Disease Control and Prevention, National Institute for Occupational Safety and Health, DHHS (NIOSH) Publication No. 2012-145.

NIOSH [2012c]. A test method for quantifying unfiltered air leakage into enclosed cabs. By Organiscak JA, Schmitz M. Pittsburgh, PA: U.S. Department of Health and Human Services, Centers for Disease Control and Prevention, National Institute for Occupational Safety and Health, DHHS (NIOSH) Publication No. 2012-180.

NIOSH [2014]. Guidelines for performing a Helmet-CAM respirable dust survey and conducting subsequent analysis with the enhanced video analysis of dust exposures (EVADE) software. By Reed WR, Kwitowski AJ, Helfrich WJ, Cecala AB, Joy GJ. Pittsburgh, PA: U.S. Department of Health and Human Services, Centers for Disease Control and Prevention, National Institute for Occupational Safety and Health, DHHS (NIOSH) Publication No. 2014-133.

NIOSH [2016]. Manual of analytical methods, $5^{\text {th }}$ Ed. Cincinnati, OH: U.S. Department of Health and Human Services, Centers for Disease Control and Prevention, National Institute for Occupational Safety and Health.

Noll JD, Cecala AB, Organiscak JA [2012]. The effectiveness of several enclosed cab filters and systems for reducing diesel particulate matter. Littleton, Colorado: (SME) Society for Mining, Metallurgy, and Exploration, 2011 Transactions 330:408-415.

Noll JD, Janisko S, Mischler SE [2013]. Real-time diesel particulate monitor for underground mines. Anal Methods 5(12):2954-2963. 
Noll JD, Janisko S [2013]. Evaluation of a wearable monitor for measuring real-time diesel particulate matter concentrations in several underground mines. J Occup Environ Hyg 10(12):716-722.

Noll JD, Cecala AB, Organiscak JA [2014a]. Effects of MERV 16 filters and routine work practices on enclosed cabs for reducing respirable dust and DPM exposures in an underground limestone mine. Min Eng 66(2):45-52.

Noll JD, Cecala AB, Organiscak JA, Janisko S [2014b]. Real-time DPM monitoring: NIOSH develops new tool for assessing and controlling exposure. Eng Min J June 2014, pp. 78-81.

Noll JD, Cecala AB, Hummer J [2015]. Instituting a filtration/pressurization system to reduce dust concentrations in a control room at a mineral processing plant. Min Eng 67(12):42-48.

Organiscak JA, Page SJ [1999]. Field assessment of control techniques and long-term dust variability for surface coal mine rock drills and bulldozers. Int J Surf Min Reclam Env 13:165172.

Organiscak JA, Cecala AB, Thimons ED, Heitbrink WA, Schmitz M, Ahrenholtz E [2004]. NIOSH/Industry collaborative efforts show improved mining equipment cab dust protection. Littleton, Colorado: (SME) Society of Mining, Metallurgy and Exploration, Inc., 2003 Transactions 314:145-152.

Organiscak JA, Schmitz M [2006]. A new concept for leak testing environmental enclosure filtration systems. J ASTM Int 3(10):11 pp.

Organiscak JA, Cecala AB [2008]. Laboratory investigation of enclosed cab filtration system performance factors. Min Eng 60(12):74-80.

Organiscak JA, Cecala AB [2009]. Doing the math - the effectiveness of enclosed-cab air-cleaning methods can be spelled out in mathematical equations. Rock Products, October pp. 20-22.

Organiscak JA, Schmitz M [2009]. Method and apparatus for leak testing an environmental enclosure. Australian Patent No. 2003286587.

Organiscak JA, Schmitz M [2010a]. Method and apparatus for leak testing an environmental enclosure. United States Patent No. 7,727,765. Washington, DC: U.S. Patent and Trademark Office.

Organiscak JA, Schmitz M [2010b]. Method and apparatus for leak testing an environmental enclosure. Canadian Patent No. 2,503,500.

Organiscak JA, Cecala AB, Noll JD [2013]. Field assessment of enclosed cab filtration system performance using particle counting measurements. J Occup Environ Hyg 10:468-477.

Organiscak JA, Cecala AB, Noll JD [2014]. Using node analysis modeling techniques to predict cab filtration system performance. Min Eng 66:52-59. 
Organiscak JA, Cecala AB, Zimmer JA, Holen B, Baregi JR [2016]. Air cleaning performance of a new environmentally controlled primary crusher operator booth. Min Eng 68(2):31-37.

Organiscak JA, Schmitz M [2016]. Method and apparatus for leak testing an environmental enclosure. European Patent No. 1554556.

Patts JR, Cecala AB, Rider JP, Organiscak JA, Zimmer JA [2017]. Quantifying and monitoring control room protection factors against respirable dust at an underground crusher booth. Preprint \#17-100, 2017 SME Annual Conference \& Expo, Feb. 19-22, Denver, Colorado.

Raynor PC, Chae SJ [2004]. The long-term performance of electrically charged filters in a ventilation system. J Occup Environ Hyg 1:463-471.

Reed WR, Potts JD, Cecala AB, Archer WJ [2012]. Use of the pDR-1500 for gravimetric respirable dust measurements at mines, Preprint \#12-001 SME Annual Meeting \& Exhibit, Feb. 19-22, 2012, Seattle, Washington.

Satterthwaite FE [1946]. An approximate distribution of estimates of variance components. Biometrics Bulletin, 2(6):110-114. 
Delivering on the Nation's promise: safety and health at work for all people through research and prevention

To receive NIOSH documents or more information about occupational safety and health topics, please contact NIOSH:

Telephone: 1-800-CDC-INFO (1-800-232-4636)

TTY: 1-888-232-6348

CDC INFO: www.cdc.gov/info

or visit the NIOSH website at www.cdc.gov/niosh

For a monthly update on news at NIOSH, subscribe to NIOSH eNews by visiting www.cdc.gov/niosh/eNews.

DHHS (NIOSH) Publication No. 2018-123

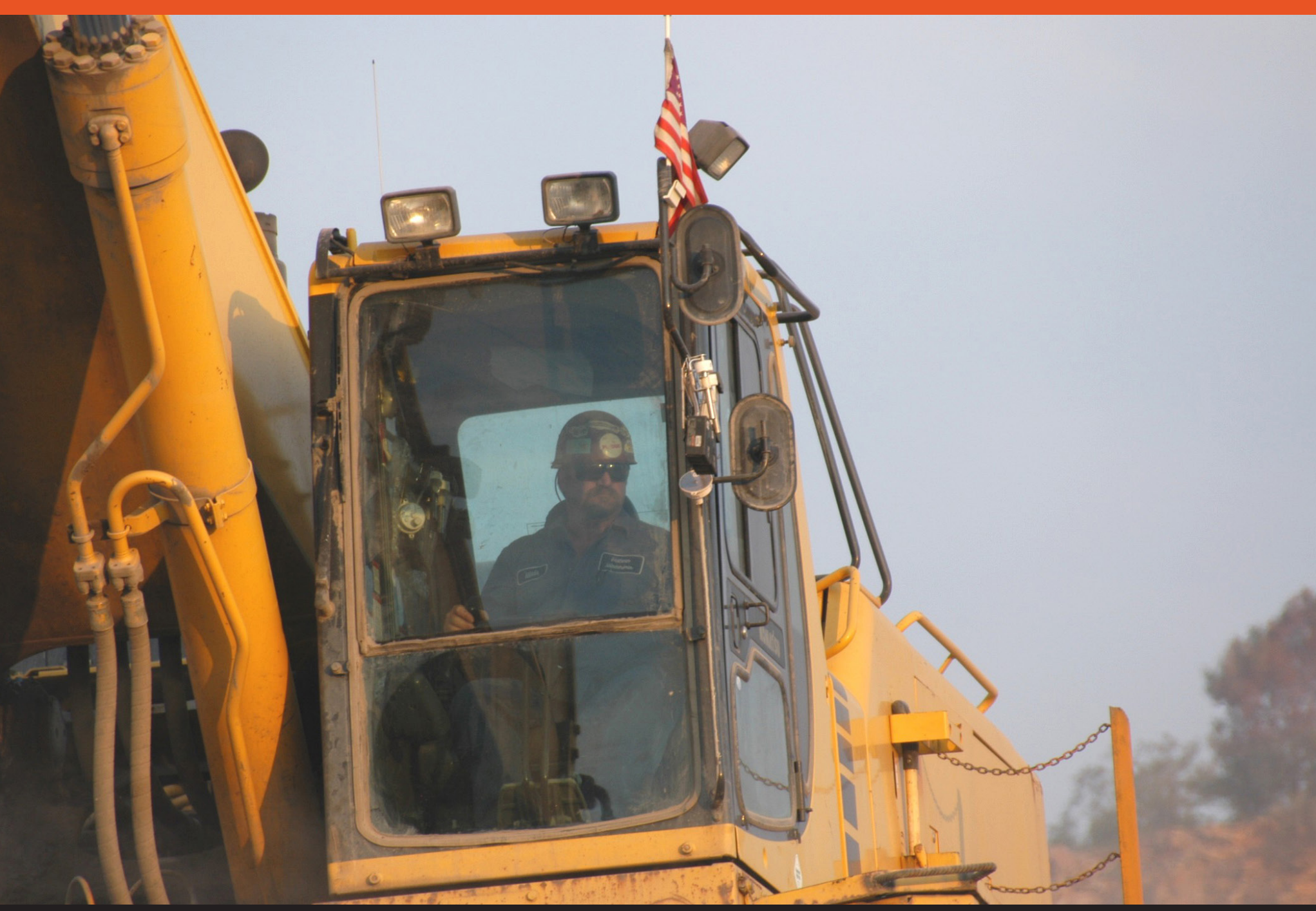

